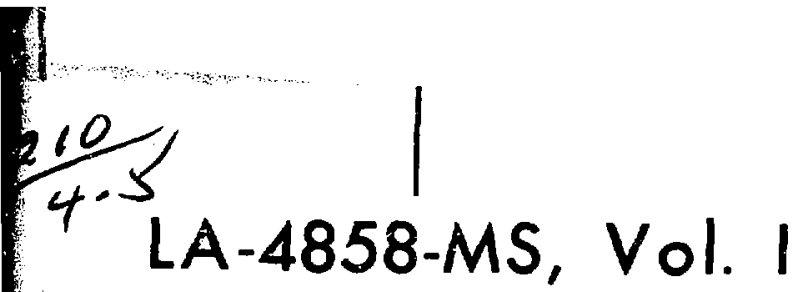

AN INFORMAL REPORT

\title{
Central Station Power Generation by Laser-Driven Fusion
}


This report was preparad as an account of work sponsored by the Uniter States Government. Neither the United States nor the United States Atomic Energy Commission, nor any of their employees, nor any of their contractors, subconttractors, or their employees, makes any warranty, express or implied, or assumes any legal liability or responsibility for the accuracy, completeness or usefulness of any information, apparatus, product or process disclosed, or represents that its use would not infringe privately owned rights.

In the interest of prompt distribution, this LAMS report was not edited by the Technical Information staff.

Printed in the United States of America. Available from National Technical Information Service

U. S. Department of Commerce

5285 Port Royal Road Springfield, Virginia 22151

Price: Printed Copy \$3.00; Microfiche \$0.95 


\section{PREBFACE}

This report has heen prepared for the Controlled Thermonuclear Research program of the 0 . S. Atomic Energy Comission, and presents the results of a study investigating an application of laser-iriven fuston pulses for commerclal pover generation. The present discusston assegses the engineering feasibility of this application. The analyses are based on a spectiflc desten concept for utilizing the fustion energy and have been carried only to the polnt where semiquantitative conclusions may be made. The work, therefore, is at an interim stage and all fIndings are preliminary.

Certain aspects of the proposed techniques for generating the fusion enerby remain classified. These matiers are discussed in volume II (IA-4859-48, Classified, SRD).

Th1: work hrs been conducted by the Adranced Conceptss grourg of the LOs Alamos Scientific Leboratory (IASS) Muclear Propulsion Division. Staff members who centributed to this report vere J. D. Balcoub, L. A. Booth, J. C. Hedistrom, D. B. Henderson, A. R. Lerson, S. H. Noore, and C. W. Watson. 
Nomenclature

Abstreat

I. Introduction $\quad 1$

A. General 1

B. General Aspects of ICTR Plants 2

C. Considerations Ieading to the Wetted-Wall Concept 3

II. Analyses of Wetted-WaIl Concept 5

A. General Description $\quad 5$

$\begin{array}{ll}\text { B. The Carity } & 8\end{array}$

$\begin{array}{lr}\text { C. The Blanket } & 15\end{array}$

III. Areas of Uncertainty

A. Radiation Damage $\quad 25$

B. Induced Activity and Afterheat 26

C. Removal of Contaminants from Lithium 28

D. Safety Features of an ICIR Plant 29

E. Economics $\quad 31$

F. Other Keans of Energy Conversion 31

IV. Conclusions $\quad 34$

A. The Wetted-WaIl ICIR 34.

B. Comparison of ICIR with MCIRs 35

C. Comperison of World Energy Resources 37

Appendix A - Some Neutronics Features of an ICIR 39

Addendum I tc Appendix A - Relative Importance of Various Iithium 47

Addendun 2 to Appendix A - Inelastic Scattering Sources for Itthium 48

Appendix B - Kethods of Calculation 51

Appendix C - Physical Properties of Iithilum 53 


\begin{tabular}{|c|c|c|}
\hline A. & Area & $m^{2}$ \\
\hline$A_{s}$ & Cross-sectional flow area, Eq. (22) & $m^{2}$ \\
\hline $\mathrm{A}_{\mathbf{r}}$ & surface area, Eq. (25) & $m^{2}$ \\
\hline$c_{p}$ & Heat capacity at constant pressure & $\mathrm{J} / \mathrm{ke} \mathrm{K}$ \\
\hline$c_{v}$ & Heat capacity at constant volume & $\mathrm{J} / \mathrm{kg} \mathrm{K}$ \\
\hline $\mathbf{D}$ & Dimension, thickness & m \\
\hline$D_{t}$ & Film thickness, Eq. (24) & m \\
\hline$D_{w}$ & Wall thickness, Eq. (29) & m \\
\hline $\mathbf{E}$ & Spscific Internal energy & $\mathrm{J} / \mathrm{kg}$ \\
\hline $\mathbf{E}_{\mathbf{s}}$ & Source energy, Eqs. (3) and (14) & $\mathrm{J} / \mathrm{kg}$ \\
\hline$F_{D}$ & Viscous arag force, Eq. (23) & $\mathrm{s} / \mathrm{m}^{3}$ \\
\hline B & Gravitationai acceleration & $\mathrm{m} / \mathrm{sec}^{2}$ \\
\hline $\mathbf{h}$ & Grevitational bead & m \\
\hline 耳 & Total heat content & $2 / \mathrm{kg}$ \\
\hline$\Delta H_{\mathbf{V}}$ & Heat of vaporization & $J / k g$ \\
\hline I & Internal energy & $\mathbf{J}$ \\
\hline$k_{t}$ & Thermal conductivity & $w / m \mathrm{~K}$ \\
\hline$?$ & Tangential aimension, Eq. (21) & $\mathbf{m}$ \\
\hline M & Mess & $\mathrm{kg}$ \\
\hline Mre & Mass vaportzed, Eq. (16) & $\mathbf{k g}$ \\
\hline$M_{s}$ & Mass source, Eq. (11) & $\mathrm{keg}$ \\
\hline III & Mass, Lagrangian cooräinate system & kB \\
\hline$\dot{\mathrm{m}}$ & Nass flow rate, Eq. (22) & $\mathrm{kg} / \mathrm{s}$ \\
\hline$\dot{\mathbf{M}}$ & Total mass flow & $\mathrm{kg} / \mathrm{s}$ \\
\hline $\mathbf{P}$ & Pressure & $\pi / m^{2}$ \\
\hline $\mathbf{q}$ & volumetric heat generation rate & $J / \mathrm{m}^{3} \mathrm{~s}$ \\
\hline$Q$ & V1scous pressure, Eq. (R-1) & $x / m^{2}$ \\
\hline $\mathbf{r}$ & Radius, also Iegranglan coordinate & m \\
\hline $\mathbf{R}$ & Ges constant & $\mathrm{J} / \mathrm{kg} \mathrm{K}$ \\
\hline SIIP & Standard temperature and pressure & \\
\hline$t$ & Time & B \\
\hline $\mathbf{T}$ & Temperature & $\mathbf{K}$ \\
\hline U & velocity & $\boldsymbol{m} / \mathrm{s}$ \\
\hline $\mathbf{v}$ & Speciflc volume & $\mathrm{x}^{3} / \mathrm{kg}$ \\
\hline
\end{tabular}


$\lambda$

$\mu$

$\mu$

$x$

p

DT

T
Volume

Dimension, also Eulerian coordinate

Young 's modulus

Coefficient of thermal expansion

Compressibility coefficient

Ratio of specific heats $\left(c_{p} / c_{v}\right)$

Average mean iree path for thermal radiation

Viscosity

Polsson's ratio, Eq. (20)

Void fraction

Density

Comined Iiquid and gas density, Eq. (12)

Tine constant, Eq. (9) $\mathrm{m}^{3}$

m

$\mathrm{N} / \mathrm{m}^{2}$

$\mathrm{K}^{-1}$

$\mathrm{m}^{2} / \mathrm{s}$

-

m

$x \mathrm{~s} / \mathrm{m}^{2}$

$-$

$-$

$\mathrm{kg} / \mathrm{m}^{3}$

$\mathrm{kg} / \mathrm{m}^{3}$

B.

$\begin{array}{ll}\ell & \text { IIquid } \\ \text { - } & \text { Initial condition } \\ v & \text { Vapor or gas } \\ \text { vp } & \text { Saturation condition }\end{array}$




\section{ABSIRACT}

The feasibility of using laser-driven fusion mulses for the comercial generation of electric power was investigated. Results are presented in two volumes. Volume I (IA-4858-NS, Uncl.) discusses the generral aspects of electric power piants based on laser-driven fusion energy sources, outlines the considerations that led to the vetted-wall concept on which the present otudy is besed, presents ietailed results of colculations that indicate the fiasibility of the concept, discusses aspects or important areas that are not well defined, summarizes related needs for ruxther study, and comares the concept with plants based on magnetically confined controlled therwonuclear reactions. Volume II (IA-4859uNs, Classifled, SRD) outlines IAST's laser program, discusses the problems of achieving laser-drtiven fusion, constders gubsequent neutronic interactions, and gives some eccnomic inplications. 
CENTRAT STATION PONER GEMERATION

BY LASER-DFIVIN FUSION

- VOTUME I -

Complled by I. A. Booth

\section{INTRODUCTION}

\section{A. GENTERAT}

It is generally recognized uithin the sclertific commanity that within the next fer generations the world's fossil and rich-ore fissile fuel supplies $w 11$ be depleted to the extent that their use for energy production vils become economically unattractive. It is also recognized that the natural supply of the comnon thermonuclear materials, deuterium and 11thium, is far greater than the estimated reserves of fossil and rich-ore flssile fuel6. Therefore, an international cooperative program (Sherwood p.oject) was Initlated as early as 2955 to find a means of producing controlled thermonuclear energy.

The concepts generated in this international program are based on using magnetic forces to compress and heat the thermonuclear materlal to Igaliton conditions and to confine this material while it burns. Howerer, in recent years, the developwent of laser technology has made compression, hesting, and confinement by inertial forces an alternative theoretical possibility for practical utilization of thermomuclear enersy. For purposes of this report, the conceptual devices based on these two means of producing tbermomuclear energy w111 be terwed:

- Megnetisally confined Thermonuclear Reactors (MFTR) and

- Inartialiy Confined Thermonuclear Reactors (ICIR).

This report describes a specific canceptual ICIR and sttendant means of utilizing the therwomuclear energy for commercial electrical power generation. The ICHR discussed in this report consists of concentric opherical vessejs (she11s) in whicin the thermonuclear energy is dexived from a deuterium-tritium (D+T) bum within a "pellet", located at the center of the ressels and initiated by a laser pulse. The resulting $\alpha$-particle energs and a small fraction of the neution energy are deposited within the pillet; this pellet energy is eventualiy transformed into sensible heat of lithium in a condenser outside the ressels. The remaining neutron energy is dissipated In a lithium blanket, located within the concentric she11s, where the fuel ingredient, tritium, is also produced. The heat content of the blanket and of the condenser IIthium Is eventually transferred to a conventional thermocynamic plant where the thermal energy is converted to elestrical energy In a oteam Rankine cycle.

For this rolume of the report, the following assumptions are made:

- The $(D+T)$ enersy released--17.6 veV per $(D+T)$ resction--is $200 \mathrm{MT}$ once each sscond.

- Twenty-five percent--4.4 MeV per (D+N) reaction-of this energy lo deposited within the pellet, and the remaining $75 \%$ is transported outside the pellet by neutrons.

The mechantisms for luser enerty eljocrption and for (D+I) Ionitfon and buring are tactity ignord. $A$ alscussion of these maters is inclualed in volume II (IA-4859-kS), of this report.

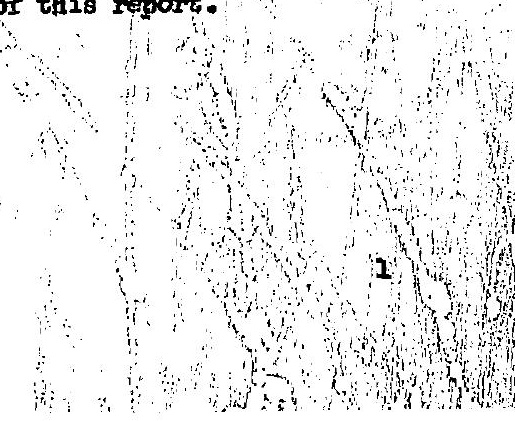


B. GENERAL ASPECTS OF TCIK PLANIS

For e (D+T) -iourning plant, two essentlal requivesents in an TCIR concept are similar to those In an WyR: (1) the need to proauce tritium artificlally because natural aupplies are Insufficient to support a large-scale power-generation industry, and (2) the need to convert the $34-\mathrm{keV}$ neutron energy Into usable form, beceuse there is no known means of using the energy of $14-\mathrm{HeV}$ neutrons alrectly except. by transforming this energy into thermal energy of another substance.

Both needs are satisfied by providing a "blanket" of 11thium which surrounds the source of $(D+T)$ energy. Tritium is generated in a major fraction of reactions between neutrons and 11thium; and Ithlum, being a light element, also converts neu. tron kinetic energy to thermel energy by means of elastic-scattering reactions. Furtherwore, acditional thermal enersy is produced by neutrons absorbed in the lithivm. It is essential that at least as wuch tritium be generated as is burned and lost, and that as much as posslble of the neutron energy be converted into thermal energr.

For cely, tritium breeding ratios in a lithIum blanket can be relatively high--in the range of 1.2 to -6 -which would proride a large operating margin to an ICWR plant. However, because tritium Iosses w17 of necessity be small, the plant w17] operate normally at a breeding ratio only slightiy greater than unity to prevent unnecessary bullaup of tritium reserves, although the plant can operate temporarliy with a high breeding ratio to butld up a fuel inventory for a new plant.

Because the major Fraction of the $(D+P)$ energy w111 be converted in the blarket 1.3 thermsl energy, the donfnant method of converting thermal energy to electriclty 111 i probabiy be by means of a heat enisine in a therwodynamic cycle. such a cycle vill be used merely because it offers the highest conversion efficiency in the temperature range in which normal engineering terlals can operate. The possibilities of directly comerting the remaining energy Into electricity are discussed in Section III; however, the amount thus generated can be, at best, criy a minor fraction of the total energy release.
A characterizing ICIR feature that is significently afferent from any MFIR aspect is the fact that the energy pulses represent substantial amounts of explostve energy. As described in detall in Volume II, the mintoum energy release, determined by both physical and economic considerations, is probably at least $200 \mathrm{MG}$ (equivalent to $95.6 \mathrm{lb}$ of Tir), which clearly cells for a sturty pressure vessel for contefnment. A major design problem in containing this blast energy is posed by the need for a Iow-pressure carlty in which the pellet can be initlated a laser pulse without prohibitive laser-energy Ioss along Its path, while, at the same time, malntaining a flnite laver of blanket materlal that surrounds the pellet.

In one proposed concept ${ }^{(1)}$ the cortty is defined by the vortex of a swlrling liquid blanket; In another, suggested at IASL, the cavity is formed by the wake of a projectile and the pellet 1s initlated before the cartity collapses. In both coacepts the liquid blanket is filled with gas bubbles, providing compressible but dense medium to attenuate the blast shock axplving at the containing pressure-vessel vall.

Another wethod of deflning the cavity region is to separate the cavity from the blanket by a Bolid wall. One signiflcant adrantage to the colldwall concept (as opposed to concepts with no wall) Is that the carity region is well defined and thus amenable to analysia. Another edvantage, which mey be even more impontant, is the posstblitity of proviaing a passage by mechanical means for exhausting the hot gases in the cavity prior to the next sinot. In the absence of a solid wall to define the cavity, mach blanket Iithium would be swept out of the ressel as these gases exhaust. The alternative approach, $1, e$, allowing these gases to condense in the blanket Ifthium, would take an excessively long time between shots.

In the solidwall concept, the inner ourface of the wall mast be protected from the damaging effects of the blast to prevent vaporizavion of the wall material by thermal radiation and erosion by high-relocity materlel, both of which emanate from the fuel pellet. Ilquid Iithlum is used to form a protective layer on the Inner-carity wall. 
This concept, subsequently referred to as the wetted-wall concept, has been selected for analysis and $w 111$ be discussed at length.

\section{CONSTDERATIONS IEADTNG TO THE WEITHD WAIT CORCHPT}

Three general features are essential to an ICIR design: a carlty within which to detonate the pellet, a pressure vessel to contain the blast, end a thick blanket containing lithium to convert the fast-neutron energy into heat and into tritium fuel. However, within these constraints there remaing a wide latitude within which to design the plant. For the present study a straightforward approach was identified and the development of a minimum of new technologies was assumed. This approach w1ll not necessarily result in a highly efficient plant nor In one satisfying all needs. However, if laserdriven fusion becomes a reality in the near future, as is certainly possible, there will be a need for a realtatic deston to serve as a basis for early plants.

As wenticned earlier, the proposed concept uses a solid wall to separate tibe reaction carity from the lithium blanket. The main design problems then become those of prorlaing for the protection from the alrect effects of the blast. Ith protection can be afforded by a thin layer of ablative material which, as It vaporizes, absorbs the energy of radiation and trupact from the pellet. A layer of Ithium, wetting the Inside of the wall, showld furnish this protection. If the well is porous, the IIthium layer can be restored after each pulse by a radial inflow of Ifthium from the blanket region. Thus the concept develops of a porous, wetted wall.

A second design proiplem concerns the containment of the blast energy. If the yorous, retted wall is thick enough to contain the blast, then intemal heating w11l lead to excessive temperatures; also, the breeding ratio in the blanket w111 be reduced to an unacceptable level. Therefore, the wall must be thin--the monentum from the blast is transmitted through the relatively incompressib]e Ifthium behind the wall to a main preseure ressel, which is thick enough to contain the energy. This pressure vessel is placed inside the lithium blanlset at a location where the bxeeding ratio is not significantly affected (see Appendix A).
Tis sonfleguration of in vessel and wetted wal1 poses another desisn problem. The preasure waves reverberating between these two valls result In imsard motion of the wetted wall. Because this wall is too thin to restrain the motion, another Inner well is needed between the pressure vessel and the wetted wall, with oufficlent thickness to xestrain the Imward motion yet not thick enough to prohtbitively recuce the breeding ratio.

The blast-contalning design thus evolves into a system with at least three walls:

- An Inwermost porcus wall, which is thin and allows the passage of Itthime to form a protective coating on the inside aurface.

- A maln pressure-ressel wall, thick enough to restrain the internal presaures in the cavity and blanket, located deep enough into the blanket so that it does not seriously affect the breeding ratio.

- An Inner structural wall, located between the former two wal1s, which is thick enough to restrain the inward motion and thin encugh so that It atill permits an adequate breeding ratio.

In the desion of these valls, the otratns and corresponding stresses wast bo limited to values which would not exceed the fatigue IImits of ths materials used. Therefore, careful desion and analysis are necessary to minimize the motions of these walls.

A Ithtum flow path is chosen which introduces the return Iithium (from the primary 100p) at the surfece of the porous wetted wall and forces it io Plow radially outward through the blanket. Thous the wetted wall is exposed to the lowest temperature in the primary IIthium 100p. This temperature Is chosen to be $400^{\circ} \mathrm{C}$, which is well above the Iithim melting point of $186^{\circ} \mathrm{C}$, but is within the acceptable range for fexritic stainless steels. The use of stainless steel reduces the costo of the vessel. Maintaining the inner wall at the minimm 200p temperature also reduses the mass transport of wall waterial by the flowing lithium to other parts of the loop ond ensures that the IIthium coating the Inner surface is relatively cool, with a low vapor pressure; therefore, the 11thim rapor density in the cavity prifor to the blast is minimized. (The 
vapor pressure of 11 thium at $400^{\circ} \mathrm{C}$ is $\sim 10^{-4}$ Torr, which should be well below tha cavity vacum required for passage of the lastr pulse.)

The temperature attained by the lithium flowing from the cuter portion of the blanket to the heat exchanger is dependent upon the blanket thermal power and upon the lithium flow rate. For this temperature, a value of $750^{\circ} \mathrm{C}\left(1380^{\circ} \mathrm{F}\right)$ was arbitrarily chosen to be compatible with existing steam technology. A maximim temperature as high as $1000^{\circ} \mathrm{C}$ or higher could be easily postulated, as has been done for sone MCIR plant studies, but this would introduce a host of presently unanswerable materials questions that can be bypassed by assuming only temperatures assoclated with existing steam technology.

Certain phenomena concerning the operation of the wetted-wall ICMR require analyses to determine the engineering feasibility of the concept. The se are listed below:

1. Pellet Interaction $\mathbf{w}$ ith the wetted-wajl layer.

2. Equilibration conditions of the cavity gases after a pellet burn and exhaustion (blowdokn) of these gases so that the initial conditions are restored before the next pellet is initiated.

3. Condensation of the exhaust gases and transformation of the cavity energy into heat content of the condenser ifthium.

4. Formation of the protective laver on the Inside surface of the wetted wall.

5. Tritium breeding and energy deposition uithin the blanket system.
6. Removal of the heat generated within the blanket.

7. Structural response of the restraining walls witiin the blanket.

8. Radiation damage to the solid materials within the system.

9. Induced activity in the materials within the system.

10. Removal of contaminants from the 11thium.

11. Safety features of an ICIR.

12. Economics of an ICIR power plant.

Items $I$ through $T$ are considered cruclal to the feaslbility of the present concept. Although Items 8 through i2 need attention, there are uncertaintles, due elther to the lack of technology or to undefined design criterle, which hinder the determination of feasibility by "paper studies". Items 8 through 12 are therefore discussed in general terms only, in section III.

Tritium breeding and energy deposition (Item 5) require analysis of nuclear processes. Because of the complexity and importance of the analysis, it is appropriate that the presentation be selfcontained; therefore, the nuclear radiationtransport considerations are discussed separately in Appendix A.

The remaining items are groumed into those concerning the cavity (Items 1 through 4) and those concerning the blanket (Items 6 and 7 ). The analyses of these phenomena follow in section II. 


\section{ANGLYSES OF WETPEMT-WAII CONCEPT}

The analyses of the cavity and blanket phenomena presented in this section are based on surrent calculational methods and avallable deta. During the few months aveliable for tisis study, the analyses have been conducted only to the point where reasonable conclusions concerning the engineering feasibility of the wetted-wall concept may be made. In some instances an analys is has not been completed, and further work is called for. These cases are pointed out as they are subsequently discussed.

\section{A. GEMERAL DESCR.LPTION}

\section{Iriroduction}

A schematic of the vetted-wall ICIR is shown in F1g. 1. The pellet (containing $D+T$ ) is infected through a port, which penetrates the blanket, and is Initiated at the center of the cavity by a laser pulse; the cavity is defined by the wetted wall 10cated at a radius of $1.0 \mathrm{~m}$ from the center. The subsequent (D+T) burn releases $200 \mathrm{MJ}$ of energy. Within fractions of a microsecond, $50 \mathrm{MJ}$ is depesited within the pellet and $152.5 \mathrm{Mr} 18$ generated within the blenket lithium and structural materials.

\section{Cavity Phenomena}

Within $~ 0.5$ us the pressure pulses generated Jy the interaction of the pellet with the I1thilum at the wetted well have subsided. Within the next few milliseconds, the cavity conditions are equiI1bxated, $\sim 1.6 \mathrm{~kg}$ of I1thium are veparized from the protective lever at the vall, and Bonic flow conditions of the carity geses are established at the outlet port.

The flow of hot gases through the carity outlet port is expanded in a diffuser to supersonic conditlons, and the gases are then condensed in a downstrean length of duct where a finely atcrized sprey of Ilquid Itthium is injected. (The opray of atomized droplets is reclrculated fran the liquid pool at the botton of the condenser.) Downstrean of the condenser duct, the mixture of gas and 11quid droplets, st11l at supersonic velocity, 10 decelerated by turbulent mixing created by a oprey of lerge lithium droplets. (The coarse-droplet opray is provided from a side-stream of the $400^{\circ} \mathrm{C}$ return flow from the heat exchanger.) The kinatic energs of this mixture is finaliy absorbed by inpacting with a pool of Iiquid ilthiun at the botton of the condenser system.

After $0.2 \mathrm{~B}$, the pressure within the cevity decreeses to less then atmorpheric, and the blordown continues during the remaining $0.8 \mathrm{~g}$ of the pulbe cycle, reducing the cavity pressure to leas then $133 \mathrm{~N} / \mathrm{m}^{2}(1.0 \mathrm{~mm} \mathrm{~Hz}$ ). The cycle 18 then repeated with the initiation of another pellet.

\section{Blanket Phenomena}

The energy deposited within the blanket is removed by circulating the 11thium through an external heat exchanger. Ithilum, flowing at $400^{\circ} \mathrm{C}$ from the heat exchanger, is returned to a plemu betreen the 1.0-cm-thick wetted wall and the 5.0-cu-thick Inner structural wall, which serves to restrain the movement of the inner blanket boundary ceused by the pressure waves generated within the blanket and the cavity presiare. Located a fer centinctere behind the wetted wall, the inner atructural vall also serres as a flow barfle for diotributing the radial outilon. The wetted vall woves alang with the structural wall through hydrodymantc coupling and, if needed, thruugh wechanical attachments.

The 10.0-cm-thick main pressure vessel sholl, located $1.7 \mathrm{~m}$ from the center of the spheres, is the outer restraint for the ICHR. Inis shell is stressed by the shock losds from the pressure pulses generated within tine carity and within the blanket. The radial outelow of lithium callects in 


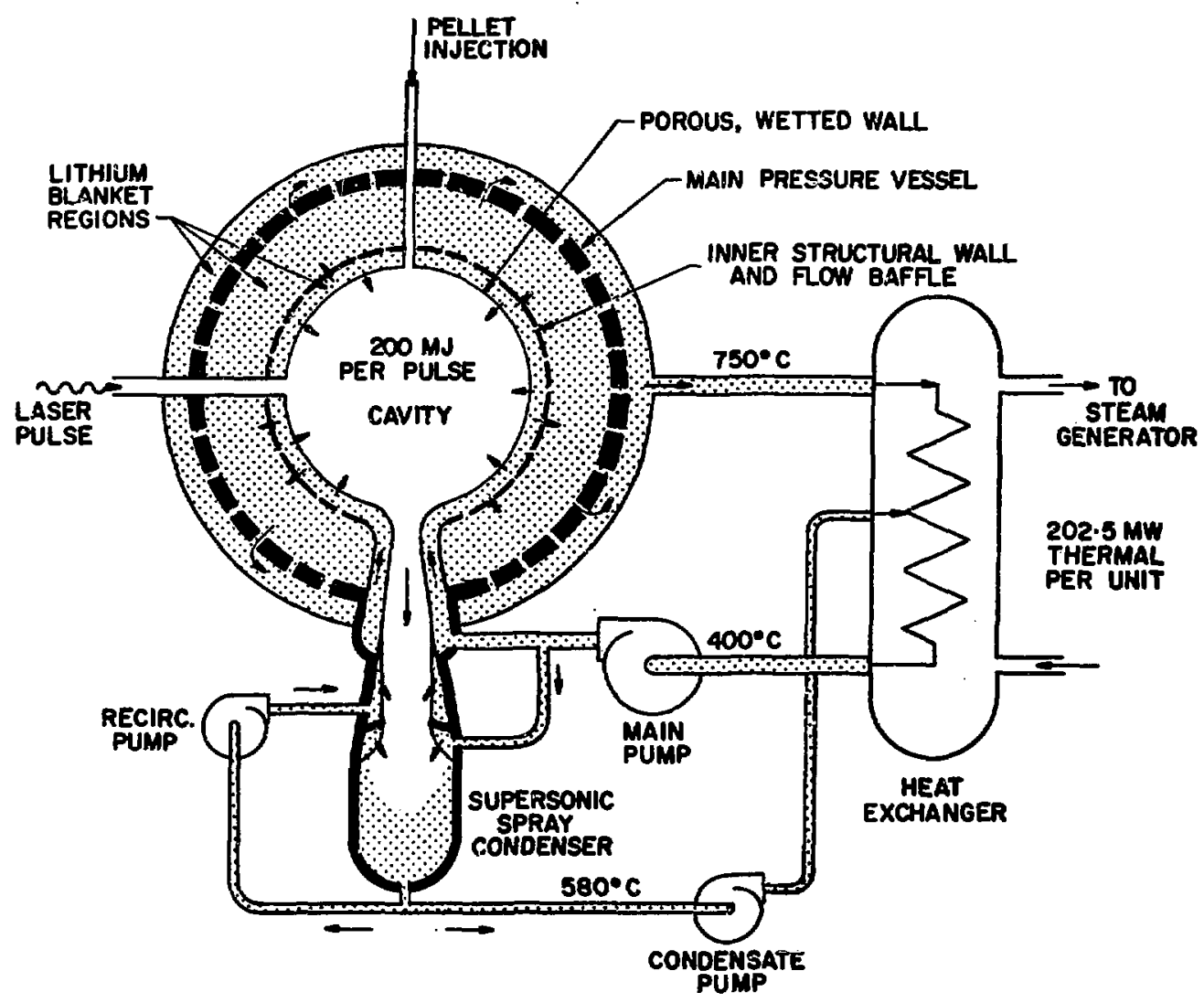

Fig. 1. Wetted-wail IOLR concept.

a plenum, defined by the outerust shell at $2.0 \mathrm{~m}$ from the center, and returns to the boat exchanger at $750^{\circ} \mathrm{c}$.

Paths for pellet injection and for the laser pules are provided by sull ports penotixating the blenket. The diffuner for the expulaton of cavity gases provides the saln structural oupport for the syoten of opherical shells.

\section{Thernodymic Plant}

The ainimum power level 18 based on a therwnl Imput of - 200 KW, Pron one ICIR. HIgher power levelo way be obtained by combining sereral IChRs in a resctor systern, thereby Increasing both the vereat1lity and the crexall ratio of actual operatIng porres to full destge porrex. The noninal therwal porrer level for a conseptual plant was axbitrartly choses to be $-2000 \mathrm{MH}$, zequiring ten nodulex ICHR.
The MoN diagren of an ICTR plant nodule 1s presented in Fig. 2. The Intexradiate heat exchanger is pleced between the tritiur-containing IIthium and the etean generator(s) to reduce the possibility of tritiun leakege Into the stoenplant components. The circulating flutd between the Interwodiate heat exchanger and the stack generatar(s) w11l be deterwined by engineering design criteria.

The stean cycle for this power plant is based on a correntional "ouble-stean-reheat design, stred for a therwal input of - $2000 \mathrm{~m}$ (2) a rlow diagran of the cycle is shown in Fig. 3. The exit steam from the high-pressure and intrawediste-highpreseure turbines f.8 reheated prifor to expanding throdgh the succeeding turbine to increase the thermodymante efflelency of the expanation. Nochanical-draft dry-cooling toirers are uned to reject waste heat, thus rejecting heat to the atron ephere rather than directly to nntural veter acurces. 


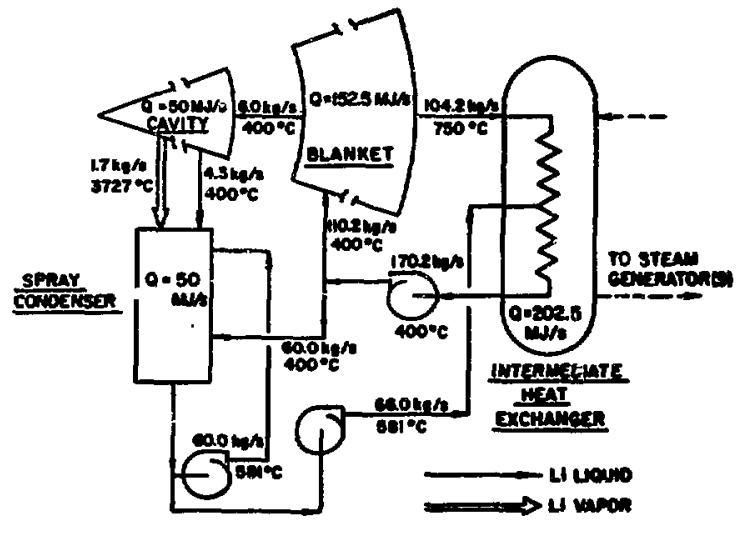

FIg. 2. ICHR plent Ilow diegrem.
The performance characteristics of the conceptual power plant are:

Thermal power generated, IN 20025

Grosi alternator output, MN 945

Steam-plent operating power, M

Net steam-plant electrical output, $197 \quad 897$

Net stean-plant eritelency, 5

ICIR plant operating power, $y_{\text {T }}$

Net station electrical send-out, NN 825

jet overall plant efflciency, of 40.7

The steamplant operating porrer Includes the requisrewent. for boller feed pups, cooling-water pueps, cooling-tower draft fans, and other auxil1aries, and the ICIR plent operting poiver includes the requirenents for lithium pupa, vacum purpa, the laser, and other aurdiaries.

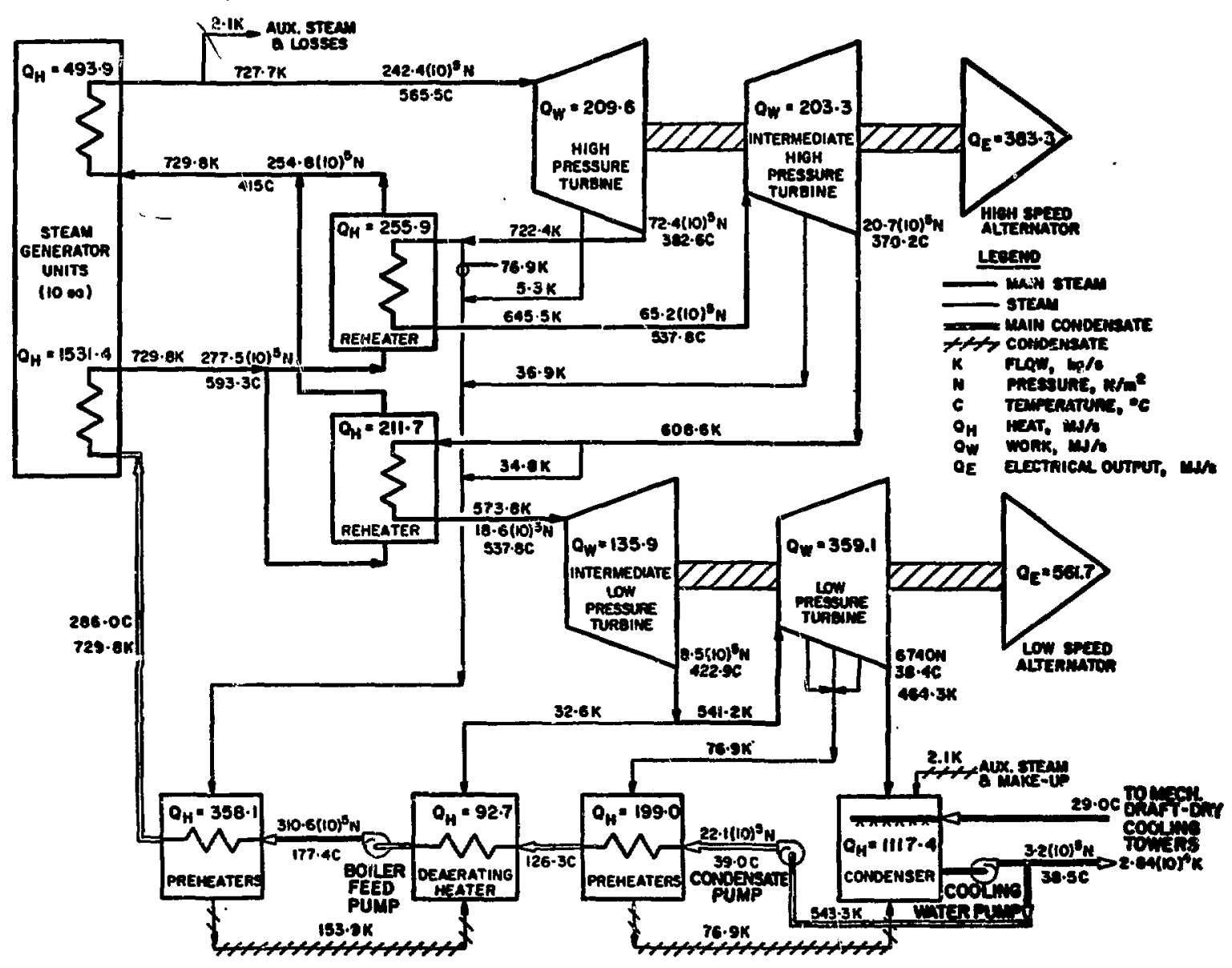

Fig. 3. Stom plent Fow diagera. 


\section{B. IIIB CAVIIII}

1. Introdiction

Phenowens within the cavity that are crucial to the feasiblilty of the vettedwall concept are:

- Pellet interaction with the wetted-wall laver - The initial Impulsen trensintted into the blanket region are inteawined by the Intitel blowoff of the protective IIthfum layer on the wettedwail eurrace by penelaration of the inftial therwal radiation from the pellet and subsequent radiation resulting from hydrodynamic interaction of the expending pellet debris with this protective layer.

- Carlty equilibration and blonders -- The quesi-equilibxium conditions (temperatiare, pressure, and density) of the cavity gases arter the blowoff of the pi tective leyer determine the size of the port through wich thece guses must exhewist, so that, within one second after the pulse, the density withIn the cavity is reduced to an acceptable value for the passage of tho noxt leser pulse.

- Condensation of cavity exhaust gases -- The exheust gases from the cavity must be cooled, condensed, and decelerated in the spray condenser in a manner that w111 maintain sonit flow through the exhaust port.

- Wetted-wall protective lavar formation -The protective laver of lithium must be formod on the Inside surface of the wetted vall prior to the initiation of the naxt energy puise.

These cart// phonouens ano discusised Indifldunly in the following paragraphs.

\section{Pellet Interaotica with Hetted-Woll laver}

The anciyses of the interaction phenoweng are based on the solution of the gag-dynante ccinservetion equations of wasn, wonentive, and energy (coupled with energy trensport by conduction and redietion difrusion) and on tebulated equetion-of-artate data. The conservation equations are formulatisd for ane-dinensional opherical geometry in the Iagrangtan space-cocoinate oystem:

veres $\frac{1}{p}=v=\frac{1}{3} \frac{\partial r^{3}}{\partial t}$,
MGpentum $\frac{\partial U}{\partial t}=-r^{2} \quad \frac{\partial}{\partial \bar{m}}(p+Q)$,

$$
\text { Dnergy } \quad \begin{aligned}
\frac{\partial E}{\partial t} & =-(P+Q) \frac{\partial v}{\partial t}+\frac{\partial E}{\partial t} \\
& +\frac{1}{\rho r^{\frac{E}{\varepsilon}}}\left[\lambda r^{2} \frac{\partial}{\partial r}\left(\sigma T^{4}\right)+r^{2} \frac{\partial}{\partial r}\left(k_{t} T\right)\right] .
\end{aligned}
$$

These equations are integrated in space and tine by a finite difference technique, as described in Appendix $\mathrm{B}$, and the tabular equation-of-state data are discusesd in Appendix C.

The calculation begine af $0.04 \mathrm{hb}$ after the $(\mathrm{D}+\mathrm{T})$ turn is Initlated, with the pellet nateriel cointaining $56.8 \mathrm{MJ}$. (For this initial celculation the amount of deposited energy whs -14, bigher than tha assumed $50 \mathrm{KJ}$. ) 19te internal and kinetic energy distributions in the pellet saterial (and Its geometry) are those from a pellet burn calculation described in Volume II. The lithium lever contadins $1.18 \mathrm{~kg}$, corresponding to a thickness of $0.196 \mathrm{bm}$, and the voluwe between the pellet materlal and the Itthium laver is vold. Frroughout the calculation the outer boundary of the Iithium (the vell boundary) is fixed at zero velocity, and urdrodynanic wotion of the 11quid phase is not perintted. The ablation is celculated as follors: euergy is absorbed in the 11quid-phase zonus as intarnal energy unt1l the teiperature reachis a $6000 \mathrm{~K}$ (selected arbitrarily), then the naterial vaporfizes at the saturation conditions (see fippendix c) and hydrudynemic notion of the zone begtns,

The celculation has been carried out to $10 \times$ us, at which tive the cavity conditions are at quasi-equilibrium with the lithim bollore rate being proportionel to the cavity temperature and dacressing monotontcally. The mressure proptle trangultted to the vetted-weIl boundary is ohown In $\mathrm{PIg}$. 4, and the integral of the lithium nase (vaporization rates) 1s prosented in Pig. 5. The firet prosure peak at 0.09 us 18 the result of 11thium blowor, caused by the radiation fron the pellet penetrating into the Ilthium laver. During this initial period of rediation penotration (up

to $-1.0 \mathrm{~kg})$, the averege radiation flow $\mathrm{L}_{\mathrm{B}}$ $\sim 2 \times 10^{5} \mathrm{~m} / \mathrm{m}^{2}$ and $54 \mathrm{~g}$ of Iithtum are vejporized. 


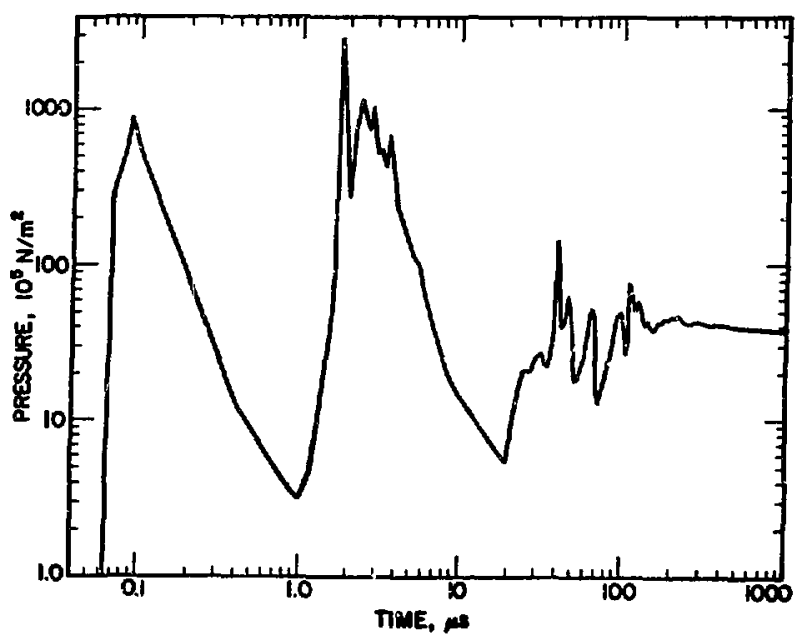

F1g. 4. Pressure trensmitted to cavity boundary after pellet intiation.

At - 1.0 ws the pellet material collides with the 11thlus. During the subsequent period from 1.0 to - 400 48, pressure pulses are generated at the boundary from additional lithium bloworf, caused by radiation as a result of hydrodymantc interaction of the pellet witerial with the lithium. The average energy flow into the lithiun during this period $18-10^{4} \mathrm{w} / \mathrm{m}^{2}$, resulting in the vaparization of an edditional $410 \mathrm{~g}$ of lithium.

\section{Cavity Equilibration and Blowdown}

For calculating the carity conditions at a time later than that determined in the previous peragraph, a couplete deseription of lithium atbate properties is necessary. The inclusion of this tope of equation-of-state information in analytical methods ior solving the hydrodymamies and heattransport equations involves a couplexity that is beyond the scope of this repart. Howsver, it will be shown that the exhaust-port alze for cavity blowdown 18 relatively insensitive to the cavity conditions; therefore, the carity conditions can be calculated by assuaing extrapolikted energy flow velues fram the results in Section II.B.2, above.

\section{a. Cerity Equilibration}

For a deposited energy of $50 \mathrm{MJ}$ in $\mathrm{a}$ volume of $4.189 \mathrm{n}^{3}$ (1.0 m radius), an "operating line" for the carlty conditions can bs constructed on a pressums-temperature diagram. As derived in

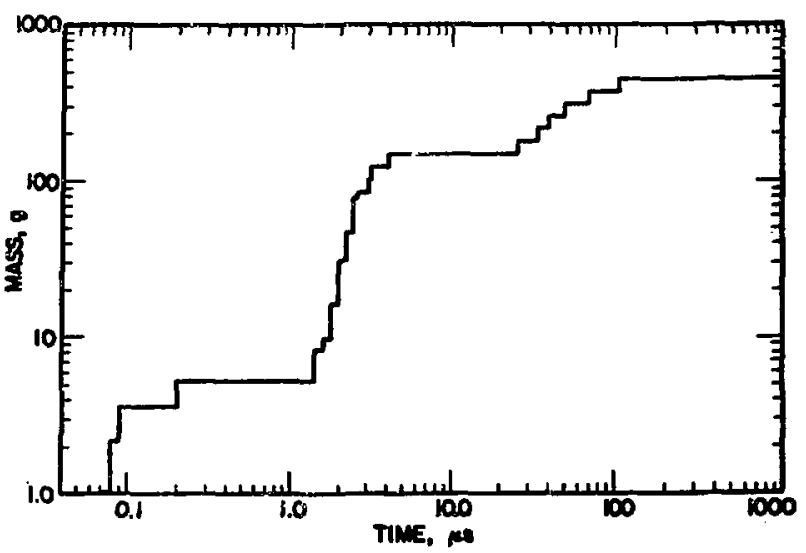

Fig. 5. Iithium mase vaporized (integral) from wetted rall during initiel interaction with peliet.

Appendix C, the equation for this oparating line $2 \mathrm{~B}$ Biven by:

$$
\frac{I}{V}=\frac{P_{v}}{T_{v}}\left[\frac{H_{v}-E_{o}}{R}+\int_{T_{v}}^{T} \frac{d T}{v^{-I}}\right]=27.9 \frac{\mathbf{K T}^{3}}{\mathbf{n}^{3}} .
$$

By extrapolating the energy Plow values fxan section II.B.2, the temperature is $188 \mathrm{~s}$ than $6000 \mathrm{~K}$ at $0.01 \mathrm{a}$; therefore, the rpereting line (Eq. 4) is plotted on the pressure-temperature alagren in Fig. 6 over the mobable range of taperetares. (The developingent of the pressuremteraperature disgrew is also given in Appenatx C.) As ahom in Flg. 6, the insensitivity of the assuned carity equilibration conditions is indiceted by the res latively suall pressure varietion over the teaperam ture range. This insensitivity will be further den mongtrated later.

\section{b. Cavity Bloudoun}

The mresaure decay in the carity can be colculated analytically by assuming an adiabatic expansion of the gas in the cavity through a choted nozzle. The equation for the cavity expanaion is

$$
v \frac{d o}{d t}=-\dot{M}
$$

and for sonic flow at the nozkie throat

$$
\dot{M}=\text { PA } \sqrt{\frac{y}{\text { RT }}\left(\frac{2}{y+1}\right)^{\frac{y+1}{\gamma-1}}}
$$




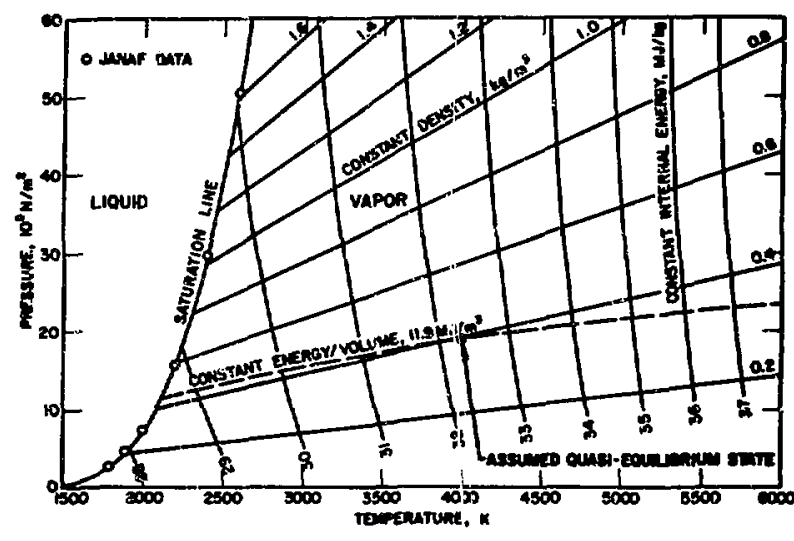

F1g. 6. Locus of quasi-equillbrium cavity conditicne prior to exhoulition of cevity gases.

By applying the 1sentropic reilations

$$
\frac{P}{P_{0}}=\left(\frac{e_{-}}{\rho_{0}}\right)^{v}
$$

and

$$
\frac{T}{T_{0}}=\left(\frac{\rho}{\rho_{0}}\right)^{y-1},
$$

the analytic expression

$$
\frac{0}{D_{0}}=\left(1+\frac{v-1}{2} \frac{t}{T}\right)^{-\frac{2}{v-1}}
$$

is obtained, where $T$ is the time constent. The tiwe constunt is $\mu_{\sigma} \dot{M}_{0}$, where $M_{0}$ is the initial wass in the cavity and $\dot{H}_{0} 18$ evaluated at the 1 in 1 tial pressure and tempersture.

By assuning that the pressure decays to 133 $\mathrm{I} / \mathrm{x}^{2}(1 \mathrm{~m} \mathrm{Hg})$ 10 $1.0 \mathrm{~s}, T$ and $\mathrm{A}$ cen be celculated with Bgs. 6, 7, and 9. Resulte of such calculations over the probable cavity texperature range are show in Table I. The Insensitivity of the assured carity equilibration conditions is further Indicated by the sall varlation in nozzle dieneter over the temperature range. Therefore, the cavity equilibration teiperature is arbitrarily assuwed to be $4000 \mathrm{~K}$; the corresponding pressure $1018.9(10)^{5}$ $\mathrm{H} / \mathrm{u}^{2}$ and the corresponding nass of vaportzed 11thiun $181.65 \mathrm{~kg}$.

The resulting pressure, temperature, and density proflles for the adiabatic expansion at an Initial temperature of $4000 \mathrm{~K}$ are shown in Fig. 7 .

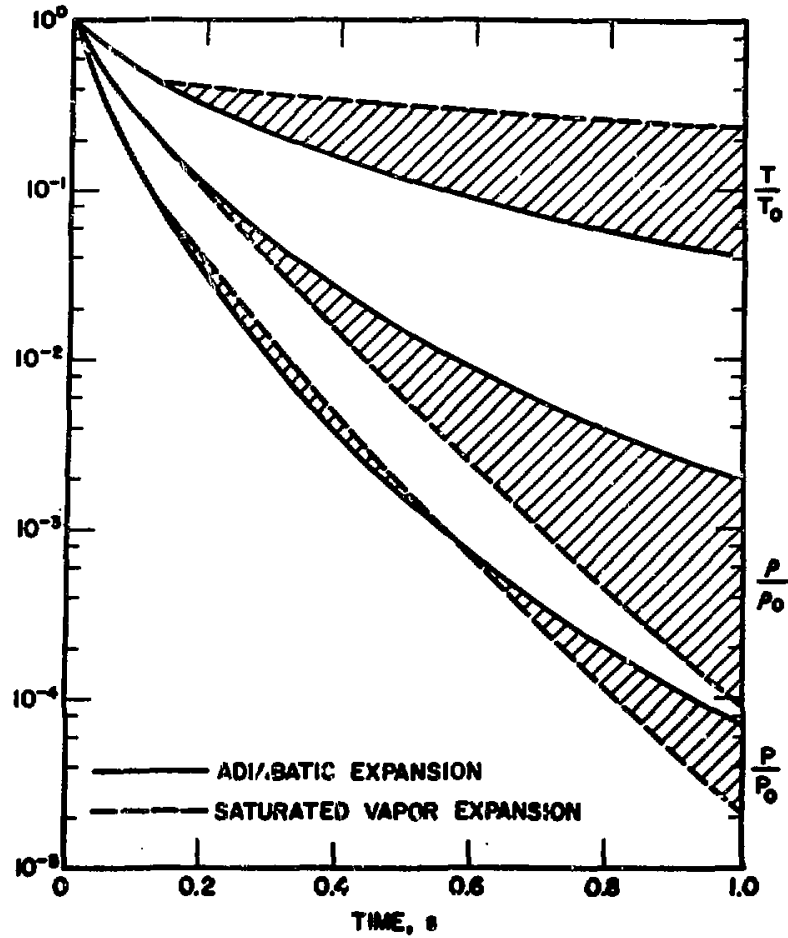

F18. T Cavity conditions during bloxdown; $P_{0}=18.92 \times 10^{5} \mathrm{~g} / \mathrm{m}^{2}, T_{0}=4000 \mathrm{~K}$, $\gamma=1.52$, and noxxle dionter $=0.235 \mathrm{~m}$.

These rosults asouw that the lithiun within the savity expands as a perfect gas; but, if the pressure decreases belon the seturation pressure at any point, condensation my occur and the uubseo ant expansion atght not be adiabatic. If the expansion were to follow saturation copditions, it would begin at 0.13 s where the temperature is equal to the saturation temperature at the correaponding pressure, and subsequent proffles would follow the saturatied vapor expansion curves shown is PAB. $T$.

The different results for adinbatic and saturated expanslun frdicate that: conjensation would decrease the density during blontorm. However, experfence at IASI with nozzle expansions of lithlue Indicate that a blgh degree of supersuturetion resulte, and condensation does not oecur. (3) Therefore, an abumption of ediabatic expansion an be more realistic and, for this ansiyg1s, is conservative besause the densities within the cavity rewain h1gher. 
CAVIIY CONDITIONS AND HOZZIE DIALETER

FOR FHERGY $=50$ MI AND CAVITY VOLUME $=4.189 \mathrm{~m}^{3}$

\begin{tabular}{|c|c|}
\hline $\begin{array}{c}\text { Inftial Temperature, } \\
\mathrm{K}\end{array}$ & $\begin{array}{l}\text { Mass Vaporized, } \\
\text { kg }\end{array}$ \\
\hline 2500 & 1.838 \\
\hline 3000 & 1.776 \\
\hline 4000 & 1.654 \\
\hline 5000 & 1.528 \\
\hline 6000 & 1.385 \\
\hline
\end{tabular}

\begin{tabular}{c}
$\begin{array}{l}\text { Intiel Presesure, } \\
105 \mathrm{~N} / \mathrm{m}^{2}\end{array}$ \\
\hline 13.14 \\
15.24 \\
18.92 \\
21.85 \\
23.77
\end{tabular}

\begin{tabular}{c}
$\frac{\text { Hozzle Dlaneter, }}{\text { m }}$ \\
\hline 0.259 \\
0.250 \\
0.235 \\
0.220 \\
0.203
\end{tabular}

4. Condersation of Cayity Exhaust Gases

a. Eeneral

During carlty blowdown through the sonic sozzle, the downstrean pressure to the "throat" must be low exough to maintain sanic flow at the throat, 1.e., the carity-to-throat pressure ratio must be maintalned at the critical pressure ratio. This condition will be mintained if the downstream duct area is divergeut, thus providing a supersonic nozzle ar diffuser, and if the domstrean pressure Is sufficiently low. As the lithlum vapor expands In the diffuser, the stete conditions will eventually cone to the point of condensation, even thougt: highly supersaturated. The amount of supersaturation to be expected prior to condensation is unknown, but, as polnted out earlier, IIthive condensation has not been achieved in supersonicdiffuser flow experiments. In any case, should condensation occur, a condensation shock w11l form In the diffuser at that point and the subsequent expansion w11l proceed at equilibrium saturation conditions.

The condensation can be prodictable and controlled if IIquid droplets are irjected into the vapors Btream, thus ungking the condensation process independent of the formation of liquid nuclel. If the dropleis are emall enough ( $510 \mu \mathrm{m})$, the liquid phuse w11l act hydrodymanically as a gas. The large ouxface area-to-volí volume ratio of the liquidphase particles enhances very high energy transfer and mass-transfer rates between the two phases, so that these transfer phenomena occur essentially at equilibriun, 1.e., are not time-dependent.

Therefore, under these conditions; the phenowerolOgy of condenser processes is as follows: the superbeated lithium vapor enters the condenser at superscoic velocity. Momentum is trangfexred betreen the two phafes, so that thetr velocities very rapidly become equal. Because the liquid-phase mass 18 much larger then that of the gas phase and the gas-phase velocity is much larger than that of the liquid phase, the momentum belance requires a large vold frection (ratio of gas to total volume) to prevent choking the flow in the condenser. DurIng the acceleretion of the Ilquid phase, the 11quid is heated and the gas is coaled becsies of the high energy traneport rate. At first the ges pressures are hteher then the corregponding vapor pressurea, so that ro vaporization occurs. Then the gas presisure decreases to 1068 than the corresporiling vapor pressure, vaporization occurs until the rolume becomes Baturated. Pasaage of the gas phase then proceeds at the equilibrium asturation condition, with raporization or condenestion dependent upon the rutio of Pluid pressure to vapor pressure; 1.e., vaporization cccurs at a ratto less than unity $(<2.0)$ and condensation occure at a retto greater than unity $(1.0)$. At the condenser exit, the gas and Ilquid pheses are at equilibrima saturation, noving at supersonic velocity, ifth wost of the mass in the IIquid phase. The exiting jet is decelerated through turbulent ixing with an injected Iitintum stream, and the kinetic energy of this mixture is then absoribed by impating in a atagnant pool of IIthiun of greater depth (Breater Brevitational heed) than the Iinetic bead of the ative. 
A conceptual 1llustration of the condenser system is ahown in Fig. 8. The atomized spray is Injected from a recirculating loop of the Itthium pool end is independent of the matn heat-rcmoval loop of the condenser Bystem. The return stream of the main heat-removal $100 \mathrm{p}$ is injected downotream to the exiting jet to yrovide deceleration turbulence prior to impingement with the lithium pool.

Analysis of the time-dependent events within the condenser section is based on a solution of the cone-dimensional differential equations for the conservation of mass, momentum, and energy, inclualng change-or-state processes and mass ani energ; trax ffer between the two phases.

The hydrodynamic conserration equations in the Bulerian- space coordinate system, with corrections for area changes, are:

$\underbrace{\text { Mas }}_{\text {Mass, phase }} \frac{\partial \rho}{\partial t}=-\left[U \frac{\partial o}{\partial x}+0 \frac{\partial U}{\partial x}+\frac{\rho U}{\chi^{A}} \frac{\partial(X A)}{\partial x}\right]$.

Mass,

IIquid phase

$$
\begin{aligned}
& \frac{\partial M_{\ell}}{\partial t}=-\left[y \frac{\partial M_{l}}{\partial x}+M_{b}, \frac{\partial U}{\partial x}\right. \\
& \left.+\frac{M_{\ell} U}{(1-x) A} \div \frac{\partial A(1-x)}{\partial x}+\frac{\partial M_{s}}{\partial t}\right],
\end{aligned}
$$

$\frac{\text { Monentum, }}{\frac{\text { conbined }}{\text { phases }}} \frac{\partial U}{\partial t}=-\left[U \frac{\partial U}{\partial x}+\frac{1}{\partial T} \frac{\partial(P+Q)}{\partial x}\right]$,

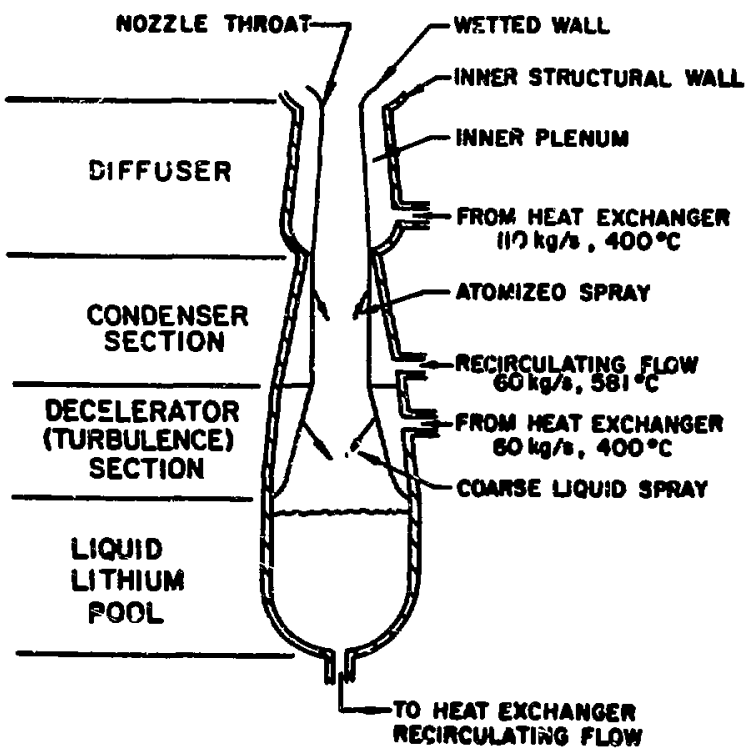

F1g. 8. Concept for supersonic spray condenser. $\frac{\text { Energy: }}{\text { gas phase }} \quad \frac{\partial E}{\partial t}=-\left[U \frac{\partial E}{\partial x}+\frac{(P+Q)}{\rho} \frac{\partial U}{\partial x}\right]$, and

Energry

Ilquid

$\frac{\partial E_{\ell}}{\partial t}=-U \frac{\partial E_{\ell}}{\partial x}+\frac{\partial E_{A}}{\partial t}$,

phase

where $P_{T}$ is the combined gas and ifquid-phase density (total mass per unit volume); U 1s elther the gas or the Ifquid-phase velocity (which remain equal to one another Irom the equilibrium momontum exchange); the vold fraction, $x$, is the rat. 0 of ges volume to total volume; and $\partial \mathrm{M}_{\mathrm{B}} / \partial t$ and $\partial \mathrm{g}_{\mathrm{g}} / \partial t$ are the mass and energy source terms, respectively, for the injected Ilquid oprey.

This system of equations is solved as an initial-value problem by a finite-difference technique; the equations are integrated in opace for so incremental time cycle as described in Appendix B.

The mass and enerey balances for the transport processes are: for enersy trangport prior to saturation,

$$
M_{l} C_{p} \Delta r_{l}=M_{q} \quad C_{\nabla} \Delta r_{q}
$$

and for mass and enorgy transpoet after saturation,

$$
\begin{aligned}
& H_{l} C_{p} \Delta r_{l}+H_{c} \Delta H_{v}=H_{v} c_{v} \Delta r_{v} \\
& \Delta \mathrm{y}_{\mathbf{l}}=\mathrm{M}_{\mathrm{ve}} \\
& p_{v}=p+\frac{U_{v c}}{A X \Delta x_{1}}=\frac{P_{v p}}{R T} \text {, } \\
& x=1-\frac{u_{l}+u_{v}}{\rho_{l} A \Delta x} \text {, }
\end{aligned}
$$

where $\mathrm{K}$, 18 the mass transparted between phases, $\Delta \mathrm{f}$ is the latent hast of vaporiration, the subscript $t$ denotes Iiquid phase, the subscript $y$ denotes gas phase, and the subscript vp denotes satureted conditions. In these latter five equations, if $P=\rho$ Fr $>P_{v P}$ condensation occurs and Mve is negative; if $P=p$ IN $<P$, vaponization occurs and Mre 18 positive. The equation-or-state for the gag phase is

$$
P=(Y-1) \rho E,
$$

and follows the eaturation Iine (see Appendix C) after saturation. 
§. Cavity Blowdown W:thout Liquid Spray

The time required to achieve isentroplc flow conditions has been determined by a calculation of the savity blowdown with the above system of equations, without the liquid phase. The gecmetric mesh for the calculation included the carity and the difruser. The calculation was carried out to 0.1 s for initial conditions of $18.9(10)^{5} \mathrm{~N} / \mathrm{m}^{2}$ and $4000 \mathrm{~K}$ in the cavity, and of $1.8 \mathrm{~F} / \mathrm{m}^{2}$ and $800 \mathrm{~K}$ is the nozzle. After $\sim 1.0 \mathrm{~ms}, \mathrm{a}$ quasi-equilibriun is established and the flow process becomes essemilally Isentrop1s. A comperison of the cevity conditions as calculuted by this time-dependent metrod and those calculated by the equilibrium method (adiabatic expansion in Section II.B.3) indicate olightly 10wer densities calculated by the time-dependent method. This is a reasonable result because the cavity conditions remain stagnant for the equilivrium calculation, whereas flow conditions within the cavity are calcr ated by the timerdependent calculation.

\section{c. Carity Blowdown with IIguid Spray}

For a typical calculation, the initial. conditions are $18.9 \mathrm{~N} / \mathrm{mi}^{2}$ and $4000 \mathrm{~K}$ withly the car rity and "chokel" flow within the converging section to the throat; $1.8 \mathrm{~N} / \mathrm{m}^{2}$ and $800 \mathrm{~K}$ within the dif. fuser and conienser sections; and a steady state flow distribution of the liquid phase with a constant mass flow rate per unit area and the voli fraction varying from 1.0 at the inlet to 0.75 at the exit of the condenser section. The geametry for this calculation consists of a diffuser length of $1.0 \mathrm{~m}$ with an outlet-to-inlet area ratio of 2.0 , and a condenser length of $1.0 \mathrm{~m}$ with a constant area. The "Eulexian wesh" cansists of 200 zones (1.0 cm each).

The time-dependent calculation includes the Now conditions within the diffuser and the condenser, and the cavity and throst conritions are calculated by the equilibriur method because of the rapid achievement of the isentropic conditions.

ithis typical calculation has been carried out to $0.02 \mathrm{~s}$, at wich time a quasi-equilibrium condition is esteblished. The intital shock passes through the condenser in $-3.0 \mathrm{~ms}$, during which time the Ilquid phase is accelerated to Mach $\approx 2$.
At 0.028 , the temperature and pressure profiles through the condenser are as shown in Figs. 9 and 10, respectively. At this time the pollowing conditions exist through the duct. Within the first $.2 .0 \mathrm{~cm}$ the gas is cooled and the Ilquid is heated with no vaporization or condensation cecurring; at $-2.0 \mathrm{~cm}$ the liquid $1 \mathrm{~s}$ hoated to saturation and raporization begtns; at $8.0 \mathrm{~cm}$ condensation begins; and at $30.0 \mathrm{~cm}$ the gas phese 18 fully "quenched" to the liquid-epray tenjerature and pressiure.

The kinetic head of the exiting jet from the condeneer sectiou $18-1.6 \times(10)^{6} \mathrm{x} / \mathrm{m}^{2}$ with a density of $-0.1 \mathrm{~kg} / \mathrm{m}^{3}$ and $o$ velocity of $\sim 4000 \mathrm{ip} / \mathrm{s}$. This kinetic head is reduced to that equivaiert to a erevily head of $1.0 \mathrm{~m}$ of Iithium $\left(-4700 \mathrm{~N} / \mathrm{m}^{2}\right)$ by turbulent mixing with an injected liquid apray to a density of $8.5 \mathrm{~kg} / \mathrm{m}^{3}$ and a velocity of $\sim 24 \mathrm{r} / \mathrm{s}$. A detalled palysis of this final mixing process is beyond the scope of this report.

\section{Wetted-Wall Protective Iaver Formation}

Proteotion from the Initial high peilet-energs fluxes is afforded by the pomation or a layer of liquid lithium on the Inside surfece of the wall prior to the initiation of the energy pulse. The minimum thickness of this layer is determined by that amount of Ifthium that could be vaparized by the deposited pellet energy (50 KJ): this amount of Ilthium is, $2.5 \mathrm{~kg}$, corresponding to a laver thickness of, $0.4 \mathrm{~mm}$. Results of calculetions describing the Interaction betreen the pellet and wetted-waIl layer, presented in Section II.B.2, Indicate that only $-0.5 \mathrm{~kg}$ of 11 thium is vaporized during the interaction time of $\sim 1.0 \mathrm{~ms}$. It $1 \mathrm{~s}$ conservatively assumed that a mininum thickness of $1.0 \mathrm{~mm}$ is sufficient to protect the vall surface from exposure during the pulse cycle.

The layer is formed on the inside surfece of the vetted vall by accumulation of the radial inflow of blanket lithium through the porous wail. It is assumed that the flow impedance within the wall can be tallored for any desired Plow distribution. Druing the pulse cycle, this flow will cease whtil the cevity pressure decreuses below the blanket pressure (assumed to be of the order of $18+m$ ). As ahow in FIg. 7 , the cavity pressure decreases to 1 ess then 1.0 atm at $0.2 \mathrm{~s}$ after 


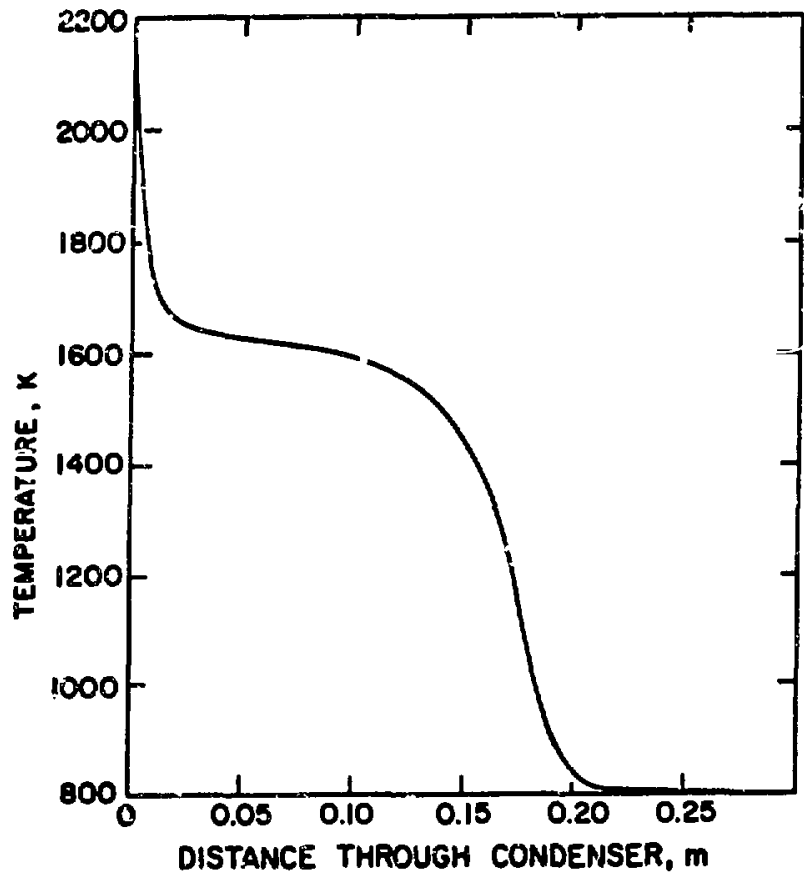

F18. 9. Temperature distribution in sprey condenser $0.02 \mathrm{~s}$ after pellet initiation.

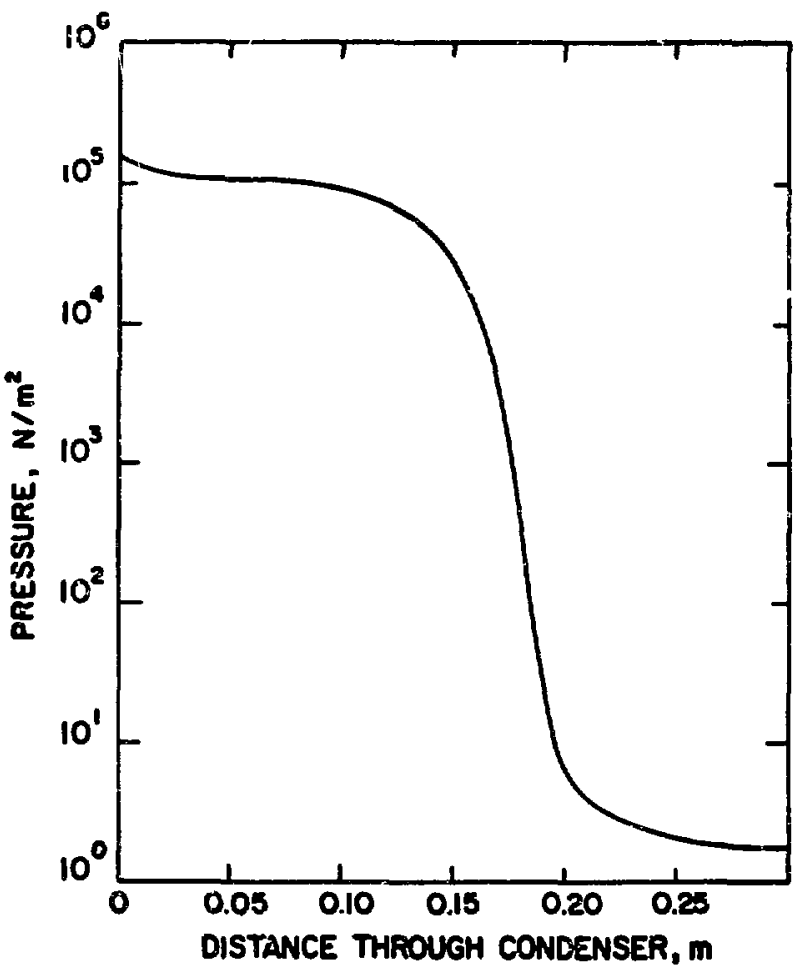

P48. 10. Preseure distribution in spray condenaer 0.02 s after yellet initietion. pulse inttiation; therefore, $\sim 0.8$ s is available for the formation of the layer.

During the collection and formation of the Laver, tine forces acting to alter 1ti unfformity are gravity, surface tension, the fluid riscous irorce, and any Imposed pressure gradients within the cavity or along the wall surface of the iayer. The equation of motion; assuming congtant density and unidirectional flow tangent to the inner spher1cel surfece, 1s:

$$
\frac{\partial P}{\partial l}+\rho U \frac{\partial U}{\partial l}-\rho g \frac{\partial h}{\partial l}+F_{D}=-\rho \frac{\partial U}{\partial t},
$$

where $\partial f$ is the circumferential increment along the direction of flow and $F_{D}$ is the viscous drag force. The surface-tension force does not appear in this relationship because this force is always normal to the tangent of the radius of curvature, 1.e., in this cese norral to the direction of Plow; and, for this ansiysis, 1 is is assumed that the curfacetension force is alwilys counterbalanced by a force derived from the ability of the 11quid to support tension through an internal stress muchanism. This asaumption 18 valid where the radius of curvature 1s large (the arder of centimeter's) and negative, 1.e., such that the surface-tension farce 18 directed toward the center of the sphere. In the upper hemiephere, should the radius of cure vature becone positive and smail, the surface may become unsteble, and a droplet may form and fall Prom the surience.

Because of the ability of littium to suppont tension, a static (velocity = zero everywhore) layer with a thickness of the arder of millimeters could be formed if pressure gradients are estabI1shed that equal the gravitationel gradients. However, at the stechy state flow condition, where the velocity distribution is fully developed, the layer thickness wili be minimim. Although the steady-state condition will probably not be schieved during a pulse cycle, an analysis of this condition, which results in a mininum thickness of 1.0 mia, should ensure that a Ifthium laver of sufficient thichness is rarwed.

*The ablitity of molten lithinn to support tension has been gbierved in high-terwerature heat-pipe research. (4) 
For this analysis, the mass-continuity equation with constent fluid deneity is:

$$
\rho \partial\left(U A_{l}\right)+\partial \dot{m}=0
$$

where $A_{\ell}$ is the cross-sectional area of the tangential flow and in is the radial inflow through the porous wall. Assuming that the wall impedance to the radial inflow is such that the pressure gradients are zero, the equation of motion (Eq. 2l) at steady state becones

$$
\rho U \frac{\partial U}{\partial l}-\rho g \frac{\partial h}{\partial l}+F_{D}=0
$$

Because the layer thickness is small, the flow is leminar and the dras force may be expressed by the Hagen-Polseuille relation,

$$
32 \frac{\ell_{\mu} \mathrm{U}}{\mathrm{D}_{\mathrm{t}}^{2}}
$$

where $l$ is the circumferential distence along the flow path and $D_{t}$ is the layer thickness. Equation 23 then oecomes

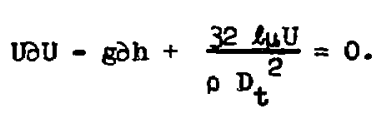

If the radial inflow is uniforn, the source in Eq. 22 becomes

$$
\partial \dot{\mathrm{in}}=\frac{\dot{H} \partial \mathrm{A}}{4 \pi r^{2}}
$$

Where $\dot{M}$ is the total radial inflow, $r$ is the cavity radius, and $\partial A_{2}$ is the increwental inside ourface erea of the wall. If $\partial h$ and $\partial A_{2}$ are expressed as functions of layer thiciness, the three equations (Eqs。22, 24, and 25) may be integrated simultar reously, Giving the velocity and thickose distribution of the laver.

Results of this integration for radial inflor rates of $1.0,2.0,5.0$, and $10.0 \mathrm{~kg} / \mathrm{s}$ are presented in F18. 11. Thase reaults indicate that a radial inflos of scmewhet $18 a s$ than $5.0 \mathrm{~kg} / \mathrm{s}$ istll provide a minimum thichose of $1.0 \mathrm{wa}$. The greater thiakness near the top of the upper homidathere is undesirable because of the positive redius of curstature, but this ney be alleviated by "tadloring" the wall inpedance in this area to reduce the redial inflow of lithiun. Because the velcolttes

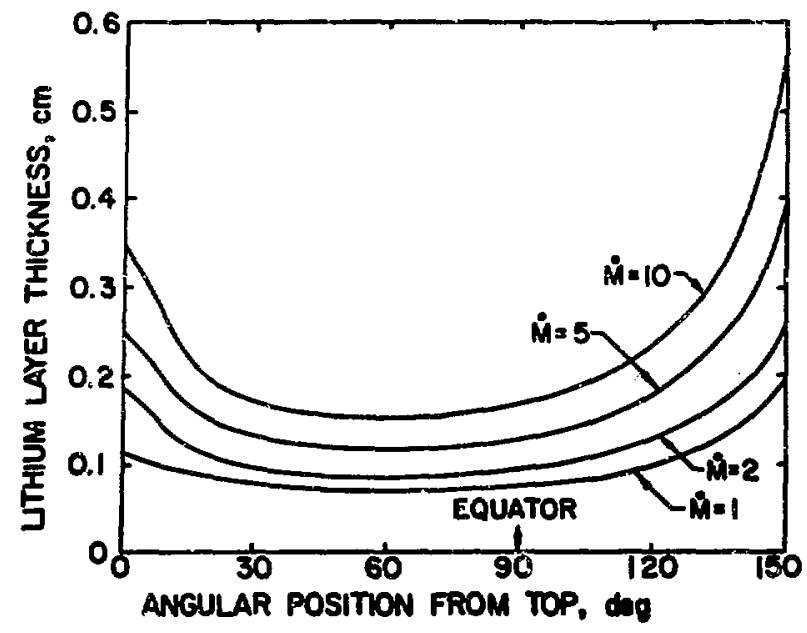

F1g. 11. Iithium layer thickness at steady-8tate flow conditions with unfrorm radial inflow through wetted vell.

are of the orier of tenths of a mater per second, the steadyostate condition will not be achieved; in any case, there w11l probably not be ouffictent time for a droplet to fam before the next pules 18 in1tiated. The important point is that a surelelent amount of lithlun be collected on the infide surface during the approximately 0.8 of reduced preso suxe in the pulse cyele. Therefors, the cruciel desien parameter in the formation of the protective laver 18 the vall Internal Impolance to the radial inflow of Iithium.

\section{THE Bnilus}

1. Introduction

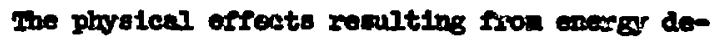
postion, requixing apectelc anvela, are:

- Reiovel of Deposited lnnirgr - Becunce the

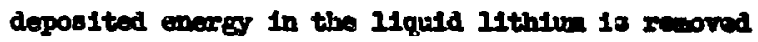
is cireulating it through in extanel beat ewhongor,

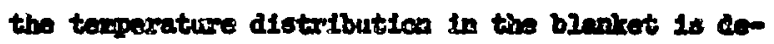

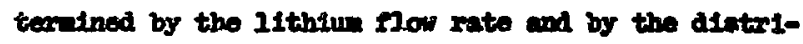
bution of deposited energy. Wh dopontted enewsy

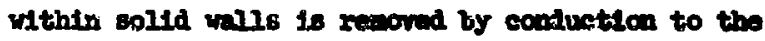
liquid as it Norr in ecntect with will ourteces.

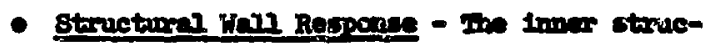
tuxal well and the cuter posture-vened maly well

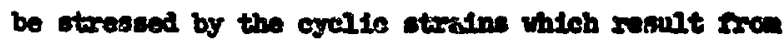
presture forees within the ovity and fxom sares 
within the liquid-blanket reglons. These stresses must not exceed the limitations of the material.

\section{Removal of Deposited Energy.}

a. General

For a temperature increase of $350 \mathrm{~K}$ in the blanket lithium, the flow rate $1 \mathrm{~s} 104.2 \mathrm{~kg} / \mathrm{s}$, for a total energy of $352.4 \mathrm{MT}$ deposited once each second. This flow passes through the inner structural wall and the main-pressure-vessel wall during trans1t through the ICTR.

The enalyses of the heat-transport processes within the liquid lithium and structural wails are besed on sclutions of the classical differential equation for heat conduction (diffusion), with a correction term added. For spherical symmetry, the one-dimensional equation with constant mass flow rate is

$$
\rho c_{p} \frac{\partial T}{\partial t}=\frac{k_{t}}{r^{2}} \frac{\partial}{\partial r}\left(r^{2} \frac{\partial T}{\partial r}\right)+q-\frac{\dot{\mu} c_{p}}{4 \pi r^{2}} \frac{\partial T}{\partial r}
$$

where the convection term is the last term of this equetion.

\section{b. Temperature I Istribution in Blanket}

The volunetric heat-generation rates

(q-term in Bq. 26) were celculated rrom the energy deposition values given in Table A-III, Appendix A. Using these heat-generation rates, the teuperature distribution in the lithium beticen the inner structural wall and the main-pressure-vessel wail was calculated by a numerical solution of Bq. 26 for successive pulses until tho steady state condition $(\partial T / \partial t=0)$ was attained. These results, presented In F1G. 12, Indicate that heat trangport by conduction is negligible and that - 100 puleed are required to attain staady gtate.

The steady-stute sulution of Bq. 26, neglecting the conduetion term, yields the distribution through the blanizet region shom in PIg. 13. The possibil1ty of alxing by natural convection curreats could elter this distribution, mobably increantag the te peratures vithis exch 11quid regicen to nox the exts temedreture of thot region; but, because the Iratial outhlor through the vals is unterm, this possibility would not eiter the vil teiperatures,

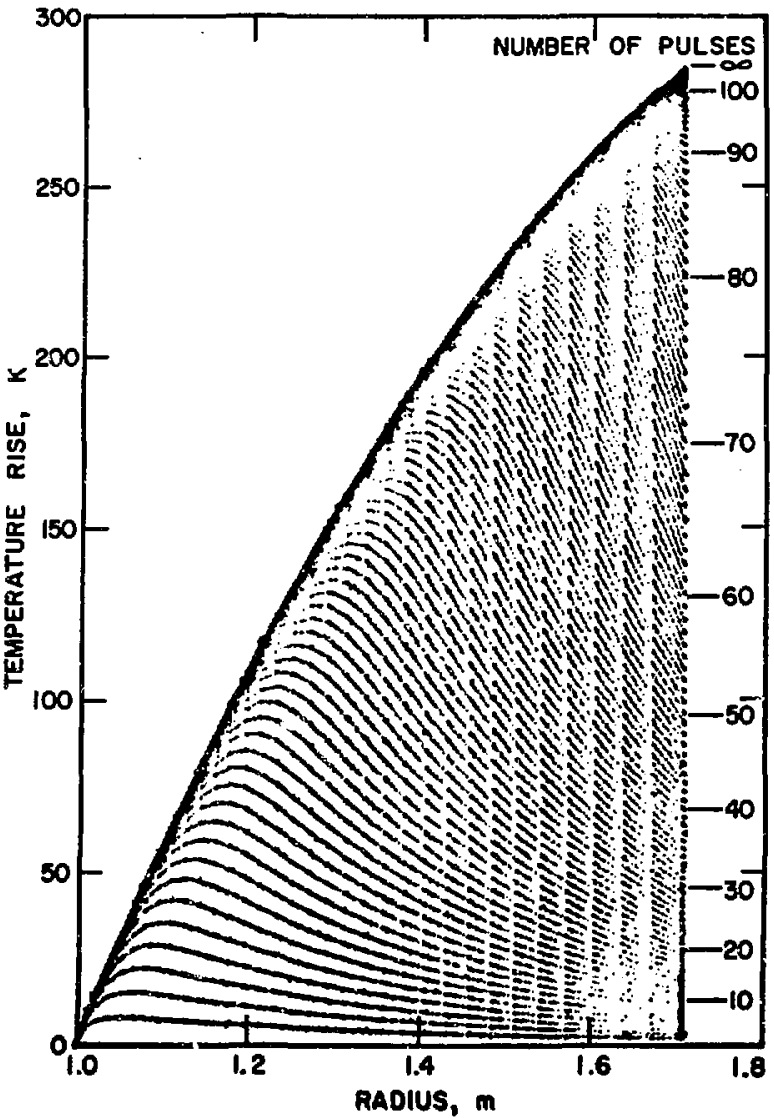

F1g. 12. Temperature distributions in blanket between structural walls for successive energy pulses

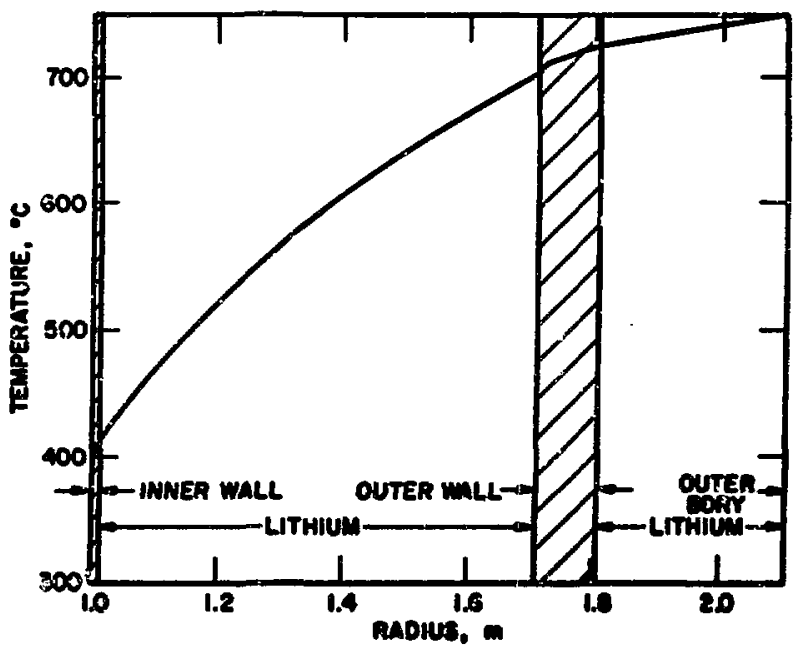

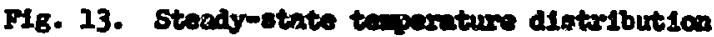
through 11thile binniet aroter. 
The "tailoring" of the wall impedences for uniform radiel outflow obviates the need for internal structure within the lithium regions to maintald the radiel outflos.

\section{c. Heat Removel in Parous Wettad Wall}

The resulting temperature distributions (by steady-state solutions of Eq. 26) through the wetted wall, with the inner and outer surfaces of the wall at constirnt temperature, are presented in FIg. 14 for 11thium flow rates of 3 and $10 \mathrm{~kg} / \mathrm{s}$. Because of the low Ifthlum flow rates (sufficient only to re-form the protective layer), the princ1pal mechanism of heat removal from this wall is by radial conduction; this is indicated by the small afference between the temperature distributions at the two flow rates. Annther calculation, with the innex-wall surfece as an adiabatic boundary, resulted in a maximum temperature difference of $67 \mathrm{~K}$. This means that the outer-wall surface wust be cooled by the flowing Iithium within the plenum beoween the vetted wall and the inner structural wall; otherwise, the wall material mav overbeat. The inside surface is cooled by vaporization of the protective I1thium layer, but it way not oe at the seme temperature as the outside surfece.

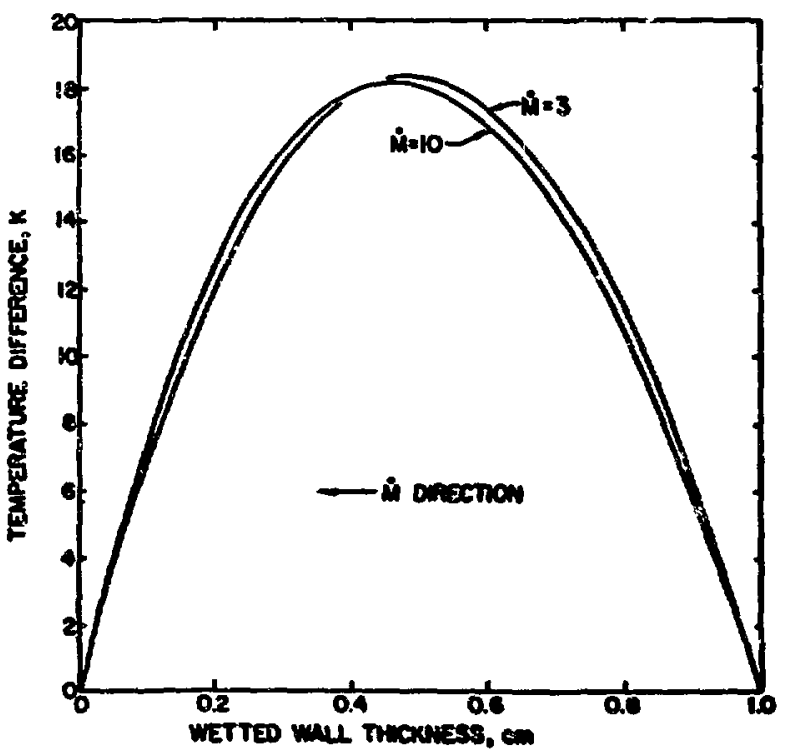

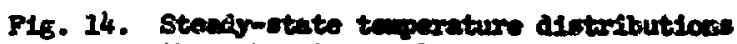
though wotted will for reding inplow rates of 3 and $10 \mathrm{ld} / \mathrm{s}$; sere and orter

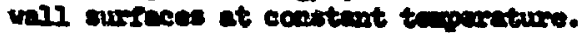

\section{d. Heat Removel in the Structural Walls}

The thicknesses of the inner and outer (main-pressure-vessel) structural walls, which are determined by the structural analyses in section II.C.3, below, are too large for conduction of the deposited heat to the inner and outer wall surfaces. Therefore, this heat must be rewoved by the IIthium that Plows through the walls. If the passages for this Iithium flow are erranged unitormy over the epherical aurfoce, the dominant temperature gradients will be tangentiai, between the passages. A conventional desigh for such rasseges is a triangular array of holes, passing radially through the valls. Results from calculationa of thperature gradients for vartous hole aizes and voll fractions in triangular arrays are presented in FLe. 15. The calculation ageumes no radiel condustion and a constant temereture around the surface of the holes. The resulting tempenature gredient is the difference between the temperature at the adlabatic center betroen the holes and that at the hole surfece.

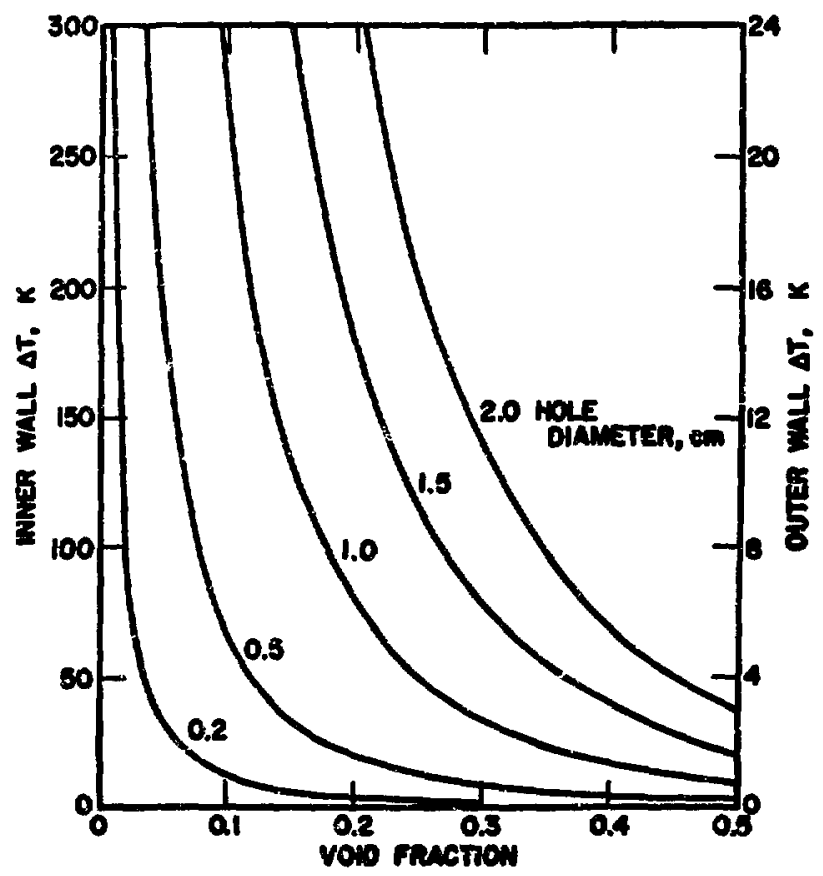

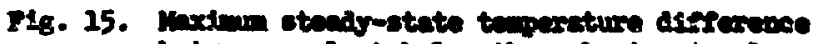

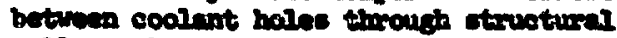
nule; hales in tepingular arwt. 
The structural design criterle for these passages ifll be to limit the thermal stresses res oulting from the temperature gradients and to IImit the vold fraction so that the vall streagth is not impaired. As discussed in section II.C.3, below, a temperature gradient of $50 \mathrm{~K}$ is easily accommodated. For the inner wall, a coolant-hole diameter of 0.25 cm and a vold frection of 0.05 , correpponding to a spacing of 1.06 cul between centers, migbt fulfill these criterla. Far the outer vall, a 0.9-cm-diem hole and a vold rraction of 0.05 vould give a 50-K gradlent and hole opacing of $3.8 \mathrm{~cm}$.

\section{e. Flor Impodance through Walls}

Beceuse the cooling of the Immer and outer atructural valls is by conduction to the Ithium Fowing through whese wals, it is essential thet

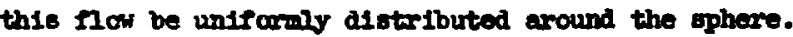
This cen be accompliahed by axting the Plow inpedance such thet the prossure $1008 \mathrm{~s}$ through the wall are signsficantl; higher than the totol prosoure changes within the Iithium blanket reglons. A reesonable asouption for this pressure $108 \mathrm{~s}$ is of the order o1 $10^{4} \mathrm{~N} / \mathrm{m}^{2}$, becaure the kinetic enerey chnnges within thece regions will necesearily be acil. A veane of supplying buch a flow rostriction could be the plucenent of ortelces in the coolent holes through the wall. For the inner will, an criflce with a dienoter of $-0.08 \mathrm{~cm}$ in each coolant hale vould poride a preanere 2008 of $-10^{4} \mathrm{~d} / \mathrm{a}^{2}$. For the outer vell, en ariplee dimeter of $\ldots .22 \mathrm{en}$ would Frovide this inpaines.

The Now inodinnes of the sutted wall is "tatlared" to provide the danired protective-laver thichess on the Instde sursace. Nthough the Ilor distribution will be onsentially untform, this is not for the purpose of cooling the wil. Iue nifor dif

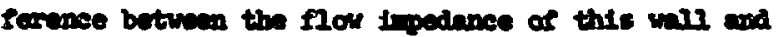
that of the structorel und is that the Irietion greacure 200 of the votted vall wat be hifher by et loant a factor of 10. The prealure in the plenu betaven the wotted well and the imas otxuctural wall will be of the order of $10^{5} \mathrm{~N} / \mathrm{m}^{2}$ (1.0 ata), and the preasure in the certity will be 100 than $10^{3} \mathrm{~g} / \mathrm{m}^{2}$

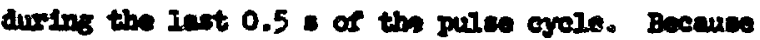

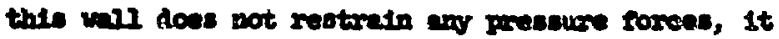

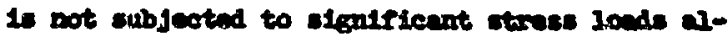
though it aut bohne alnotienity dus to the hydrodyneite and probable wechanical coupling with the inner structural wall. Insrefare, the wall may be pornus, with an Intricate Internal structure to sotabl1Bh this h1gh-irpedance flow path. Postib1lIties for such otructires are sintered wetaje or a wire-round ahell.

\section{Structural-Hall Response}

e. Cenexyl

The pressure forees from the carlty tend to wove the valls cutraxd, but the preasure forees wthin the 11quid (gemerated through the myarodynowle coupling between the walls and the Itthin expansion caused by noutrou beating) and the mallrostratnine forses cave a high-frequency ascillation (ringing) of both wils. Ithis ringing is superimposed on the cyelic notion fren the cuesper-second exexcy pulse. Because the otrences are cyclic with a correoponding high-requency ringing during each cycle, it is quite expaxent that for any recsonable vesel 1 lfeturs the ade of rallure vill be that of satigue.

\section{b. Natorial Conatibility wth Ithing}

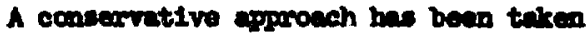
to investigate materials of high purity or inown corrosion properties. Nay ellors haring higher strength and fatioue proportios ay find appliear thon; howerex, thotr carxostce propentiles would necd fusthor imestigation.

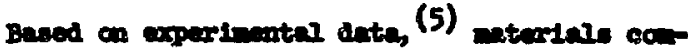
patible vith 11thin in the terperiture renge of intarest are the antanitic statniese steale, the refractory atols, Iroo-ebronila alloy, and pure Iron. Of thas meterials, the antenitic atainess

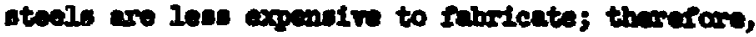
this mateatel io peforable if gratn-toundery

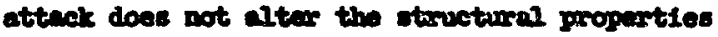
pechlbitively.

Moes transfor of steinlens oteel in lithin appeare to be a ance protilex at $540^{\circ} \mathrm{C}$, sith only very ainor painmbcundary attakk, 0.0015 in. 00 curring in $3000 \mathrm{~b}$ or a dyomis tast at one oscle par inute. (5) Basod on those date, statinless stevl should be ecegtable for the innar wall at $400^{\circ} \mathrm{C}$. Hoinver, alguificent eount of groin-boundary atteck and was trunnfer would be expeoted for the 
atainless-steel pressure-vessel wall at $700^{\circ} \mathrm{C}$ for extremely long operating times, and greater wase transfer than indicated by data for one-cycle-perminute tests would be expectod for the continuously operating system. The refractory metal, pose a significantly bmaller corroston and wase-transfer problen; but, as will be discussed later, the decrease in strength of the stainless steel caused by corrosion is probably insignificant.

One of the major aterials problems $\$ 117$ rematn that of maintaining edequate corrosion resistance in parent materlals, welds, and brazes nocessary for fabrication of the walls.

\section{c. Hall Strains}

The analysis of wall strains 18 based on the boundary motion of the 11quid, as determined from the solution of the hydrodymante equations for conservation of mass, monentum, and enorsy. The equations are focwulated for ono-dinensional opherical gecmetry in the Ingrangian-opace coardinte bystem. The equations for wase and wonentum conBervation are 1dentical to Bqs. 1 and 2 of Section II.B.2, above. The conservation of energy equation 18

$$
\frac{\partial E}{\partial t}=-(p+q) \frac{\partial y}{\partial t}
$$

The equation-or-gtate for Ilquid Itwhim, developed rron derinitions of the adiabatic compessiblitty factor and the voluvetrelc coasficient of thenrin expansion (oee Appewdix c) 18

$$
P=\frac{\left(\rho-\rho_{Q}\right)}{\rho B_{c}}+\frac{B_{q}}{B_{c}} \frac{5}{C_{p}},
$$

where $p_{0} 16$ the raference daresty of $507 \mathrm{~kg} / \mathrm{a}^{3}$ at 473 K. Presaures in this equation are reatricted to a minimin of $200 \mathrm{~g} / \mathrm{t}^{2}$ to sinulate reporisetion, which w117 precele ary signifseant negative preswre (Fuid tension).

The restrainting force of the vesed walls is accounted for by the addition of a stanin tarm to the montue equation at the Imax and outar boundaries of the problem. The nonertur equation for the problea boundaries is

$$
\frac{\partial U}{\partial t}=-r^{2} \frac{\partial(p+Q)}{\partial t}+\frac{e r D_{v}}{(I-\mu)} \frac{\partial r}{\partial r} .
$$

These equations are integrated explicitiy in space and time by a finite-difference technique, as described in Appendix B.

For the calculation, the configuration is a hollow ephere, divided into 150 zones of equal thickness, with a 1.0-m Inner radius and a 1.7-m outer radius. The intitial conditions are deteemined as follows. The denstty distribution is found (by using $\mathrm{Eq} .28$ ) tron the texpereture a1stribution in $F 1$ g. 13 at a constant pressure of $10^{5} \mathrm{~N} / \mathrm{m}^{2}$; with this deesity distaribution the pressure diotribuivion, shorn in F18. 16, is detesined (again Iran Eq. 28) by adding the energy d1otaribution (ohown in Fig. 17 and calculated from the eneray deposition in Table A-III, Appendix A) to the originel steady-atete enerey distribution.

Imroughoit the calculation, a messure prorlle,

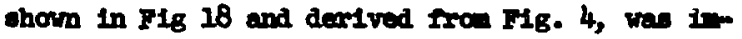
posed as the Innerewall boundary conditica.

The rooults fron a typical calculation are

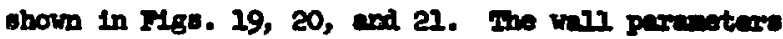
for thin calcution are: $\rho=8000 \mathrm{~kg} / \mathrm{m}^{3}, x=$ $2 \times 10^{11} \mathrm{w} / \mathrm{m}^{2}$, innex-wa $\mathrm{u}_{\mathrm{w}}=0.01 \mathrm{~m}$, outex-mall $D_{\mathrm{W}}=0.10 \mathrm{~m}$. The messures in Fle. $20(\mathrm{~g})$ and $(\mathrm{b})$ we the prescures in the 11thitu zones adjecent to the wall. Whe outer wall intingly mores outara due to the sudden Iithiwn expannion caused by the neutaron-enersy deposition. The Imner vell aleo Inttielly noves outward, due to the ingules from the cevity presaure butlalup. purting these initial wall movements, the intexnal proseure rave stron the nathen depoettion woves outrand at the rpeed of sound. At 0.18 we (the tim for sound to teavel a distance of $0.7 \mathrm{w}$ ) the presurue wave raplects afy the outer vall and returns to the imes vall at $0.36 \mathrm{~ms}$. The wotion of the imer vall is nomatartis revereed, then continues outinad due to the eavity pressure force as this Firat internal presaure mo diseipates. At 0.6 as the Imorerail notion 18 rovereed and 18 accelerated forvard by the Innear wil restratinting face coupled with the fare exerted by the preseure ware that has been bullaing up imodiataly behtin the wal. At this tim the outer wall wotion also is roversed by 1 to renteratning foree. Whe produre wave, which orlginted at the Innex wil, axyives at the outer wall at $0.78 \mathrm{~m}$; as the rave rullects, its Intensity is aplified by 


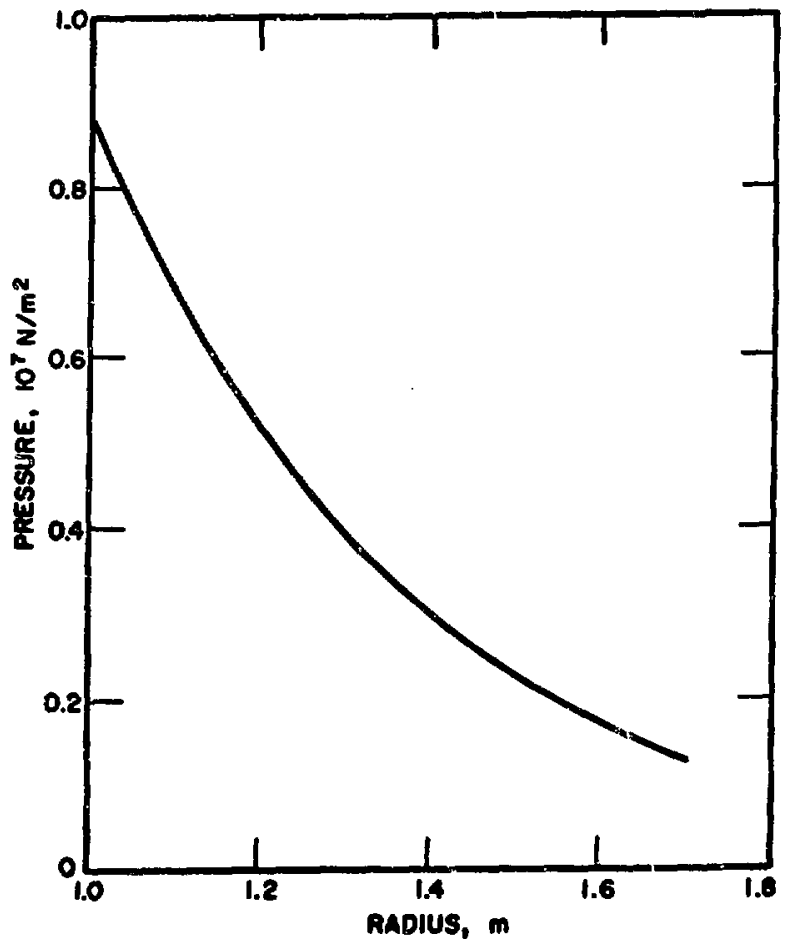

FIg. 16. Intilei presaure distribution in blanket It thium resulting from neutroneones: $y$ aposition.

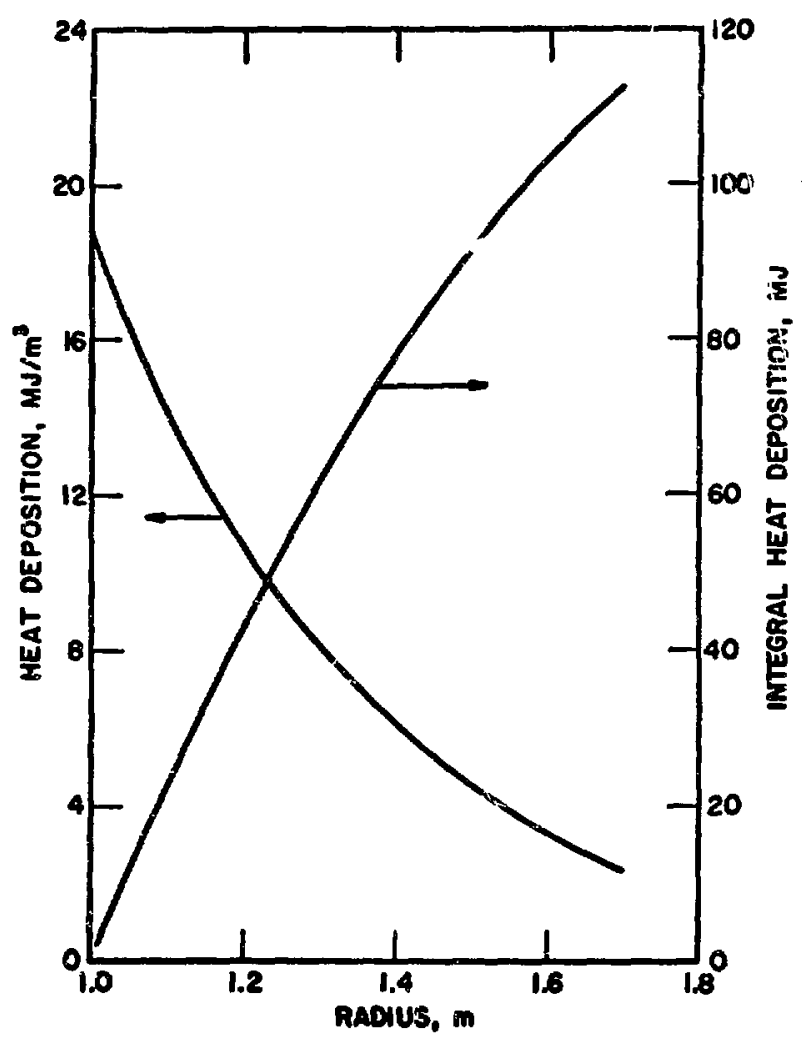

Fg. 17. Beat doposttion in blenket 11thium - used in sull starin aniyets.

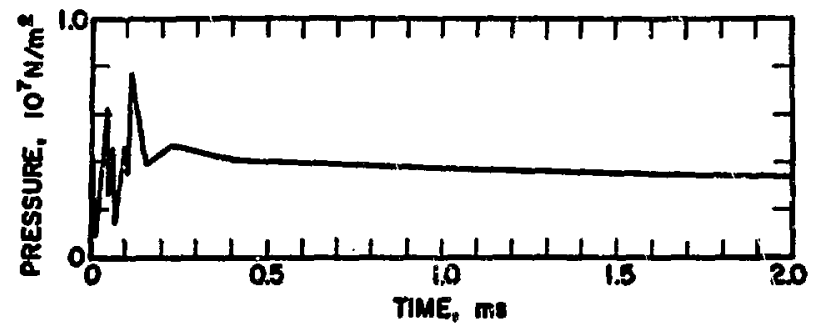

Fig. 18. Cavity preselure prordle transintted to inner rail, derived from Plg. 4.
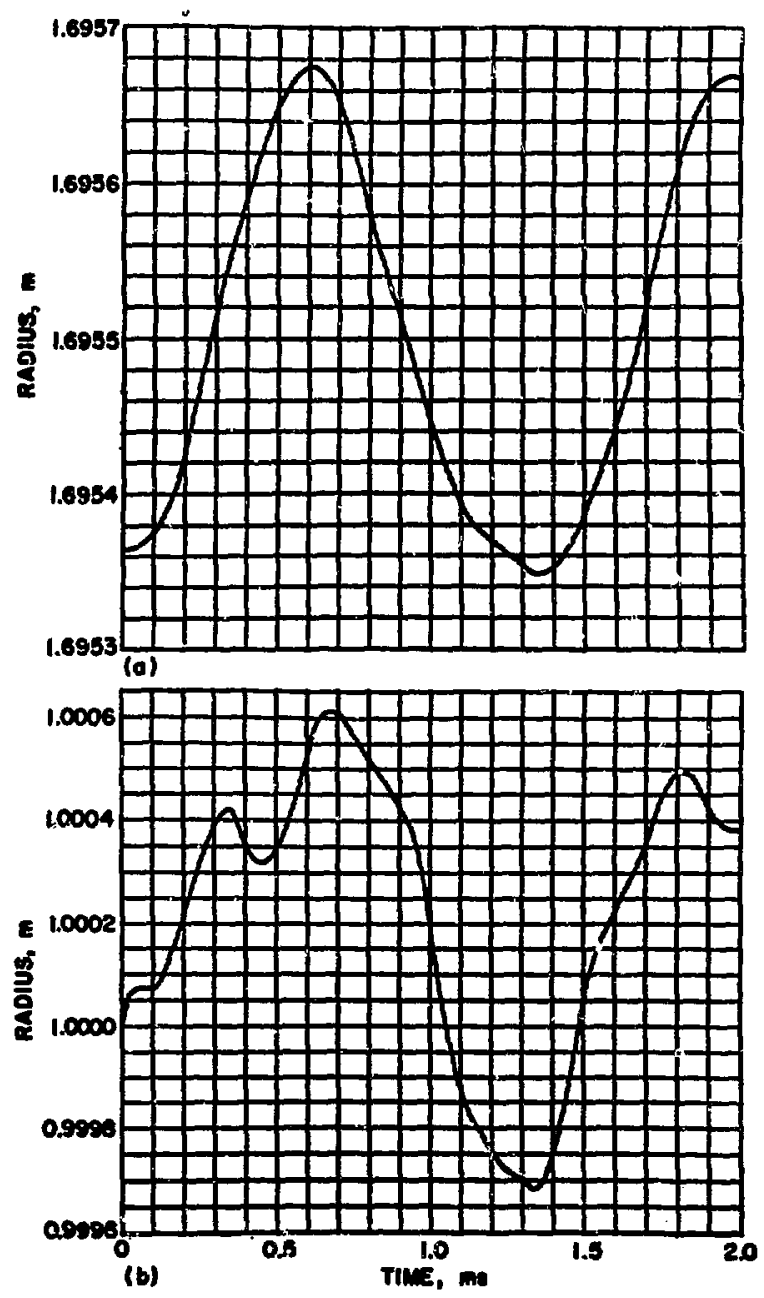

P16. 19. Diopleceneat of stmuctural valle during intilal pexiod of oscillation; (a) outer trall, (b) imer wall. 

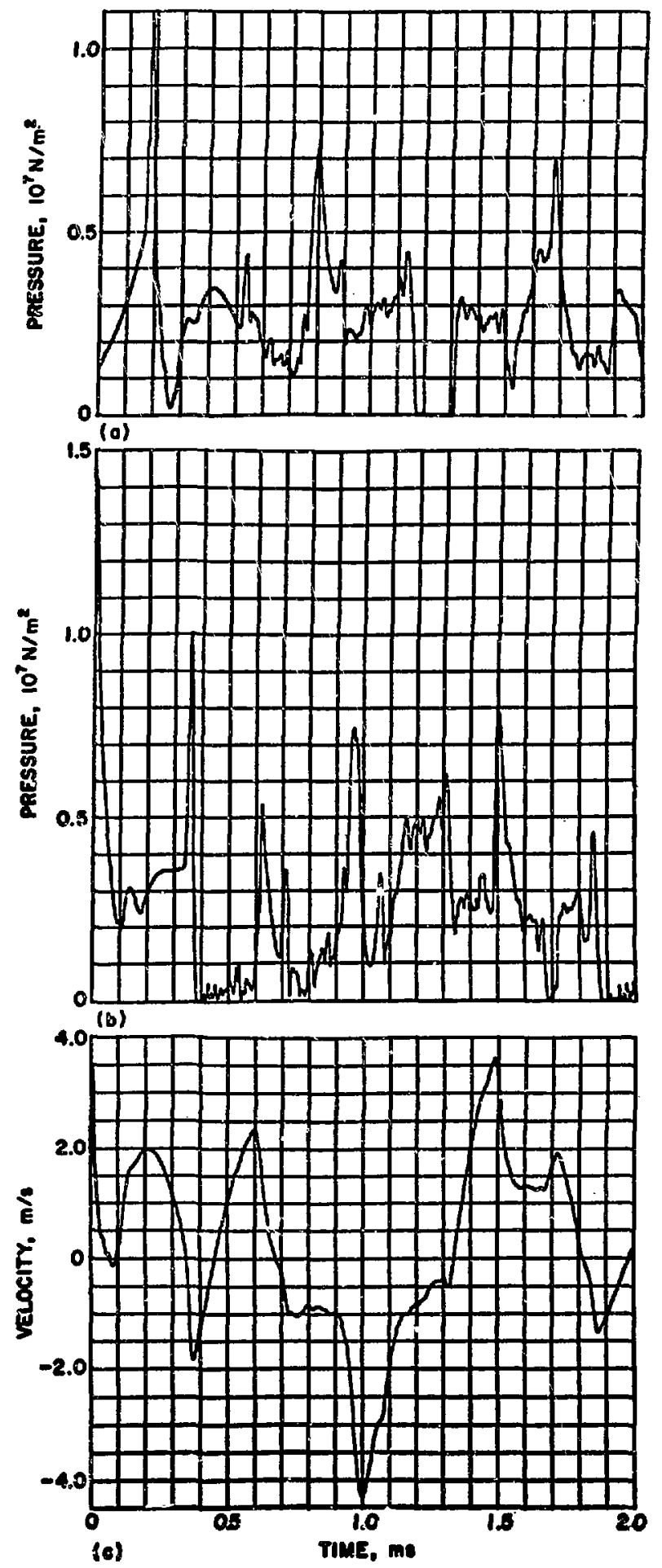

F18. 20. Pressure in I1thlum zones adjacent to: (a) outer wall, (b) inner wall, (c) velocity of inber vall, during initial period of oscillation.

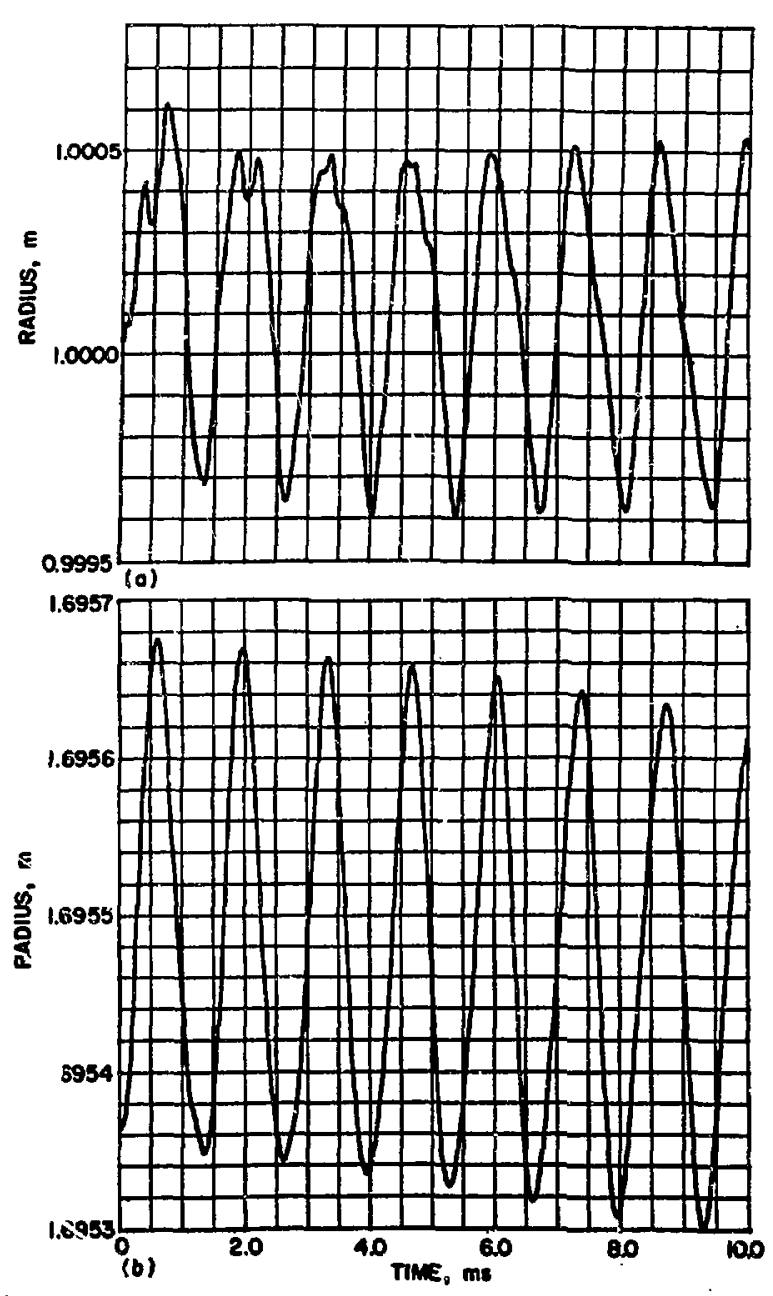

Fig. 21. Displacement of structural valls indicating oscillatary motion; (a) inner vall, (b) outer wall.

the Inward motion of the outer wall. When this wave returns to the inner wall, at $0.96 \mathrm{~ms}$, the wall is driven into compression and is accelerated further Invard until the restraining force and the cavity pressure force again reverse the motion, accelerstins the vall outward at $1.35 \mathrm{~ms}$. At 1.8 ws the events, which began at $0.6 \mathrm{~ms}$, are repeated, and the syrtem continues to ascillate, driven by the natural frequency of the outer wall. This is shown by the reoulte of a calculation to $10 \mathrm{~ms}$, plotted in F1g. 21 . Fo dexping mechanism that could reduce the above motions has been prorided for eltber wall. Deraping will exist but will not signifieantily affect the first few cycles. 
Waxtmum strains thet rewlt rrom vary ing the Inner-wall thickness, the modulus of elastleity, and the denoity are shown in Flg. 22. In all cases the Iraximum strain occurred with the wall in tension, frequently on the second cycle. With stiffer walls (hisher nodulus of elasticity) the strain is less but the stress 18 increased. A discussion of these resuits w117 follor in the subsequent section. Denelty changes of the inner wall have ittile effect on the resulting atrain.

The thicloness of the outer wall was also varied to determine the effect on wall strains. These results, shown in P18. 23, Indicate that for thiders outer walls the strain is reduced in the inner wall, as well as in the outer wall.

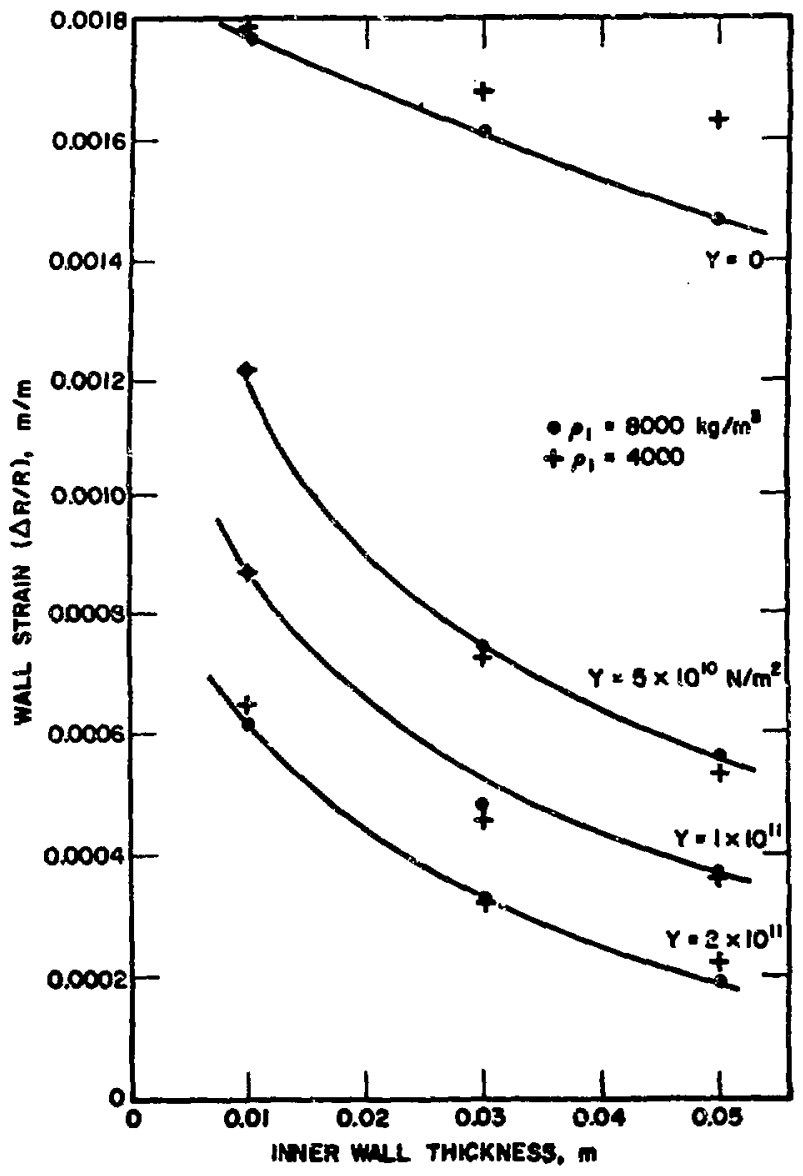

F1g. R2. Maximum strain of inner wall as a Iunction of inner-wall thickness for varlous meterial propenties (density and nodulus of elesticity); guter vall paramgtexs: $\mathrm{Y}=2 \times 10 \frac{1 \mathrm{f}}{\mathrm{H}} / \mathrm{m}^{2}, \mathrm{p}=8000 \mathrm{~kg} / \mathrm{m}^{3}$, $Y=2 \times 10^{11} \mathrm{r} / \mathrm{m}^{2}$; Imen vall thickness $=0.01 \mathrm{~m}$.

\section{d. Structural Anglye1B}

As mentioned previous $2 y$, the fallure node 1s Patigue. To obtain a conservative comparison vetween imposed and allowable fatigue stresses, allowable fatigue properties obtained from the literature $(6,7,8,9)$ were based on elther $10^{7}$ or $10^{8}$ cycles, whlchever was longest. Although $10^{7}$ or $10^{8}$ cycles are equivalent, respectively, to only 100 or 1000 days of operation at one cycle per becond, an extaremely minor decrease in al1owable fatigue properties would be expected for exposures beyond the $10^{7}$ to $10^{8}$ cycles. Other than the normal cyclic fatigue damage, allowable matertal fetigue poperties will be degraded by corrosion or mass transfer and posstbly by Irradiation domage. The structural propertieg of concen are then fatigue strength and Young:s modulus of elastinity. For comperison of stainless steel with prospective refrectary metols, a latigue analysis was conducted which included T1-55, $21-70, \mathrm{Zm}-1.58 \mathrm{n}$, and $\mathrm{Kb}\left(0.001 \% \mathrm{O}_{2}\right)$ as well as 300-series stainless oted. The fatigue strength and Young's modulus of these materials are shown in F1gB. 24 and 25, respectively.

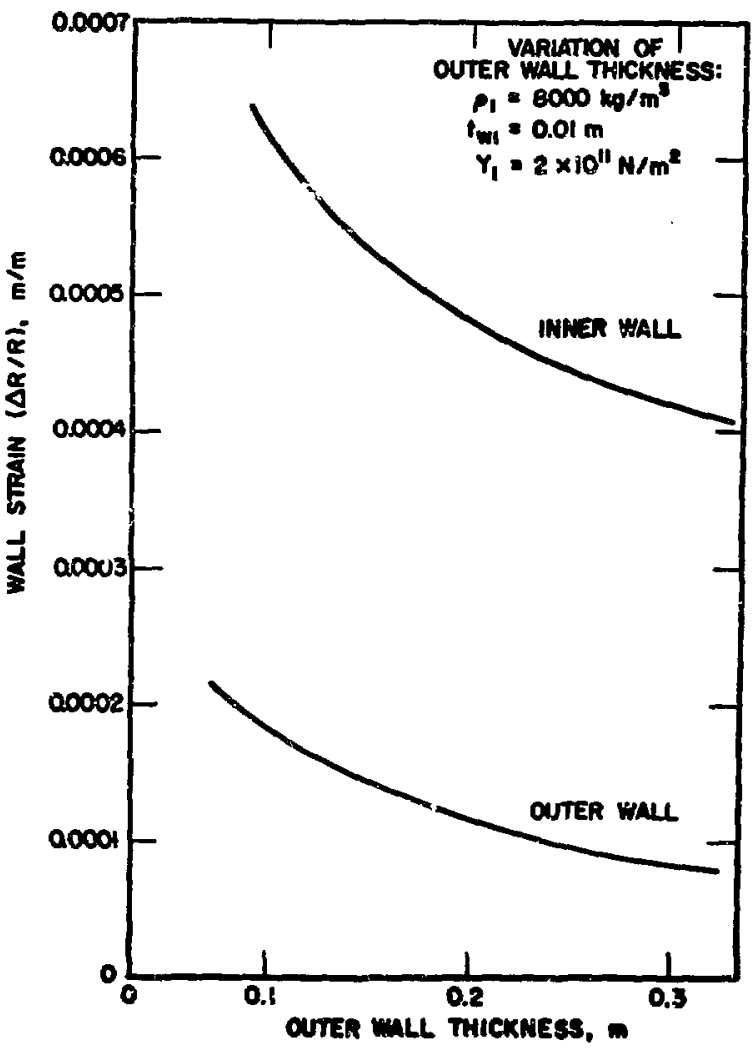

FIB. 23. Madine vall strains as a function of outer wall ticloges. 


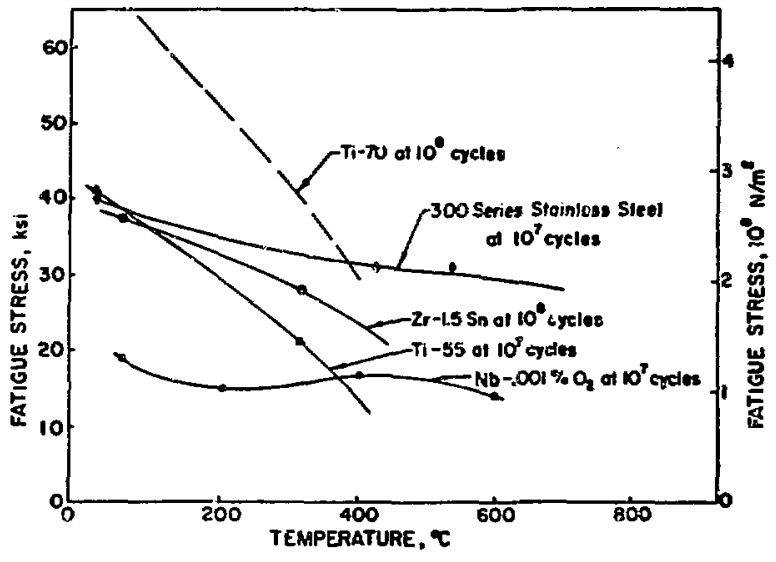

Fig. 24. Allowable fatigue-stress Iimits for prospective wall structural materials.

As can be sein in Fig. 22 the inner wall is subjected to a radial deflection affected primarily by the modulus and thickness of the material. Imposed stresses, plotted in Fig. 26, are calculated from these radial deflections for stainless steel, niobium, zirconium, and titanium, based on the modulus values in $\mathrm{Fig} .25$ and on a stress-soncentration factor of 2.2 , based on the vold fraction of 0.05 . The imposed stress curves have taken into account the variations in Young's modulus, Polsson's ratio, hole-stress concentrations, and the effects of ligament efficiencies of the triangular hole pattern on these properties. Allowable properties are based on published tensile-fatigue date $(6,7,8,9)$ at $10^{7}$ or $10^{8}$ cycles (Fig. 24) and, for a conservative estimate, have beell corrected for biaxial effects using Gough's approximation.

As can be seen from FIG. 26, the shell thicknesses required are $0.072 \mathrm{~m}$ for nioblum, $0.043 \mathrm{~m}$ for stainless steel, and $0.024 \mathrm{~m}$ for zircontum. Two grades of commerclally-pure titanium, Ti-55 and TH-70, are also plotted. If the carrosion properties of TH-70, with Its higher concentration of $\mathrm{O}_{2}$ and $\mathrm{Fe}$ were adequate to permit Its use, the 211aksble thickness could be reduced from $0.046 \mathrm{~m}$ $f$ In T1-55 to 0.014 m for T1-70. A simflar comparison could be made for nioblum, where the thiaknews could also be reduced significantly if a higher $\mathrm{O}_{c}$ content could be tolerated.

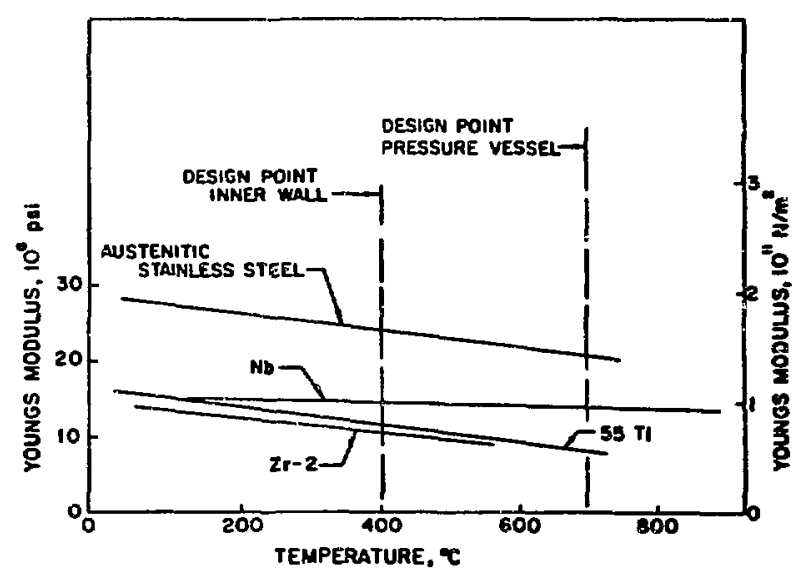

FIg. 25. Modulus of elasticity of prospective wall structural materials.

Any imposed thermal stress $w 11$ reduce the allowable fatigue stress. As shown in $\mathrm{Fig}$. 2 ? Por a limiting gradient of - $50 \mathrm{~K}$, the imposed thermal stress results in only a infor reduction in allowable fatigue properties. Obviously, for a final design, more margin in the form of Increased thickness will be required than indicated by the predicted faflure points show in FIg. 26.

The imposed alternating stresses in a ntoblum or Btainless-gteel outer wall, shom in FIg. 28, have been calculated from the deflection charaster1stics in FIg. 23. The alloweble stresses are bused on the same type anslysis as for the inner wall. Imposed stresses for tiranlum and zircons:m, which have relatively low tensile and alternating-stress properties at $700^{\circ} \mathrm{C}$, are not shown. To 111 ustrate the effect of Young's modulus on tinis imposed stress, moduil of $Y=1 \times 10^{11} \mathrm{~N} / \mathrm{m}^{2}$ for stainless steel and of $Y=2 \times 10^{11}$ for nlobium have bees plotted.

The wall deflection of the outer vessel is very small conpared with that of the inner veseel. For a $10 \mathrm{~mm}$-thick vessel, stainless steel has a large margin in fatiglie strength. Althe digh the corrouton and mass-twansfer resistances are better for niobtur, additional corrosion alowance is prokably not nes cessary for a stainless-ated pressur: veasel, which would be an extremely thick atr weture. The thermal stress resulting from a 50-K taperature gradient will present no problem. 


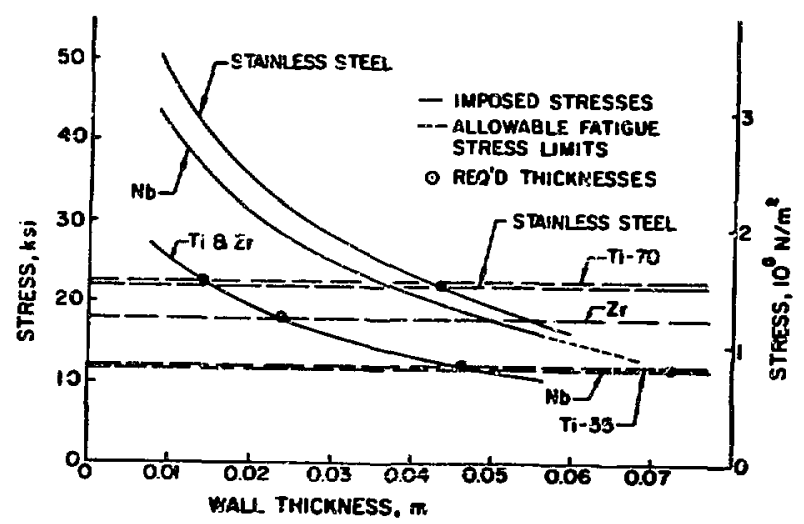

F1g. 26. Iryposed sitresses in inner wall as a function of thickness for jrospective wall neterials, besed on streins from Fls. 22.

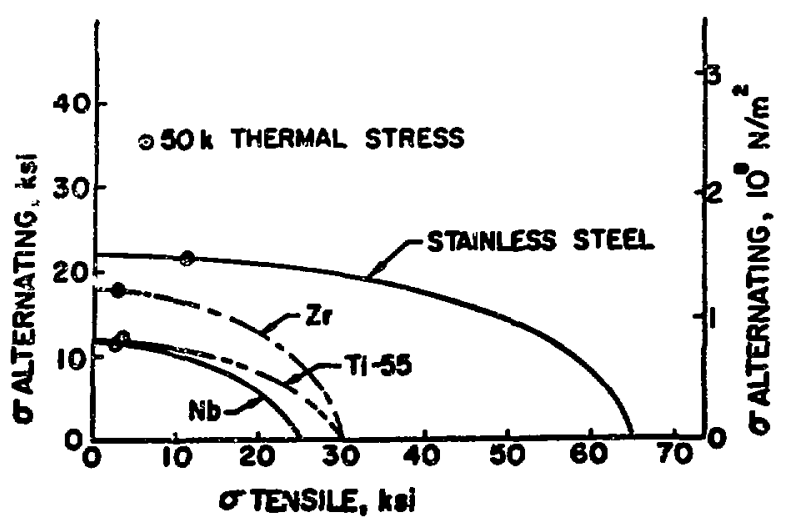

F18. 27. Reduction in allorable fatigue stresses by imposed stress.

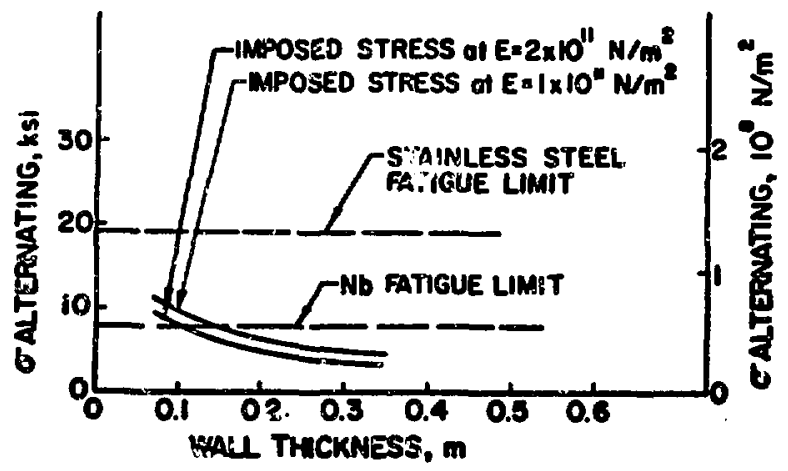

FIg. 28. Imposed stresses in outer wall as a function or thicluess for stainless otcel and nloblus, based on starins from Fig. 23. 


\section{AREAS OF UNCERTATNTYY}

\section{A . RADIATION DAMAGID}

Neutron damage to the inner walls of the confining vessel cruld limit the design power level and, more importantly, require replecement of the inner walls during the Iffetime of the power plant. This neutron damage becomes an important factor affecting both the feasibility and economics of the plant. This damage to an ICIR Inner wall is similar. to that to the reaction cavity wall of a ikrIR, which must endure comparable fluxes of neutions with similar energy spectra. Noreover, most magnetic systems, which do not have the protective Ilthium coating of ICIRs on the inner wall, must also endure significant fluxes of charged particles and lar-energy photon radiation.

Unfortunately, neutron radiation lamsge cannot be predicted accurately because the expected finences are beyond present experlence. The prerage flux of neutrons at the wetted wajl is $\sim 2 \times 10^{15}$ neutrons/s $\mathrm{cm}^{2}$ with an energy sfectium as shown in F48. 23. Fact-fission reactors projuce seutron fluxes of comparable magnitude, sut oniy at lower energies ( $<2.5 \mathrm{MeV}$ ). However, because many Inportant neutron reactions have energy thresholds exceeding 2.5 MeV, extrapolation of data from such fission reactors is inadequate. Coskcroft-Halton accelerators produce the appropiciate ceutron spectra, but only at fluxes lower by a factor of $\sim 10^{3}$; therefore experiments equivalent to ten or twenty years of fuston-reactor operation would be clearly ingractical. Underground explosions of thermonuclear veapons could provide appropriate fluxes and spectra, but only in short, single pulses, with the result that the totai fluence would not be adequate, amonting to only a few minutes of reactor operation. Vartous experiments are under way to model some aspects of the radiation-armage problem to be encountered in fusion reactors, but all are deficient in etther Pluence or spectrum. Nrit experiments with appropriate IJuxes and energies are proposed, (10) but noas are under way.
There are two major categorles of neutron damage: (1) atomic displacements, 1.e., Frenkelpair production, nnd (2) nuclear transwatations. The production rates of Frenkel. pairs and trallsmutation products can be estimated: the trensmitation production from standard cross-sections; (11) and Frenikel-palr production from the elastic and inelastic differential scattering cross-section (coupled with a slowing-down model of the primary, knock-on, atsplaced atoms, (12) as siven by KInchin and Pease ${ }^{(13)}$ ). As an example, estimuted displacement and transmutation production rates for nioblum, the comon inner-wall inatertal for MCTRs, are shown in Table II. These results were calculated by using the above-cited cross-section data

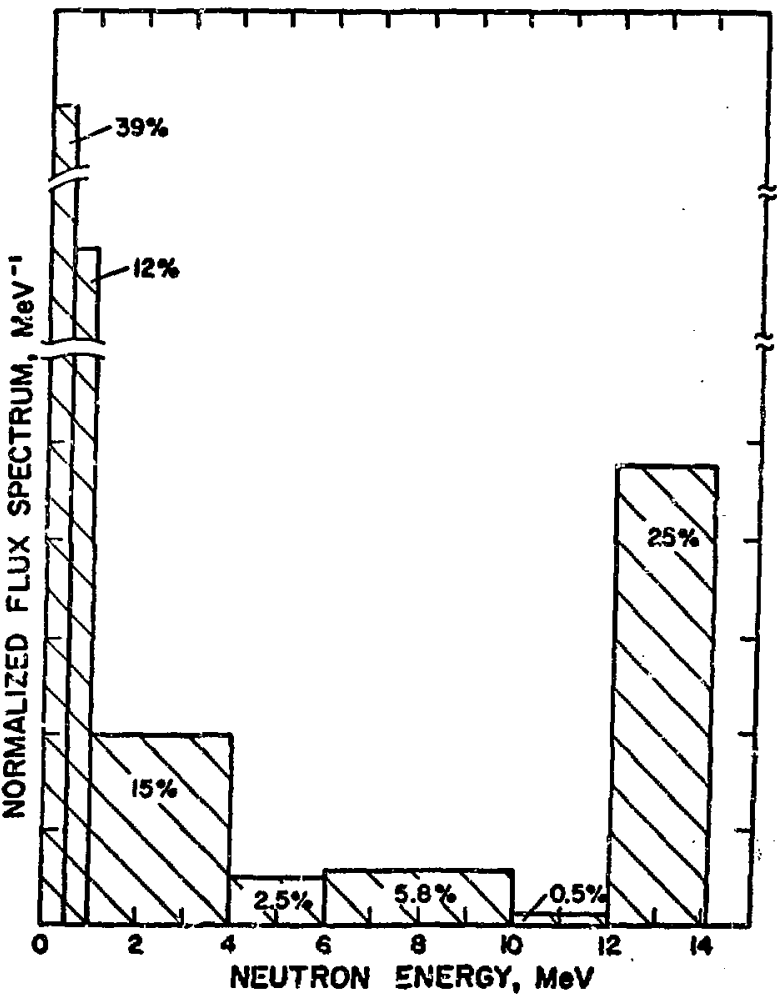

Fis. 29. Neutron spectrum at the ICIR inner waill. 
and the npetrum in $F(B .29$. The amount of meterial sweliing can also bo computed, as done by Martin. (12) infortunate $l v$, the effect of these transmatation and Frenkel-pair production rates or of the swelling on the important structural properties (ductility, yleld strength, fatigue strength, and creep rate) carnot be calculated.

TARTE II

RAMAEE PEACTIOH RATES FOR A NIOBTMM INNER WAIS

\begin{tabular}{|c|c|c|}
\hline Product & Reactions & $\begin{array}{l}\text { Production } \\
\text { Rate, f/Year }\end{array}$ \\
\hline Prenkel pairs & see text & 21.7 \\
\hline ifydrogen & $(n, p)$ & 0.037 \\
\hline Jfelium & $(n, \alpha)+\left(n, n^{\prime} \alpha\right)$ & 0.001 \\
\hline Zirconiun & $(n, 2 n)+(n, p),(n, \alpha)$ & 0.76 \\
\hline Yttrium & $\left(n, n^{\prime} \alpha\right)$ & 0.017 \\
\hline
\end{tabular}

For we stainless-steel inner walls of the suggested ICTR, the theoretical approach outlined above is more difficult than for niobium because of the many constituents in stainless steel, the great number of isotopes for each constituent, the large cross sections for some reactions at thermal energies, and the necessity of inciuding non-linear effects due to isotopic "burr-in" and "burn-out". Because of these Afficulties, the calculations of, e.g., helium production, do not agree well with dat,a from fast reactors. (14) More importantly, large amounts of data concerning the effects of fast. fission fluxes on the structural properties of stainless steel are available, ${ }^{(14)}$ but these date de not agree with calculations and must be correlated empiricelly. In view of the apparent complexity of these damage processes it is difficult to see how such enpiricel correlations can be extrapolated for a radiation spectrum such as that shown in Fig. 29.

In summary, the neutron-äanage effects expested in the ICTR are similar to those to be expected for MTRs because the rluxes anc spectra are similar. For the ICTR the lithlum westing the wall protects the wall from high-velocity particles and low-eneres photons, which in magnet ic systems interact with the cavity wall. On the other hand, cyclic loading, which occurs in the ICTR walls, does not ocm:s in most magnetic systems. It should be pointed out, however, that radiation demage coupled with yclic loading may not be necessarily detrimental to the fatigue strength. It has been auggested that cjrclic loading cortd promote recombination of the Frenkel pairs, (15) thus reducing the damage caused by atonic displacemert. Because of the general similarity of the present ICTR with other fusion concents, the results fiom present radiation-damage research being conducted for the latter should also be applicable to the ICIR.

\section{B. INDUCED ACTIVITY AND AFTERHEAT}

Several investigators $(16,17)$ have commented upon the smaller ievels of redioactivity to be expected in a fusior sower plant, compared to the gross fission-product activity in an analogous fission plant. Of perhaps greater significance, from the standpoint of potential inadvertent releases to the plant environs, is the fact that the radlosctive products of a fusion plant $w 111$ generally exist in a more tractable physical form than In a I'ission reactor, 1.e., as Induced activity in the structural components of the fusion reactor, rather than as fission products. (A singular exception is the tritium activity in a fusion reac.. tor; however, studies (17) Indicate that the Implied tritium handing problems will not negate the overall relative advantage of a fusion plant.)

Induced activily and attendant afterheat in fusion-reactor struclures will, however, be inportant factors in the ensineering design and in the operation and maintenance of such a plant. Afterheat levels $w i l l$ Imply substantial couponent-cooling requirements for long periods of time after shutdown; and many orders-of-magnitude of $(\gamma$-ray) shlelding will be needed to allow even limited personnel access to the vicinity of the fusion reactor structural components. This latter point is particularly Iumortant if maintenance (or replacement) of structural vessels is required.

Although the absence of fission products is a paramount advantage, the relatively large induced activity in fusion-reactor structures, coupared to that in fission reactors, is basic, and derives from two findamental characteristics of the fusion reactor. First, fusion reactions are neutron-rich; the ratio of excess neutrons produced per megessatt in a $(D+T)$ reactor, to excess neutrons nxoduced per megasatt in a fjission reactor is in the range of 
- 2 to 3. More importantly, most fission neutions do not leave the core, whereas most fusion neutrons will reach at least the inner wall; thus, the effective neutron flux ration (rusion-to-Nssion) for structural vessels are byplcaliy mor itre 20 to 80 . Secondly, neutrons impinging upon rugion-reactor (blanket) materials $u I l l$ be very fast; perhaps 20 to $40 \%$ of these neutrons will have energies of 6 to $14 \mathrm{keV}$, as shown in FIg. 29. At these neutron energtes a preponderance of particle reactions, e.g., $(n, 2,1),(n, p)$, cen bo expected in structural waterials, and such reactions generally lead to radio. active daughter products, wany of uhich have long half-1ives.

In the present study, the afterbeat and the dose-rate levels after shutdoun vere not extinated accurately. Such eotimates have been made by othors for typical ICMR oyotems, $(18,19)$ and the ICMR under discussion should not be very dirrerent in these respects. (The wain difference is that the present ICIR pressure-rosel naterial is otalnieso steol, instead of a refractory extal.) Difrerencos vould be expected in angaitudes, but not in the qualitetive implications of the results.

Sowe raugh order-or-angnitude relwes wi1l be estimated to Illustrate the netirity lwols to be expected. consider a 5-cu-thick inwer wall in an - 200 wt ICLR (P1g. 1). The Fux of hich-enerw netitrons $(\sim 6$ to $14 \mathrm{kev})$ at this wall u12 be $\sim 7 \times 10^{14}$ aeutrons/s $\mathrm{c}^{2}$ (plus laver-eners pluxes of $\sim 2$ to 3 tisss this wagnitude). Being colculated ICWR fluxes, =ough ertinated reaction cross sect lons, (II) and appropriate decay dnta, ( 20$)$ the posstble neutron-induced actirities in fron, niebel, and chromium were sconned. Whe resuits indicate thit the folloring reactions are of principal ingrtance (for operating tines greater than a fed Inoths):

$$
\begin{aligned}
& { }^{54} \mathrm{Fe}(\mathrm{n}, \mathrm{p}){ }^{54} \mathrm{~m} \frac{303 \mathrm{~d}}{\mathrm{DC}}{ }^{54} \mathrm{Cr}(\mathrm{stable})+0.835 \mathrm{meV} r-\mathrm{rrr}
\end{aligned}
$$

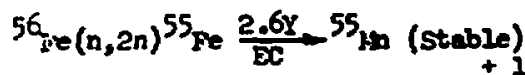$$
56_{\mathrm{pe}}(\mathrm{a}, \mathrm{p})^{56_{\mathrm{m}}} \frac{2.58 \mathrm{~h}}{\mathrm{\beta}-} 56_{\mathrm{Fe}}+(\mathrm{stable})
$$

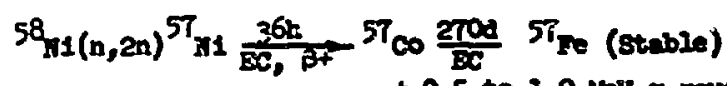

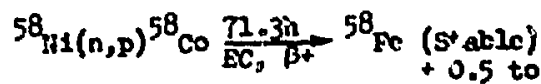

$$
\begin{aligned}
& { }^{52} \operatorname{cr}(n, 2 n)^{51} \mathrm{Cr} \frac{27.80}{\mathrm{BC}}-54 \mathrm{y}(\mathrm{stable})
\end{aligned}
$$

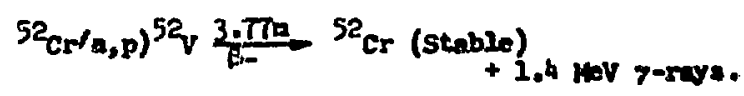

Bstinted activitioo (is curles) Nor thece reaction protucts in the Inner vall are shoun in poble III, for a ahutdoun $t$ ine $(t)=0$.

\section{TATE III}

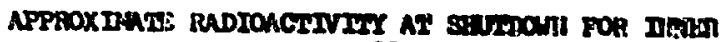

\begin{tabular}{|c|c|c|c|c|c|c|}
\hline \multirow[b]{2}{*}{ Species } & \multirow{2}{*}{$\begin{array}{l}\text { Hente- } \\
\text { tire }\end{array}$} & \multicolumn{5}{|c|}{ 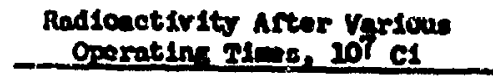 } \\
\hline & & iod & $180 \mathrm{~d}$ & $1 x$ & $5 x$ & 0 \\
\hline & 3034 & 0.24 & 0.70 & 1.2 & 2.0 & 2.2 \\
\hline & R.ty & 0.49 & 2.8 & 5.3 & 16.6 & 22.5 \\
\hline & $2.58 \mathrm{n}$ & W. 0 & 10.0 & 10.4 & 10.4 & 10.1 \\
\hline & atod & 13.09 & 0.44 & 0.73 & 12 & 12 \\
\hline & 71.30 & 0.01 & 3.1 & 3.7 & 3.8 & 30 \\
\hline & 27.80 & 2.0 & 3.7 & 3.7 & 3.7 & 3.7 \\
\hline & $3 . T T a$ & 1.5 & 1.5 & 2.5 & 1.5 & 1.5 \\
\hline & & 11,2 & 22.2 & 26.5 & 39.2 & 45.2 \\
\hline
\end{tabular}
HAl, of 200-int Itat

For en cromating tive or on year, ors anth arter ahutdoun the total actirity is $-1.1 \times 10^{8} \mathrm{cl}$.

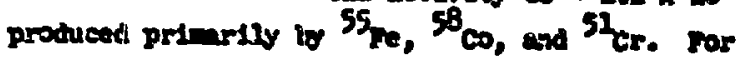

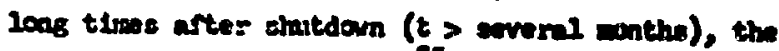

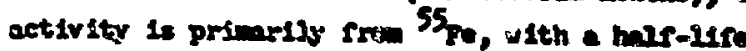
or 2.6 years (Fire years after sutacan, the 55. ectivity is stind $\left.\sim 1.4 \times 10^{T} \mathrm{ol}\right)$.

The activities in Itbie In ingly methe hat

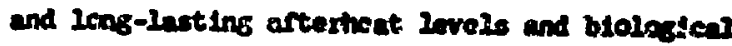

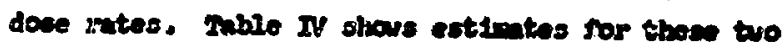
quentitles as suetiens of tive urter fhutdor. Although those cotintep are uncertath to, pertaps, an order of angitude thoy ar indleative of the

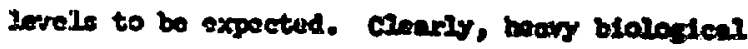
chleldins would be requined for the rmevel or maticenance of such a component. 
(Operatefof sece, 2,75$)$

Rsex Arter stiutedo

\begin{tabular}{|c|c|c|c|c|c|c|c|c|}
\hline \multirow[b]{2}{*}{$\begin{array}{l}\text { nuelear } \\
\text { Specleg }\end{array}$} & \multicolumn{2}{|c|}{0} & \multicolumn{2}{|c|}{$30 d$} & \multicolumn{2}{|c|}{$1 y r$} & \multicolumn{2}{|c|}{ sys } \\
\hline & $\begin{array}{l}\text { After } \\
\text { fleat }\end{array}$ & $\begin{array}{l}\text { Doseg } \\
\text { pante } \\
\end{array}$ & $\begin{array}{l}\text { Arter- } \\
\text { inat- }\end{array}$ & $\begin{array}{l}\text { Dose } \\
\text { Mate }\end{array}$ & $\begin{array}{l}\text { Areor- } \\
\text { lieat }\end{array}$ & $\begin{array}{l}\text { Dosese } \\
\text { thece } \\
\end{array}$ & $\begin{array}{l}\text { REver- } \\
\text { Heas: }\end{array}$ & $\begin{array}{l}\text { Dose } \\
\text { Rate }\end{array}$ \\
\hline & 0.10 & 0.22 & 0.09 & 0.135 & $0.0: \mathrm{i}$ & 0.20 & 0 & 0.014 \\
\hline $55_{p z}$ & 0.07 & 0 & 0.07 & 0 & 0.05 & 9 & 0.02 & 0 \\
\hline 56 in & 2.23 & 13.0 & 0 & 0 & 0 & 0 & 0 & 0 \\
\hline${ }^{57} \mathrm{co}$ & 0.02 & 0 & $0.0:$ & 0 & 0.02 & 0 & 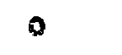 & 0 \\
\hline${ }^{5 B_{60}}$ & 0.50 & 2.83 & 0.37 & 2.21 & 0.02 & 0.07 & 0 & 0 \\
\hline${ }^{52} \mathrm{Cr}$ & 0.16 & 0 & 0.08 & 0 & 0 & 0 & 0 & 0 \\
\hline se & 0.36 & 2.93 & 0 & 0 & 0 & c & 0 & 0 \\
\hline potels & 3.5 & 19.7 & 0.65 & 3.0 & 0.12 & 0.60 & 0.00 & $0.02 \cdot 1$ \\
\hline
\end{tabular}

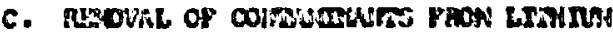

contcalnares ehat aust to renoped row elsc

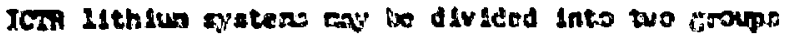
- moncordeneshlet and cordenezbles. The nancordersables are tolum-a (prg) tratedon tromoduce (niso

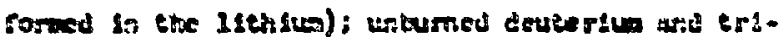
esur fras the pellat: and telefur forme fros tets-

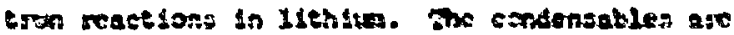

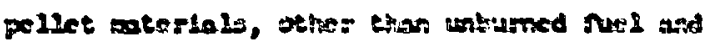

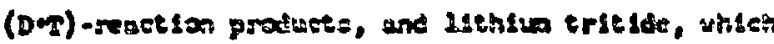

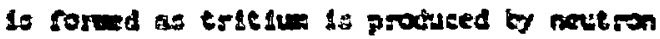
reactlore.

Ansther contusinart, not sroated by aucleos

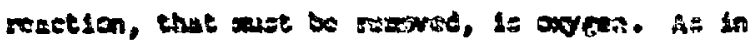

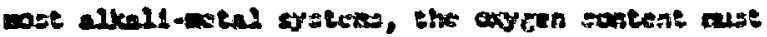
be antadred at a rey $10 \mathrm{y}$ loved. Whate of oxgew anoval ate discused execulve, $(21,22)$ and aro beyond the sesos af this report.

of these contelinats, trittw and lithsues

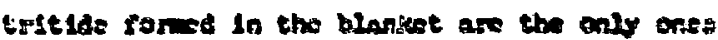

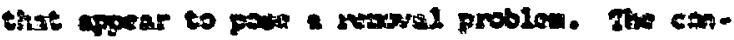

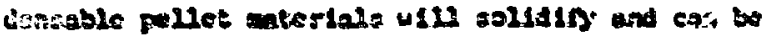

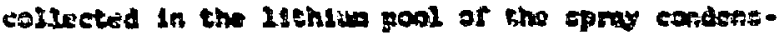
c5. uhes they can be rowoved by Ratratien. Hellu vall collect as a cos and can he nowod

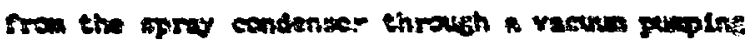

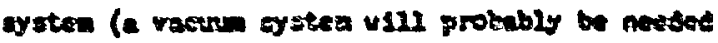

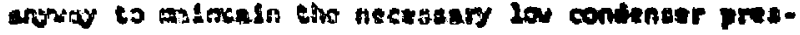

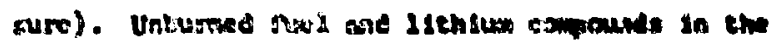
carity can frobubly bo canfined to the conluner

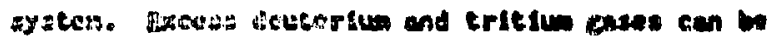

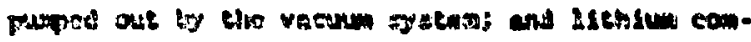

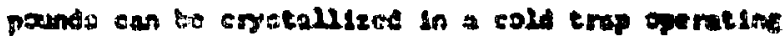

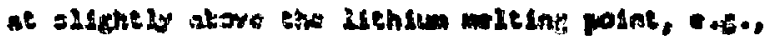

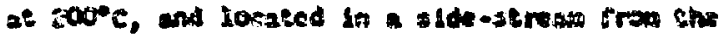

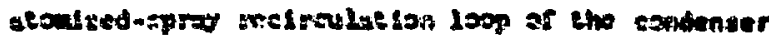
tyote

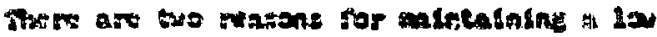

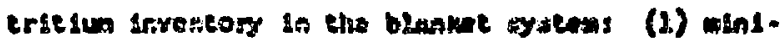

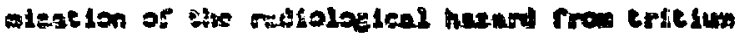

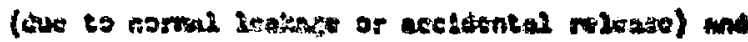

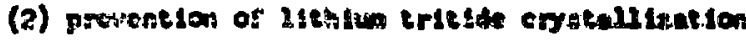

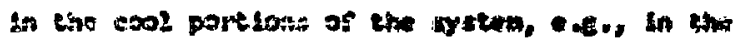

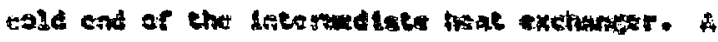

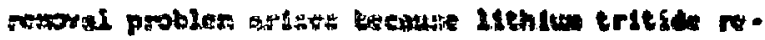

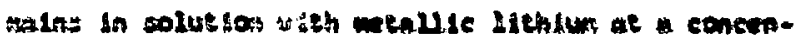

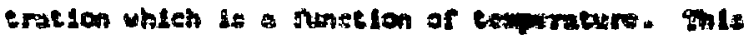

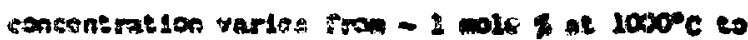

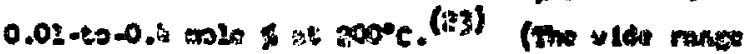

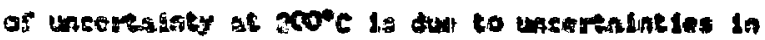

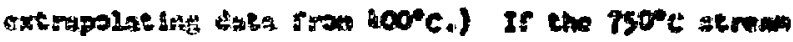

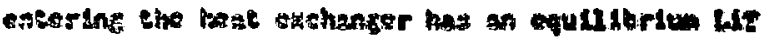

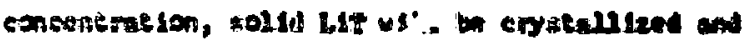

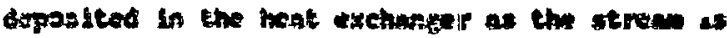

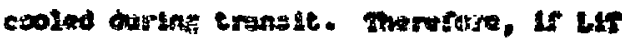


exyeteulisation in the heat exchangar do to in po-

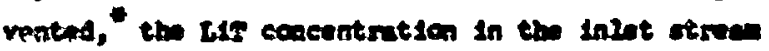
(750\%c ror the present row) wat be retuced to, of bion, the squllibrits the concentrution of the outLet streen (1000 ror the prount resi).

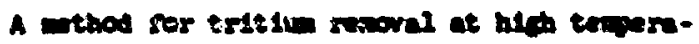
turn, valch valld be astedble for the promit con-

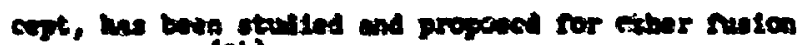

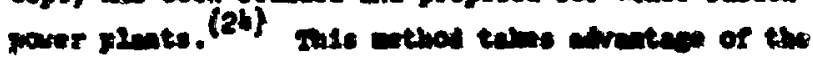

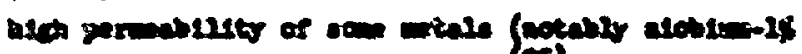

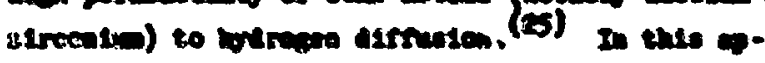

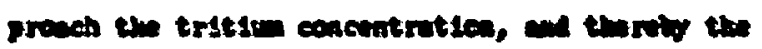

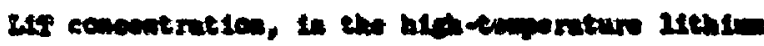

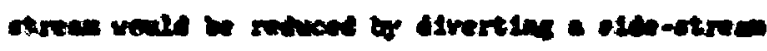

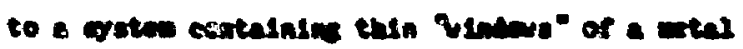

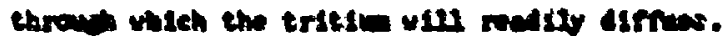

Deverer, the temency of briven (or trittin)

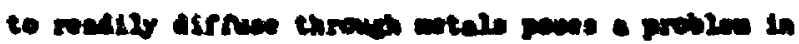

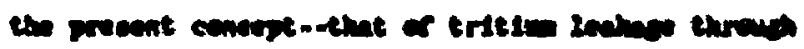

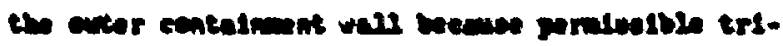

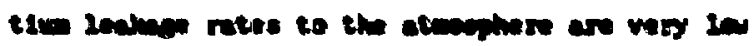

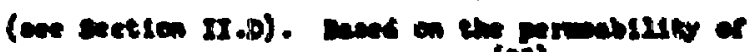

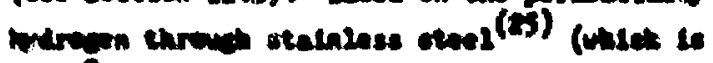

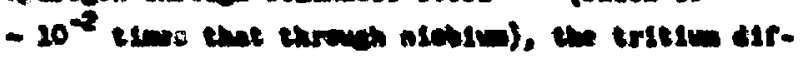

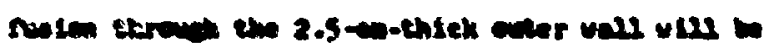

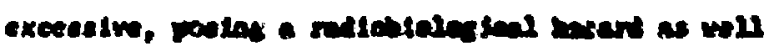

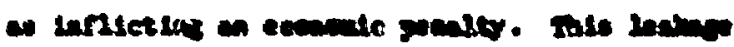

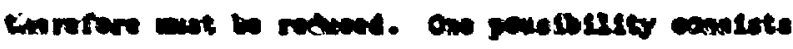

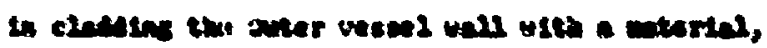

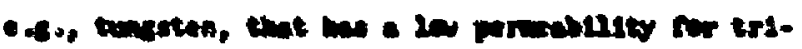

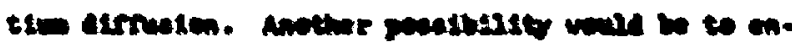

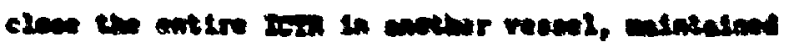

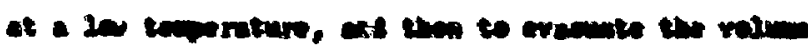

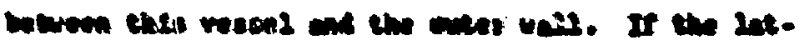

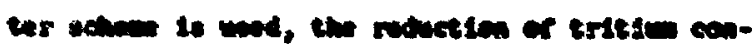

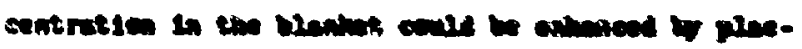

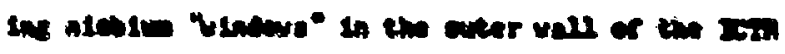
as dom in Me. 2.

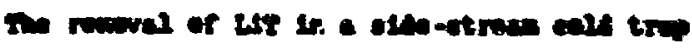

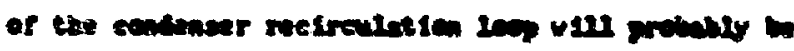

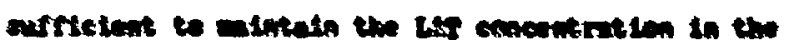

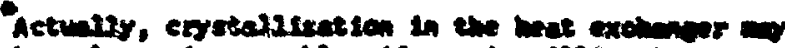

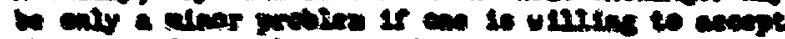

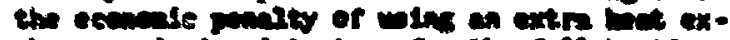

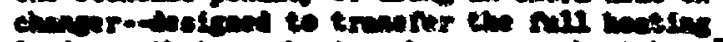

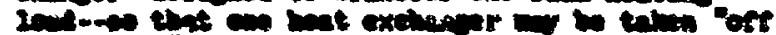

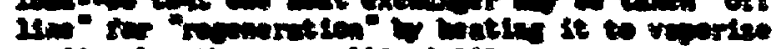

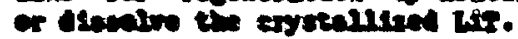

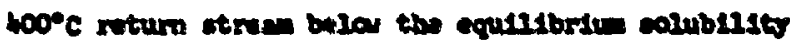
concentration. If this is not mrrielent, caotber olde-struan cold trip, locnted in the enes $400^{\circ} \mathrm{C}$ wetum strex, ay be neceseary.

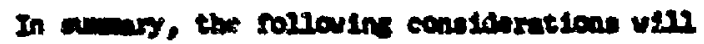

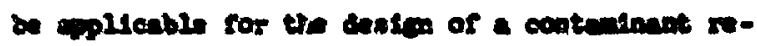
woral protem sor the presast Irih concopts

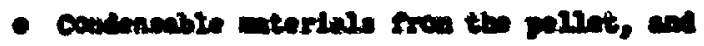

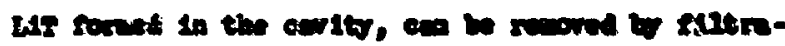

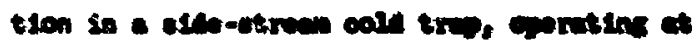

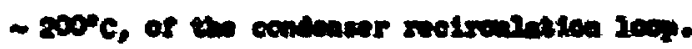

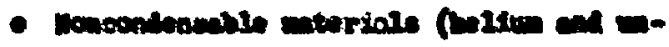

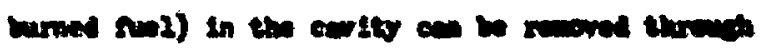

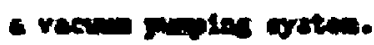

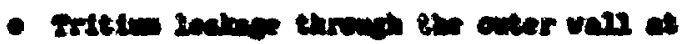

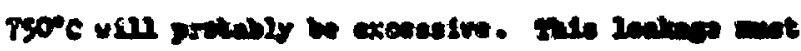

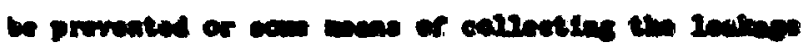
ent to groviend.

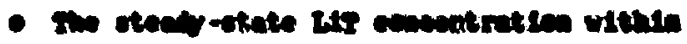

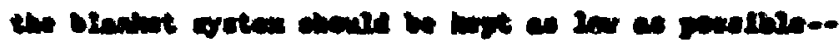

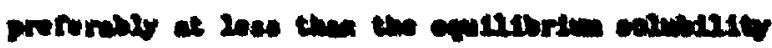

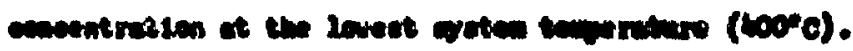

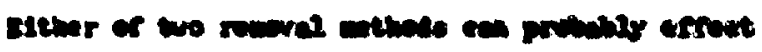

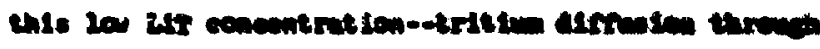

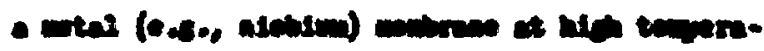

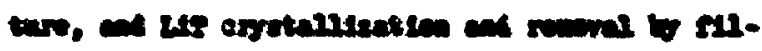

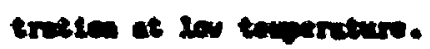

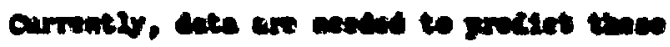

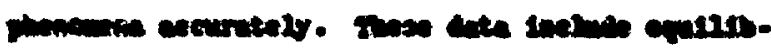

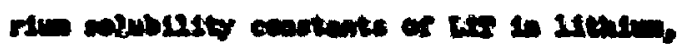

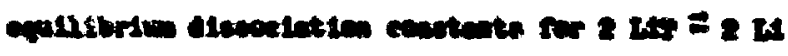

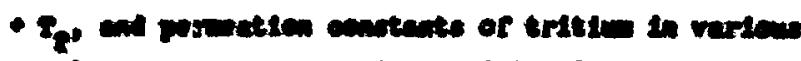

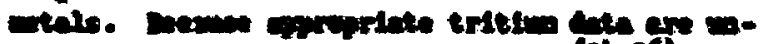

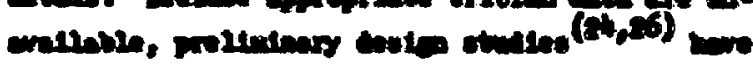

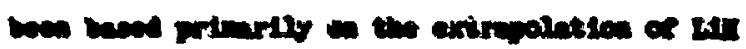

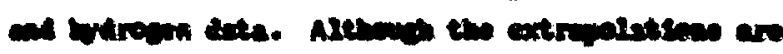

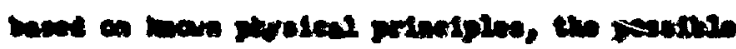

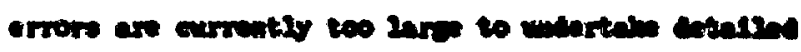
coln or proenstas apulpunt.

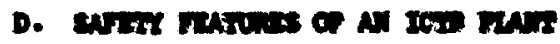

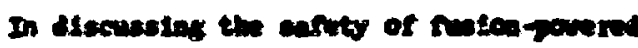

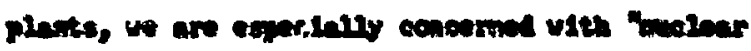

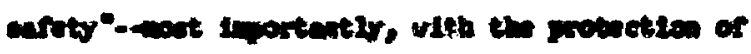

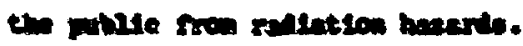




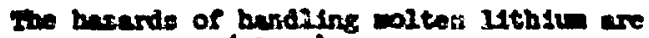

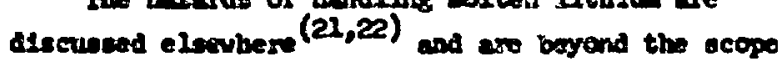
of this ingre.

As in a fiston-puvered plant, thare 150 melsar soctlons vithln the rulion yovered plant; there-

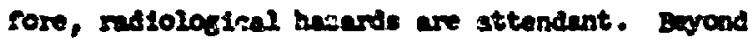
this fact it is alsficult (and often futile) to dres anviogies between riosica and suolon basarts. As polited out in sectica LI.B, elas hwe been ando

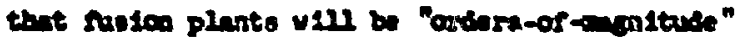
enfer then fisedon pleste, beed on the copariece of Ineson-product activity to the entinated actirLty of tritiu and of the not irated atruetures in

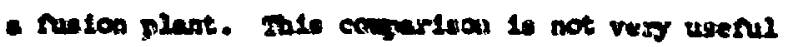
atply becues jerrels of actirtele per es are ee-

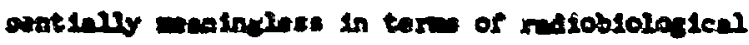

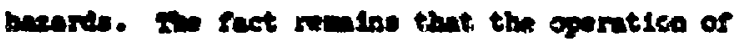

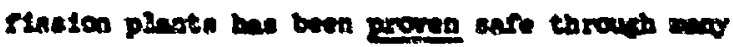

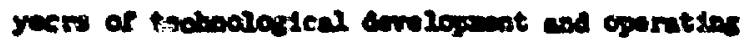

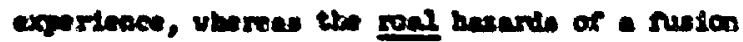

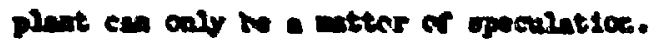

Downer, a 1,portent besic ateresence extate

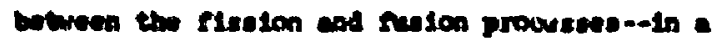

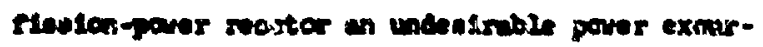

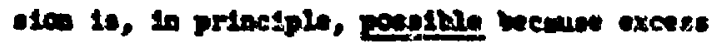
mectivity is mecentry sor contenud opertions in

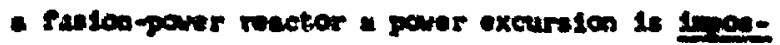

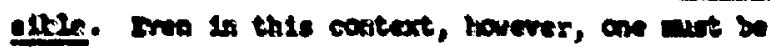

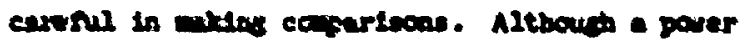

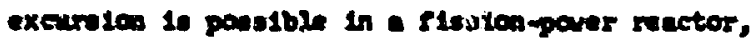
It cranot endibly lead to a explostwe mary to.

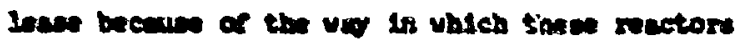

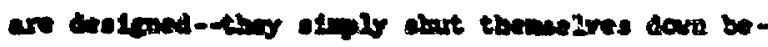

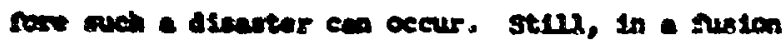

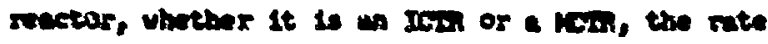

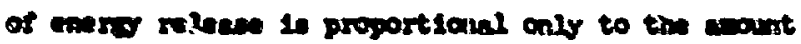

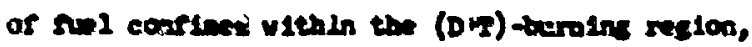

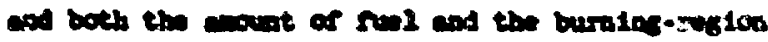

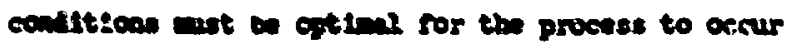

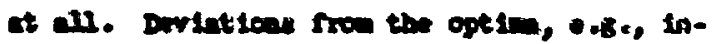
crevens is the cout of nel or in the ererv in

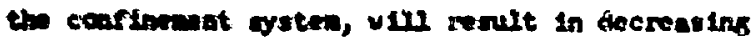
parer proinetten.

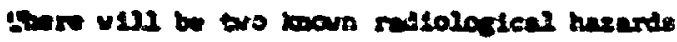

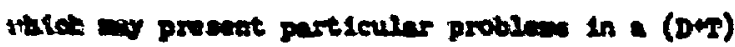

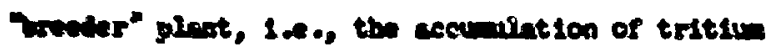

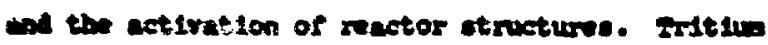
is a redoblolosted hasend onty ir ingeted (tri- tive enits only a lov-onergy bete particle), and therefore poses no hasard if contained ulthin a leattight emelepe. The problem, boverer, is in wai-

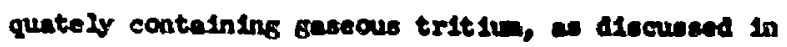
the preplavo section. In particular, tritiv learage

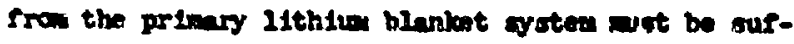
rlalently low so that triviu coacentrotions uithin and outelde the plant area ers lees then preoordbed 21nde (the allowable trits concentretion ot a boundery to the publede(2T) is $2 \times 10^{-7} \mathrm{~mol} / \mathrm{cos}^{3}$ or

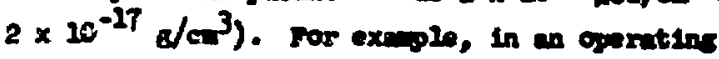
plart vith this boundary at a radius of $100 \mathrm{a}$ the Nowable tritsu Ientege rate frow the plat is of the order of $10^{-9}$ to $10^{-10} \mathrm{c}^{3}$ (Sap)/o it the trine-

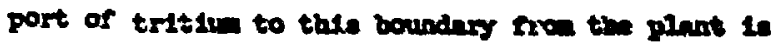

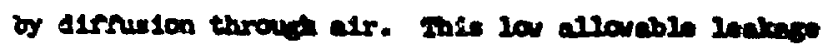

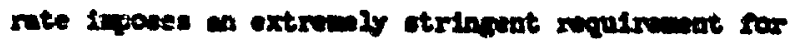

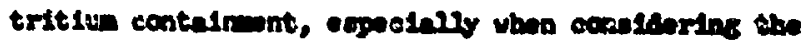

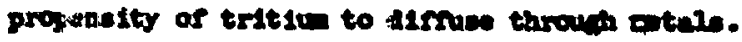

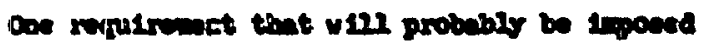

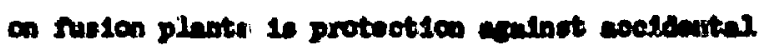

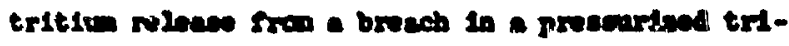

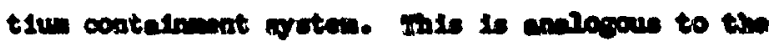

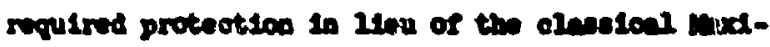

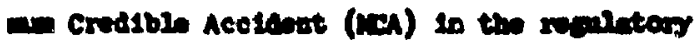

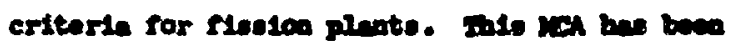

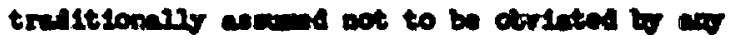

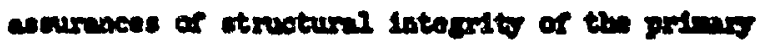

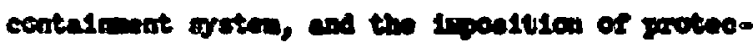

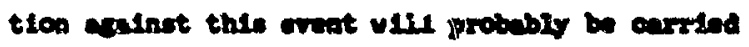

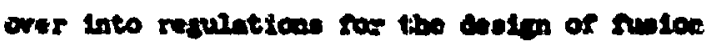

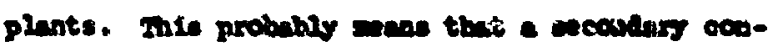

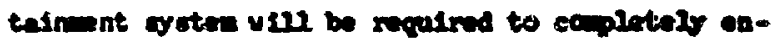

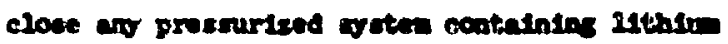
(bearins tritiv) or canecue tritsu.

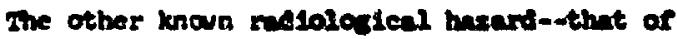
ectivated structurial neterl-20-4121 be en operetlanei problew, not a ratetion protection problem. Radintion protaction from thewe cetivated materile is tractable becange the an colld and imoblie, and the rudition can be atterunted by atply chtoraIns the ectsvated materiel. Foumer, the wory hich blolodteal doce rates $8 \times 0$ there structases, as

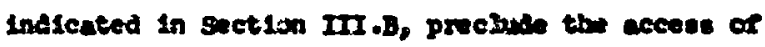
prachnel for contect enterennes or Iplesermet of the blanket structure vithin aw wasable Insth of time arter sturdoun. 


\section{Echouncs}

The enrent congtitive exterion for counelal electrienl porer earation in the totel pro-

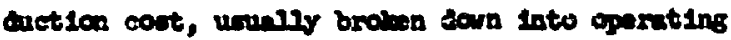

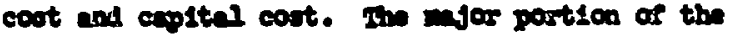
geratins cot for compentionel porer plants is the sol cort, and thlo is expeted to be the case for

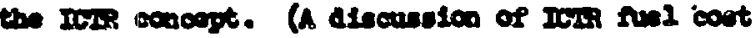

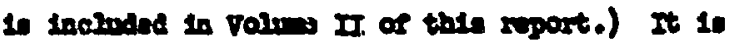

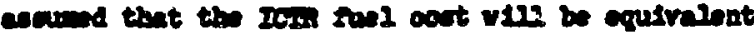
to the ectivented sxetson of totel production cost

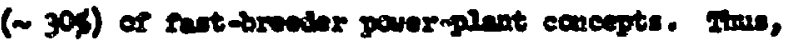

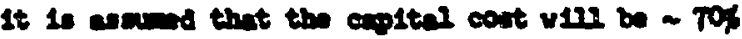
of the total production cent for the ICrit.

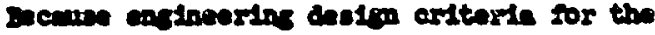
Iot canoget bore oot ben ectablishad, it in in-

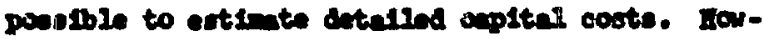

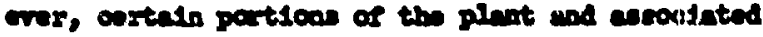

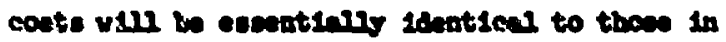

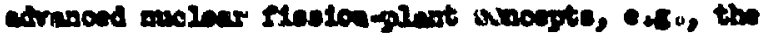

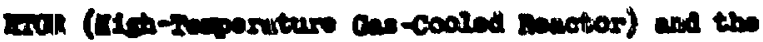

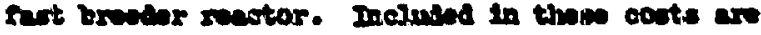

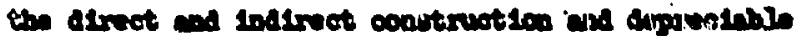

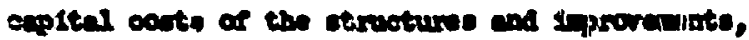

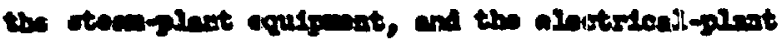

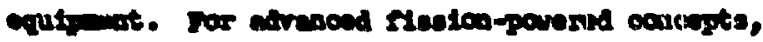

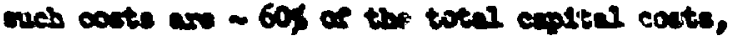

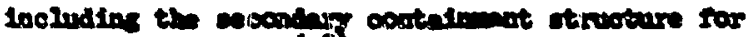

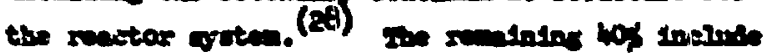

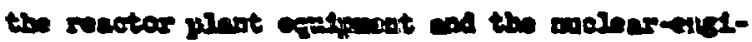

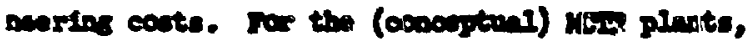

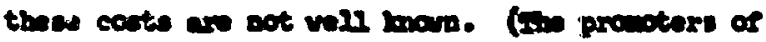

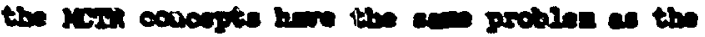

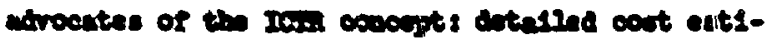

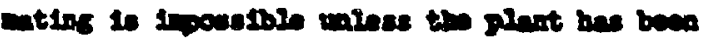

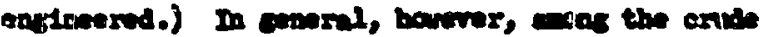
ectivites thut boe ben and the suleter plat

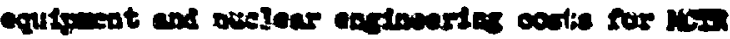

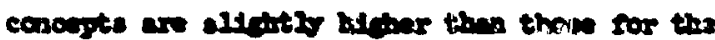

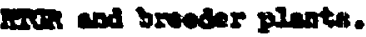

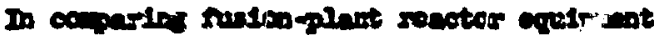
and wothar enstwerthe cont to thore of adravend

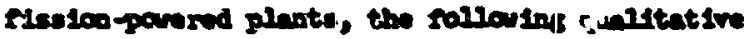

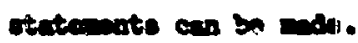

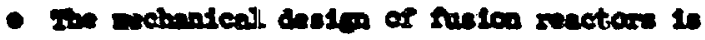

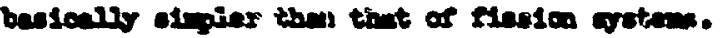

Therefore the cont of the rusice ruactor and its internel componente obould bo 100 than thit of the flecton rector.

- Incioar saroty waten to provent inmercriti.

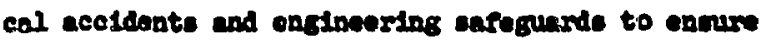

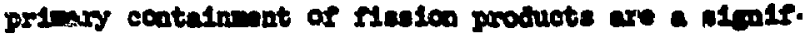

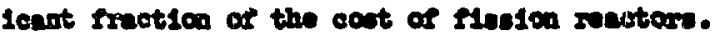

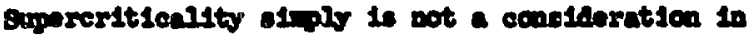

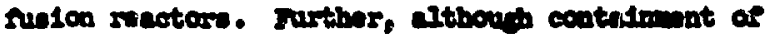
trition is a mapr coneser in a Sulen swator, woh

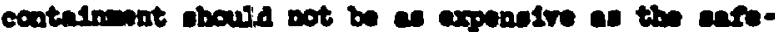

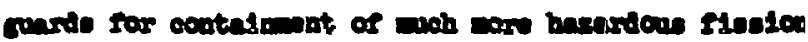
proincte.

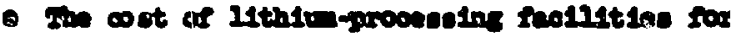

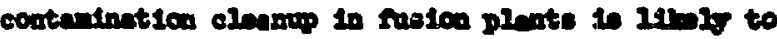

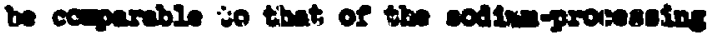

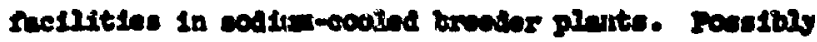

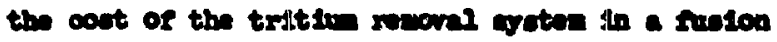

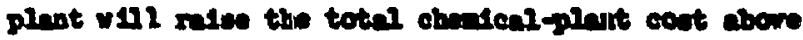

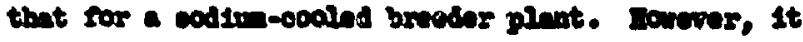

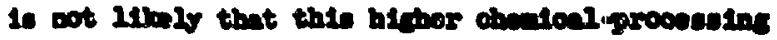

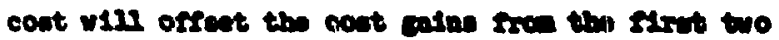
cost asmateres.

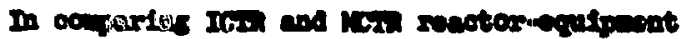

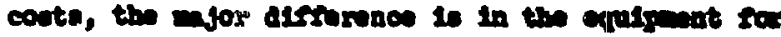

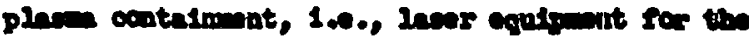

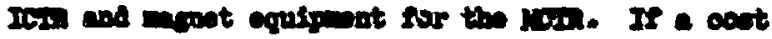

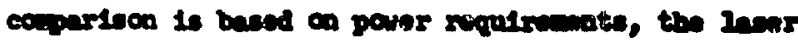

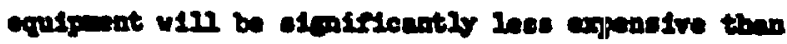
the engent coutgrant.

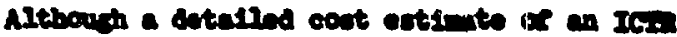

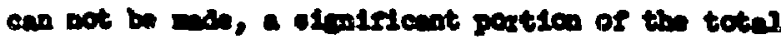

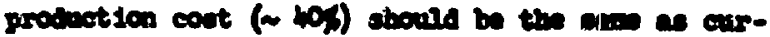

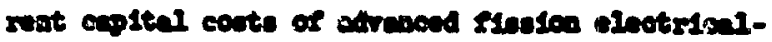

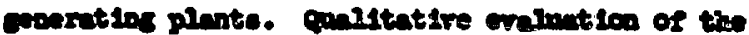

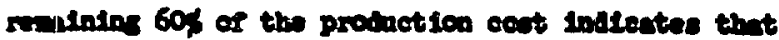

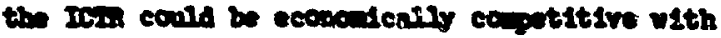
otorr arraced cencepte tor electrien porer coertion.

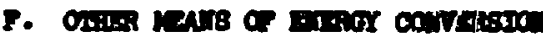

\section{Cogere coulderstion}

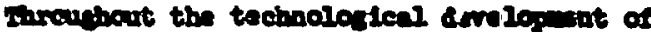

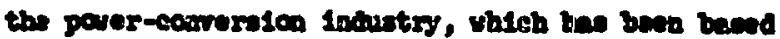

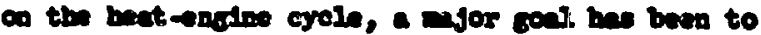

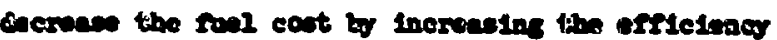


of converting thermal energy to electrical energy. Theraodyantually, the conversion efficienoy is directly affected by the maximan tedperature in the process, 1.e., the higher the temperature, the higher the corversion efrictency. Hexetarore, this maxima tewperature has been IIndted because of phosical and chemlcal properties of the matoriols (usuelly for contairuent) in contact y1th the therwodynatc Horking flutd".

In addition to decreasing ruel cost, there has been an srpetwe In the part fer yeers to decrease the amount of hest refected by increasing the conversion effyciency. WIth the advent of Inro porer plants (1000 we or larger) rejecting their vatebeat to natural vater scurces, the problen ariese of altering the ecalogy of thase sources bo incresing the vater temperature (tharmal pollutia). Swe anount of vaste beat can be stoniricantly decreas

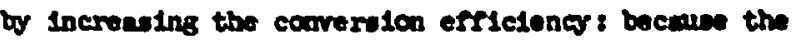
weste het is proportional to $1 / \mathrm{m}_{0}-1$, where $\eta_{0}$ is

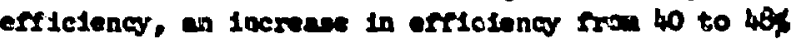
(a suctor or 1.2) results in a decrence in the ecort of varte hast by a factor ar 1.38. Hoverer.

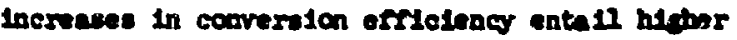

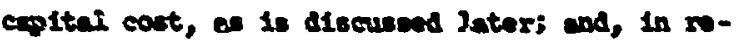
grone to public juesurv, porer-plant deatoners bre discoremd that the protuction cot of exleting plente nodifled at increaned cost to reject but to the atoophere (even et the expense of decrened comerston efticleney) is lese then the cost for a pen plant destoped for higher courersion efrioleng uolng wor expenasve naterinis. Frens $(29)$ hes cus-

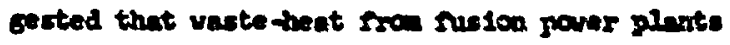
could be ued for buslating bating and atr-coad-

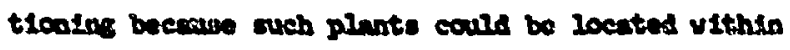
utan capioxes, thes elininatios the thernel. gristion problen.

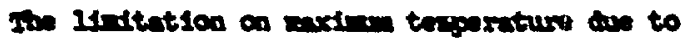
ntariel propertion bu polted not ont to besteagine creles but also to various direct-comveriten scberes that are bead on enory extruction disctIy now churged purtiche (e.6., 10as). Beaun

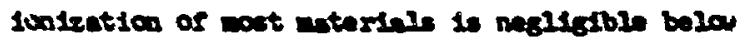
$\sim 2000^{\circ} \mathrm{C}$ and the math vorites temperatur sor

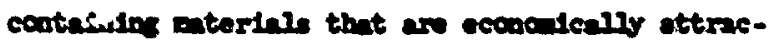
tive is biley a 1000\%c, now of these divet-

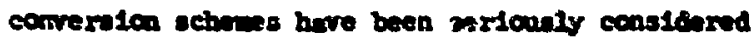
as and for the electrical pover indurtisy.
Proponents of rusion pouer have claimed that tis prospect of fusica reactors oporating at extrensily high soaction temperatures (In the bov runge) and, particularly, MCH aystems where the hot plame does not cowe in contact with contalning waterials, proutses high conversion efrlciency by zeans of direct corversion. Unsorbunately, susionreactor deslgns, elther ICH or MCL, are based a the (D+P) reaction, vhere the wafor frection (0.75 te 0.8 ) or the total enersy ant be comrerted to

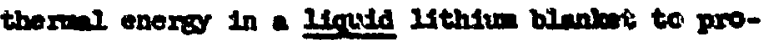

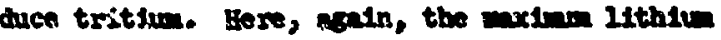
terperature is lindted to $\sim 1000^{\circ} \mathrm{C}$ bo the pirveleal and chadenl propertios of the nateriels contaluins the 21thiu. Thedefore, this anjor fraction (0.T5 to 0.8$)$ of the $(D+g)$ enerw can only be courerted to electrintity by wens of a wre comretican

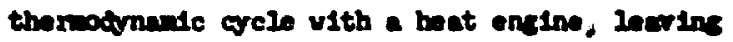
orly the unar fruction (0.9 to 0.25) for alnet

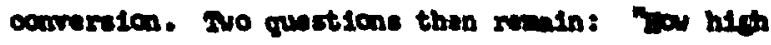

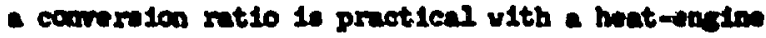

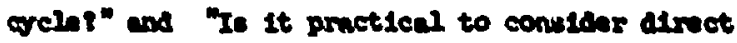
comereton of 20 to 25 or the totel enory ${ }^{*}$

\section{Fatsoln areise}

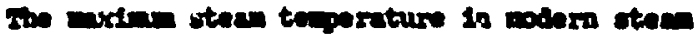

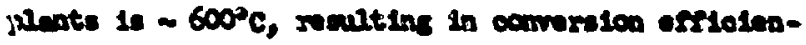
cles of to to 45,. cas tarbine, uad in comina-

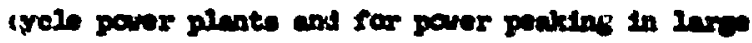

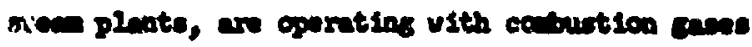

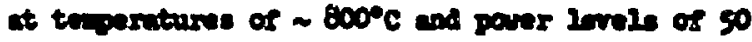

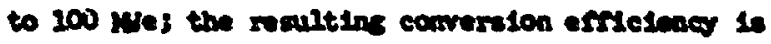

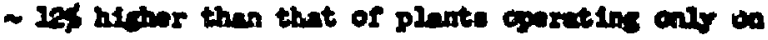
- ctece arele. Cas turbina un belas ameloged in

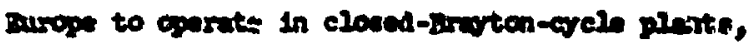

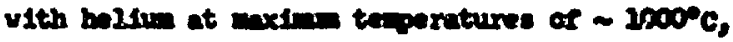

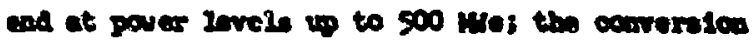
erpletencles of these pinnts would be fonter then

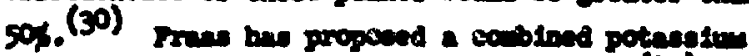

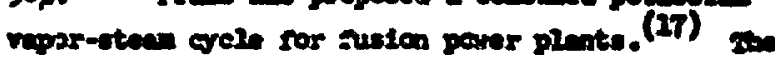
potesesil turbine would goarate of $\sim 1000^{\circ} \mathrm{c}$, and the

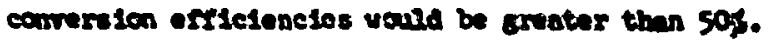

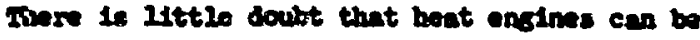

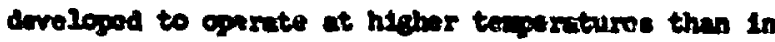

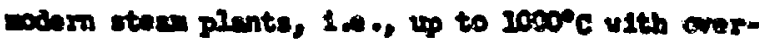

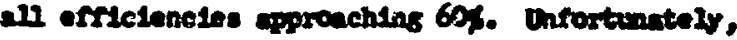
the nereins that rat bo uned in thes mangses

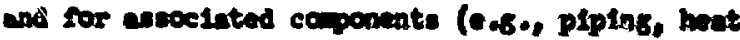


exchengers) ure rory expannive, so that the capital cost of such a paser syoten vould be efply too high to ccipets econocianly, even though the piants would operate ot higher arryctencses.

To esparte this goint, consider the follouins exarple of a breic economic principle (31) If a groposed plent can operste at an efficienes Xs/ hiches then that of an existins plent and for a eapleal

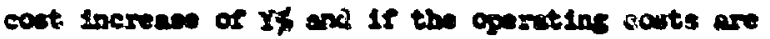

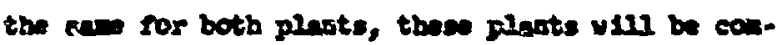
petitive (total productiog ante are equal) vhes $x=x(g) / C$, vine $c$ is the expitel cont and $p$ is the totel production cort (espitel cost plus ogerutifs cost). If the retio of copltal cost to-total pro-

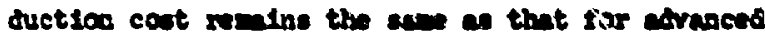
muclear-paresod plaste (we precedins cection), tben the parcentege Incsese in cepltel cost far a Fropoes plant to compate vith ex existing pirat de $Y=x / 0.7$. Iterefore, if the poponed plent oparates at 60 , arMelency. the incruese in capital coxt of this plant is Ifitad to Woy or that of en ex-

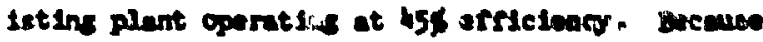

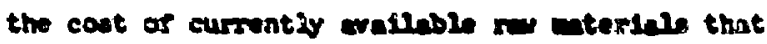

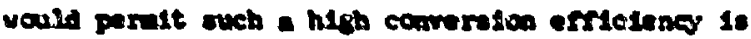

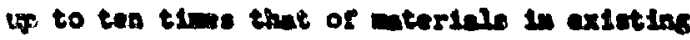

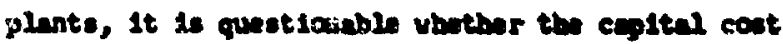
of the diphy enicient plant woutd be ecoendenlis competitive vith that of the exietion pinit.

\section{Dinet-courereion Fous ibusties}

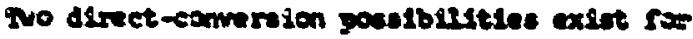

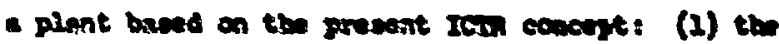

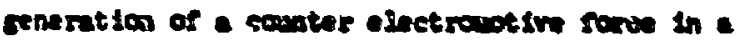

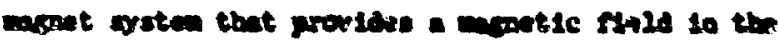

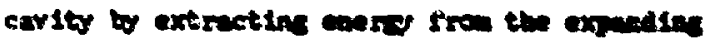

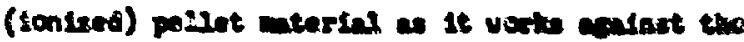

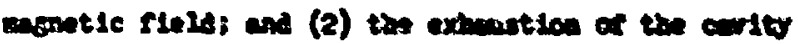

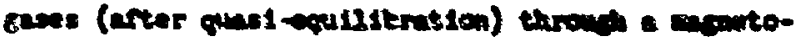

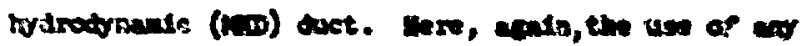

dives-corversion netilod $\mathbf{1 1 1}$ be based on the econotse principle dascribed above. Eourver, becoure only 25\% of the total anery is avallable for courereion, a Ejor fraction of this chesw ant be cowrexted at hish esliciency to arfeet the adad

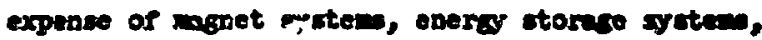

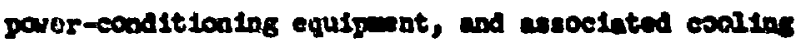
equipant.

Bren if it the sirct gethod it wer poushe

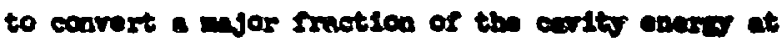

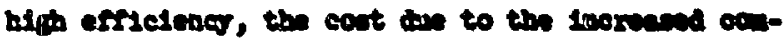

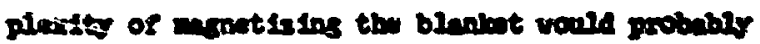

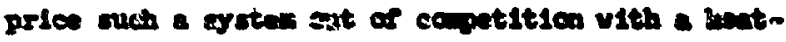

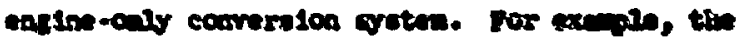

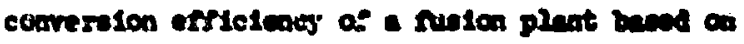

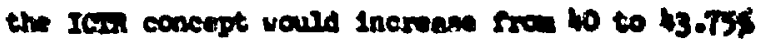
If 50, of the enery in the exity vere atruats

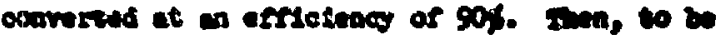

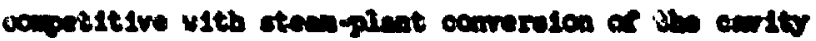

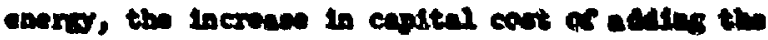

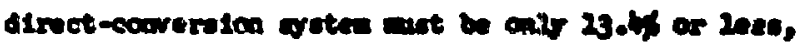

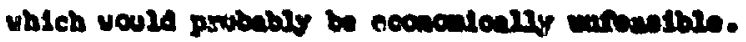

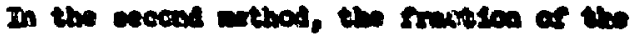

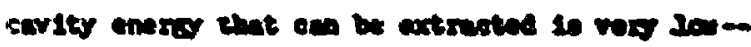

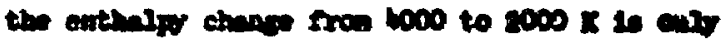

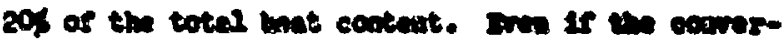

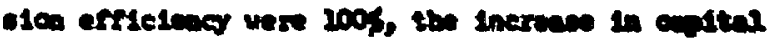

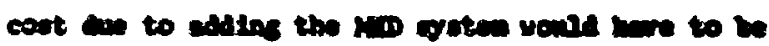

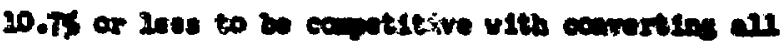
te carry in a teen plent.

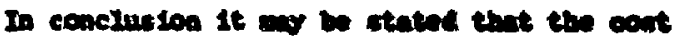

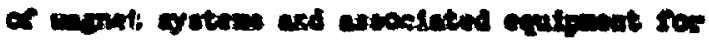

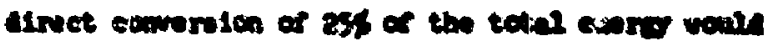

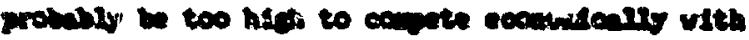

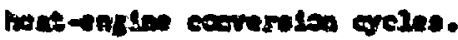




\section{IV. comprosins}

\section{A. IB MEYUDWATI ICLR}

\section{Introduction}

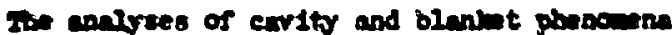
deseribad in Section II do not indfeate ar unalrable ensiberias problene in developtos a vethed-

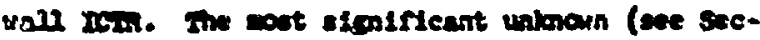
tson III) is the ermet or rediation demase on the lirutis of the Imer valls. Morver, it aut be remebored that lacer-driven ruston is not yet a reality nor eves an mashuel certelnti. Twerefore

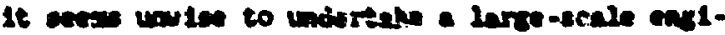
nertias effort to establish a reference rectos deses that is baed on esonptions bout eurvently

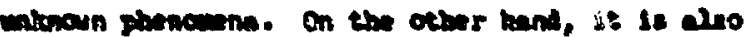

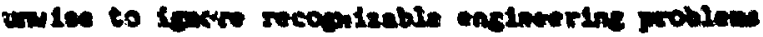
Ia e potantidiy attrective concept. suth problem

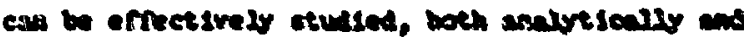
exprimentally, Irrorts on certath or chea prob-

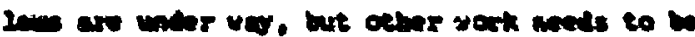
rested.

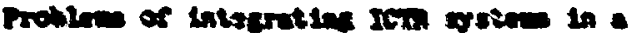

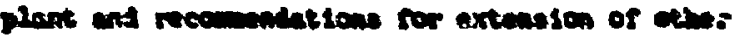

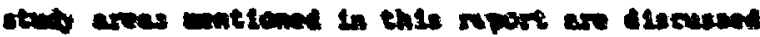
in the ralier ins sangonite.

\section{Rint reteng reterniten}

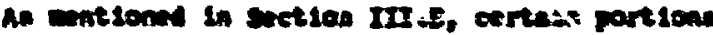
of an Ita porer plact vill be sinllar to the or

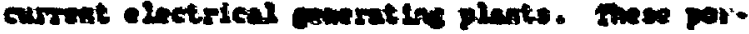

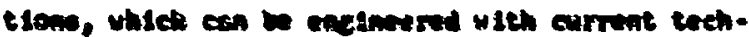

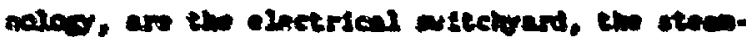

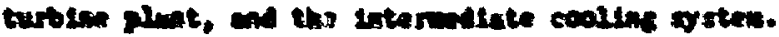

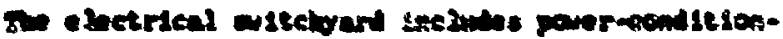

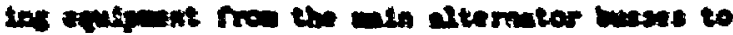

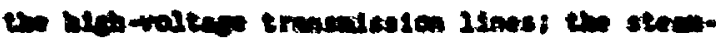

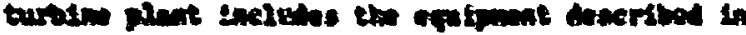

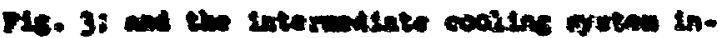

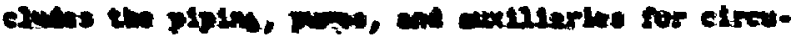

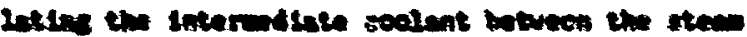

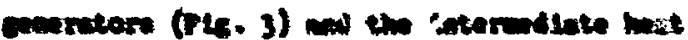
exclumerer (Fe. a).
Other portions, vilch eannot be enclowered be-

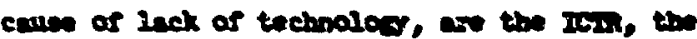

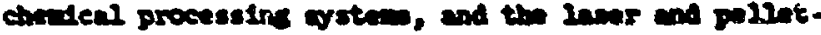

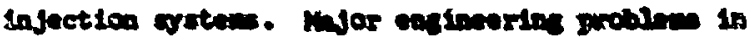
etw Iren and in the trittin-procecelos orotem vore been discusend eveller.

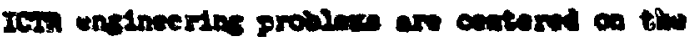
ourstral of the lorer vall sogeratine the cority

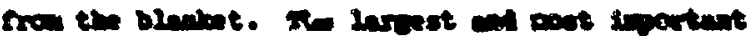

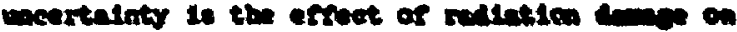

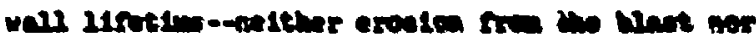

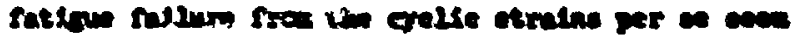
to linit the lisution. If the vall isfotso 10 ealy

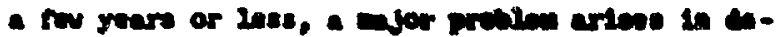

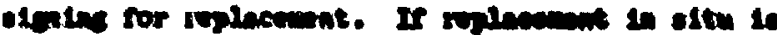

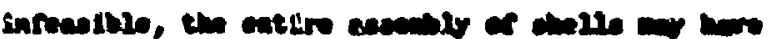

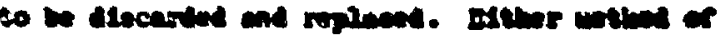

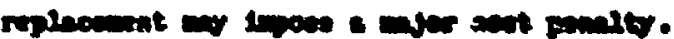

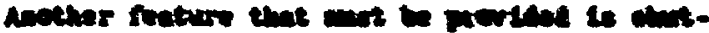

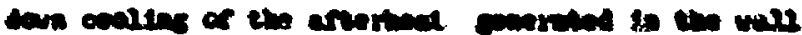

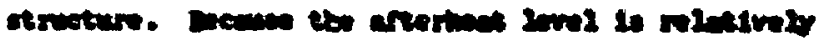

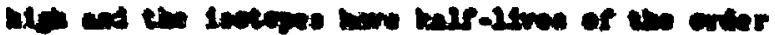

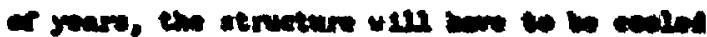
incistatitaty.

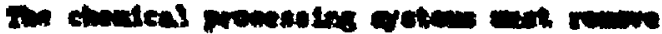

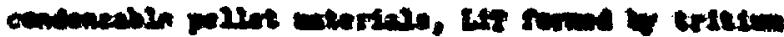

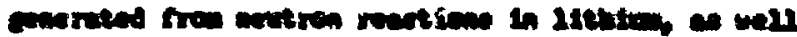

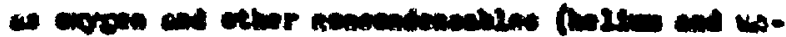

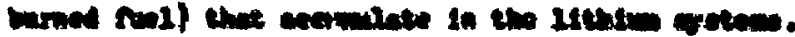

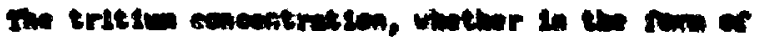

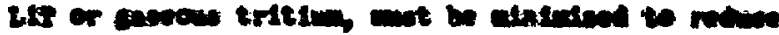

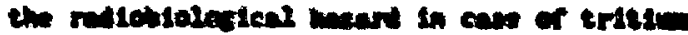
Lrature.

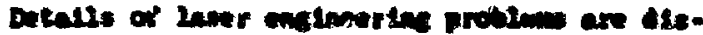

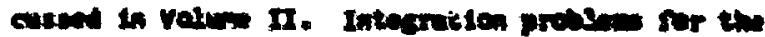

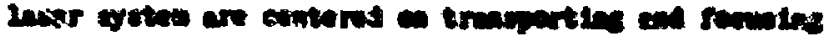

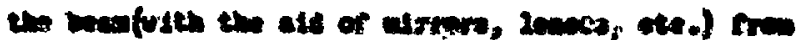

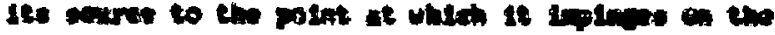
mellet. 
20 doein of the pillt-infection waten vill

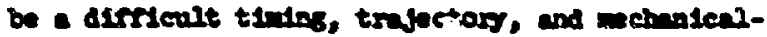

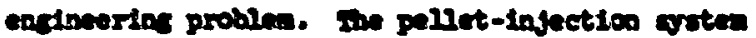
not be Integented vith the Ines frotem wo that the

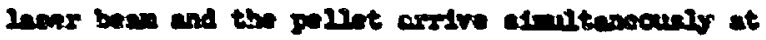

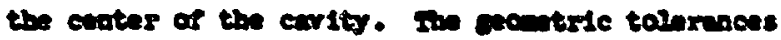

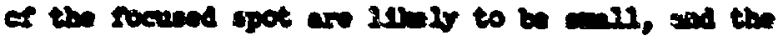

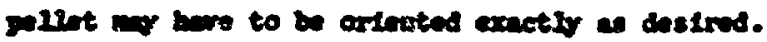

\section{Ixtenten a recent gork}

mint of the cantrees prevest is suction II

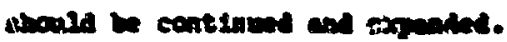

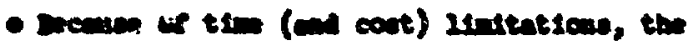

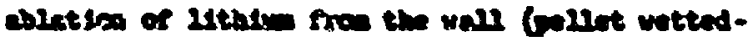

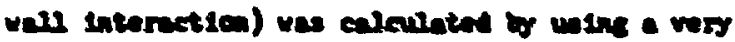

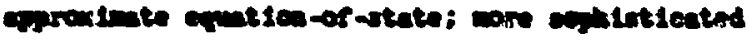

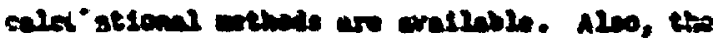

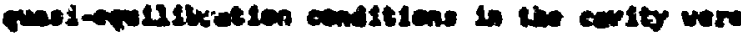

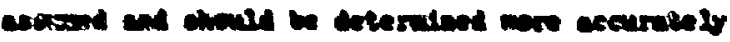

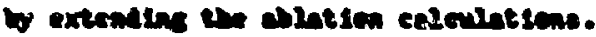

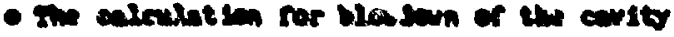

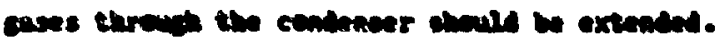

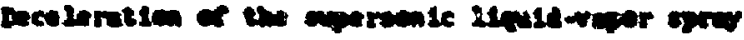

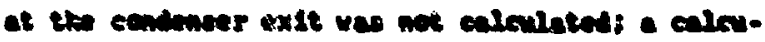

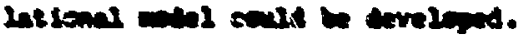

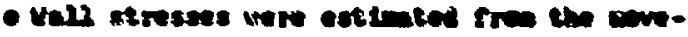

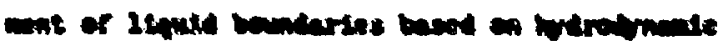

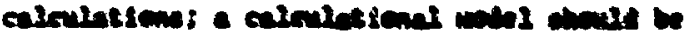

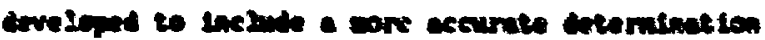
of satninter sures.

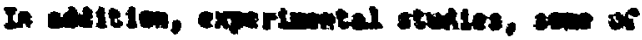

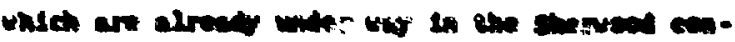

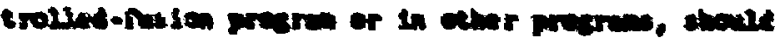

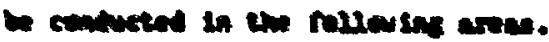

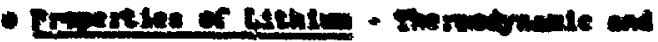

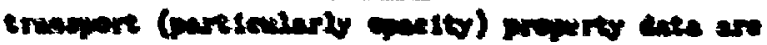

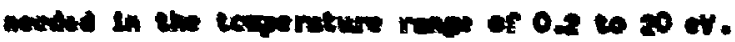

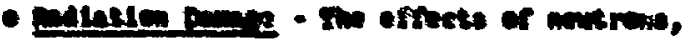

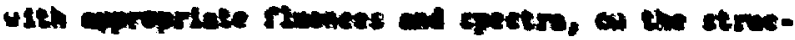

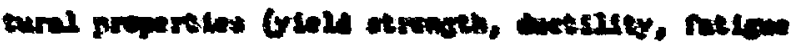

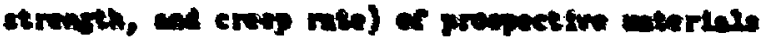
mot to thens.

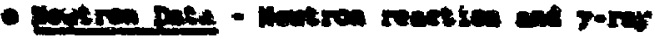

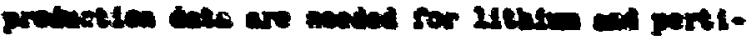

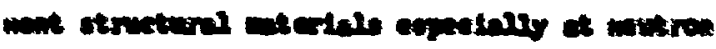

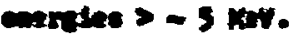

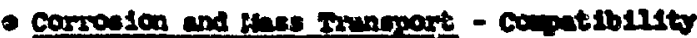

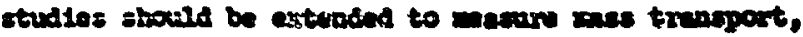

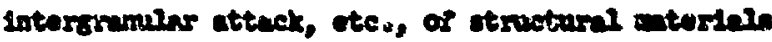

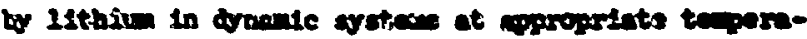
tare.

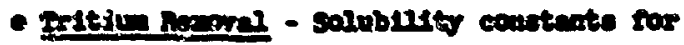

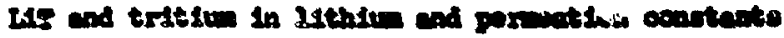

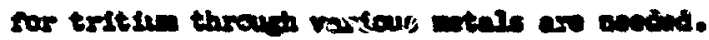

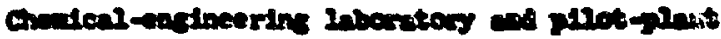

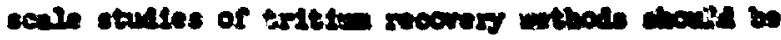
Intestes.

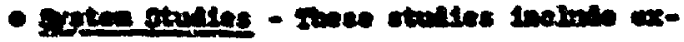

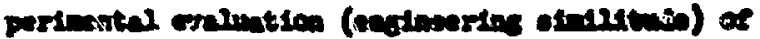

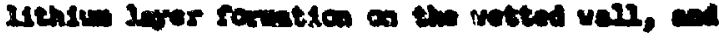

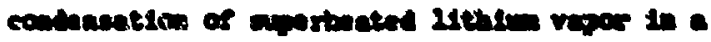

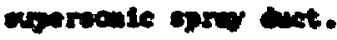

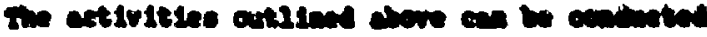

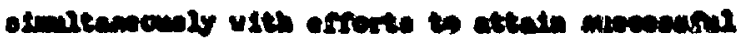

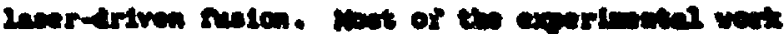

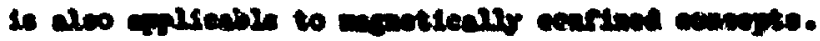

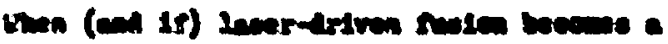

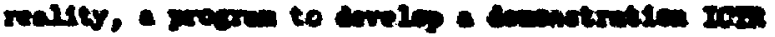

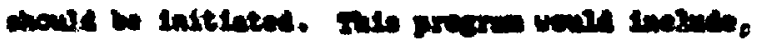

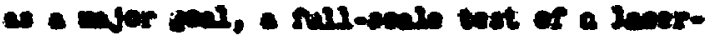

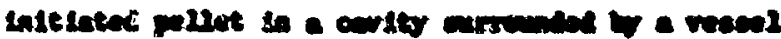

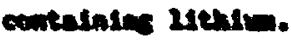

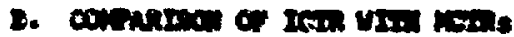

\section{Intrinstien}

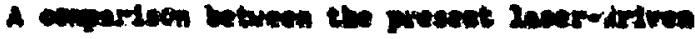

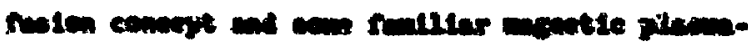

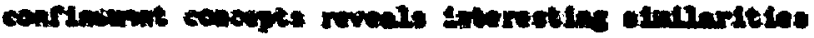

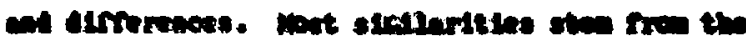

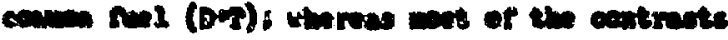

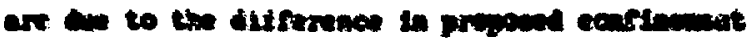

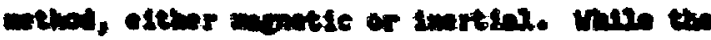

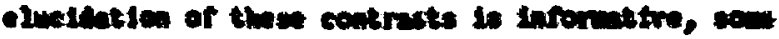

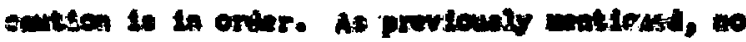

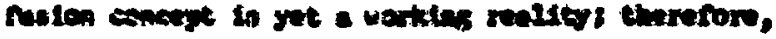

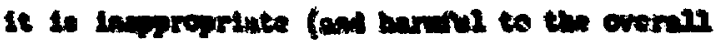

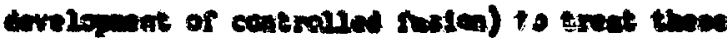

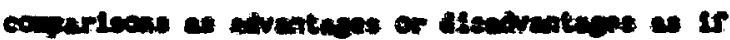

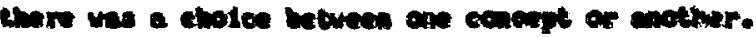

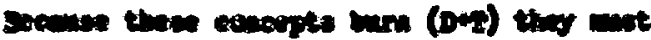

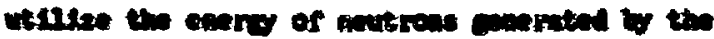




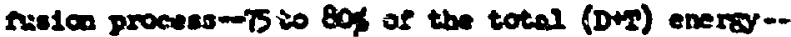
which escaps the reaction ralum, and they not

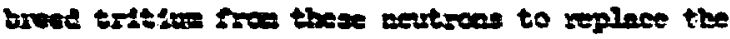

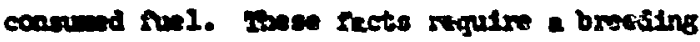
blankert, largely copoesd of lithlus, that ourrounds the reaction volum. In adalition to remoring the beat semereted by diestpation of the neutron enery, the Itthli wat be procesasd to move the tritiun. In the wetind-vell conergs, the llthtu vill be conparatirely rasy to fiou for beat trunefer and trit1-

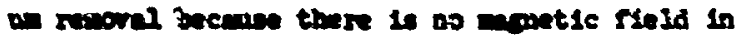
the blankat. Thls u112 ellatrate ay and ror cas

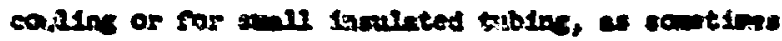

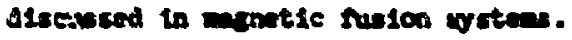

\section{Ineryall}

Dres ate the eserdy output is proportional to the acrish sutput, structural menrinl of sulon

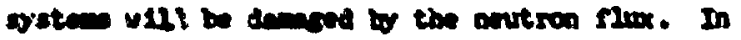

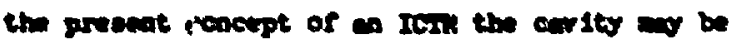

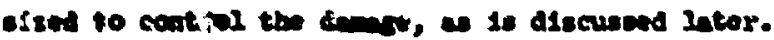

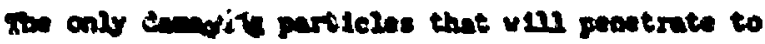
the vetted rell vill be autrms; the vall ourfuce

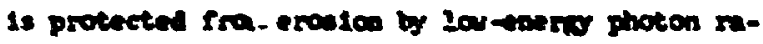

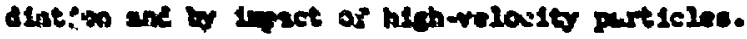
The vettend vell anet not sore particular slectrlcul properties and ine carlty soase not bure to be

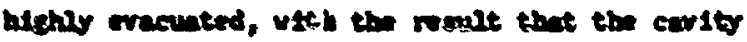
ralum soes not bave to be derened by a canled resul. The, fo: the greant bencrgt, pester latituste is alloved in tho etolce of both vall m-

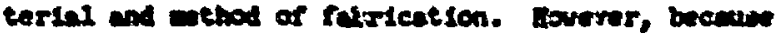
the vetted wall motula donificant struth uner

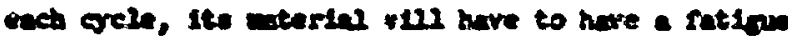

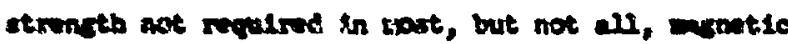
ruston cencogte.

\section{Consin ant suto}

For eponticaly conflined conerpts, the plawe

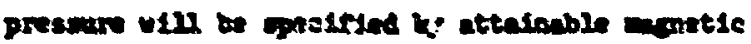

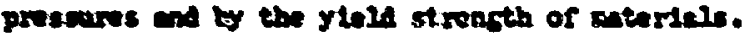

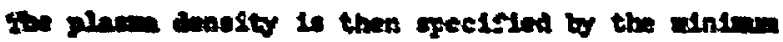
Ionstien tecparature ( 5 bor) and to the roquiseeat ac untwi roturn on invected eners (ar). No-

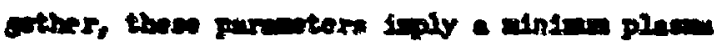

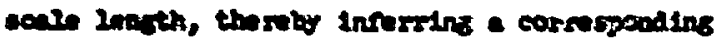
rewctor atse. In the cace of the $\mathrm{Kth}$, the dimen-

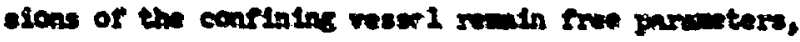

Independeat of confineant and ignition problems; tharufore, the disengion: wy be chocen to oust rodiation-darase levels cr other criteria.

Anotber reature of angotic cenfinement is the requirement for inge anounts of stond energy in the engnet systen: $4 \times 10^{10} \mathrm{~J}$ for a pokank renctor manot (32) or $5 \times 10^{9} \mathrm{~J}$ ror a thota plnct reactor. (33) A corresponding foature in the preent gratem night be power arply to the laser, but this anply us:11 be auck loukr and the power source can bo located way from the renctor resecl. Twa, the poselbility of a stored-enerw accident imnaiviog the rector was not exist ror an Itist. A further consequance of exparatine the porer souroe fron the rector v1ll be the relatirely ender protection from neutrons leviling through the zlthitu bienlant.

\section{Nourer Iovel}

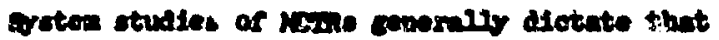

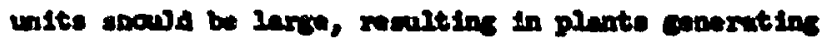
2000 to $5000 \mathrm{me}$, to be ecoponlcelty suatble. Opon mellur of weh unite, lare trenalents woukd be introduond into pouer networke, mider low edfurt-

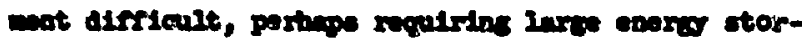
co artes. Fellure of the cooling aroten for

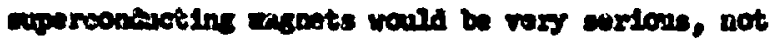

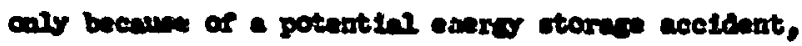
but 2100 besme of the 200 tin (60 deye for a

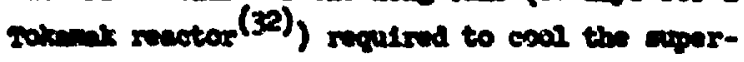
conductins manet doun prior to its opention.

In contrast, ICxis need not be large-the

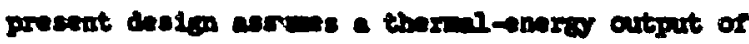
$200 \mathrm{M}$. Ino could be atther seeled up to larser olses or could be cluctered, and probably vould bo served by a single laser arsten. Indiridanel unit. could be shut durn or rentarted yithout opeciel dirrieulty, and the poles rates conle be changed cs acded to apply a varying loed. Wis flexibll.

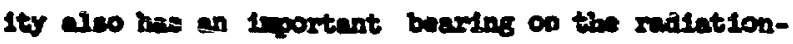
drange problen: Individual units could be shat cown ror roplacenat of parte vithout complecely interrypt ins power eoneretion.

\section{Scolordent serects}

Dinetustion of the ecological ippect of fucion reactors has centered upon the relatively vartenee sul crele (compred to fieston ronctors), on 
the posstble hazande lnvolved, and on the poss1bility of iurning westes (particularly the longlived Plssion products ${ }^{85} \mathrm{Kr},{ }^{90} \mathrm{Sr}$, and ${ }^{137} \mathrm{Cs}$ ). Most of the general discussion of fuston aiso applies to the ICIR system. The suel cycle is the same, resulting in the sawe waste products; and the breeding 1s she same, presenting the same harard of accidental tritium release. With regard to buining wastes, the posstbility of burning fisston products or cther wastes is much greater in the ICIR because, unlike magnetic systems, no ultrahigh vacurum is required.

\section{COMPARISON OF WORLD ENERGY FISSOURCES}

Up to the present, economics has been the sole consideration in determining fue 1 usage and wethods of energy conversion, 1.e., the quest for ever-decreasing electrical porer production cost wrerrode all other - nsideratione. However, during the past few years, the public has become aware of a host of socioecological problems, same the result of advancing technology, but most the refult of the everexpanding population; these problemo will no doubt affect any future fuel usage and energy converaion considerations, but econonics $v 111$ probably remain the wost iquortant factor.

The known and (estinated) und locovered reserves of the vorld's supply of fossil, fisille, and fuston suels, as of $1968^{(34)}$ are shown in Table $v$. In many treatises on the effects of an expanding population It is reasoned that the world's population w111 reach an asyptotic value of $\sim 10^{10}$ within the next 100 years. If the U.S. per-capita energy consumption rate of 1970 is applsed to this asymptctic total population, the world's total energy-consump$t$ ion rate $w 112$ be $2.8 \mathrm{Q}$ per annum $(35)\left(Q=10^{18}\right.$ Btu $=1.06 \times 10^{21} \mathrm{~J}$ ). At this consumption rate the supplies in pable $v$, would last for the durations shown in rable VI.

These results clearly indicste the relative shortage of fossil and rich-ore flssile fuels. In the past decade, the shortage in fossil fuels has been reflected in a changeover to power plants burning pissile fuls in areas where fossil-fuel costs are high. This change has not occurred becense nuclear power, per se, is preferable, but simply because this form of energy production has become econouically cametitive. However, fissile
TABLE V

\section{WORTD ENERGY RESOUKCBS}

Energy Avallable, $Q^{\mathrm{a}}$

Foss11

$\cos 1$

19

270

atl and natural gas

5.1

90

Flosile

Burners $(1.5 \%$ eff)

Rich ore $\left(<20 \$ / \mathrm{kg}_{8}\right)$

Iast-grade ors $P$ 20s/kg?

7.5

20

Breeders ( $60 \mathrm{f}$ eff)

Rich ore $(<20 \$ / \mathrm{kg}$ )

Low-grade ore $(>20 \% / \mathrm{kg})$

300

$9.5(10)^{5} 3(10)^{6}$

Fuston ( $50 \%$ aff)

Deuterium

Lthium

$\overline{a_{Q}}=10^{\mathrm{BD}}$ Btu $=1.06 \times 10^{21} \mathrm{~J}$

$\begin{array}{ll}4(10)^{9} & i n(10)^{9} \\ 3(10)^{6} & 3(10)^{6}\end{array}$

TARTE VI

WORLD ENIERGX RESEERUES

\begin{tabular}{|c|c|c|}
\hline & years at & ger. Annum \\
\hline Bnergy source & Inown & Possible \\
\hline Fossil & & \\
\hline coal & 6.8 & 96 \\
\hline O1l and natural gas & 1.8 & 32 \\
\hline Total & 8.6 & 128 \\
\hline Flsetle & & \\
\hline Rlch-ore burners & 2.7 & 7.1 \\
\hline Low-grade ore burners & $1.0(10)^{4}$ & $3(10)^{4}$ \\
\hline Rich-ore breeders & $10 \%$ & 340 \\
\hline Low-grads ore breeders & $3 \cdot 4(10)^{5}$ & $(10)^{6}$ \\
\hline Total rict ore & 210 & 347 \\
\hline Total 10s-grede ore & $3.5(10)^{5}$ & $(10)^{6}$ \\
\hline Fusion & & \\
\hline Deuterium & $(10)^{9}$ & $(10)^{9}$ \\
\hline Lithtum & $(10)^{6}$ & $(10)^{6}$ \\
\hline
\end{tabular}


fuel costo $\mathrm{H} 1 \mathrm{ll}$ increase as the rich-ore reserves are depleted: and, unless new inining and oreprocessing techniques are leveloped, fissile-fue Iburning plants w1ll become economically unattrictive and other forms of energy w1li ve sought. At fresent, It is established national policy that the fast-breeder reastor (In which low-grede fissile fuel, $238 \mathrm{v}$, is converted to fissioneble ${ }^{239}$ Pu whlle producing paer) will replace the fisstle-fuelburning plants as ricl:-ore deposits are depleted. Although the supply of low-grade ore is vest, there remitins the question whether a fast-breeder-based pover industry is desirable or even feastble. (36) The prublem of large-scale fission-product wasto disposal, alone, could make a fission-power economy very expensive.
If our fuel sources are in fact restricted as indicated in Tuble $V$, nuclear power (either flssion or fusion) must be used for the world's future needs. Electric-power generation by controlled fusion processes is, of course, not a certalnty; but from the foregoing discusstons there is little doubt that, if rade to work, fusion power could have vast econonlc, technical, and socioecological advantages over fast-fission breeders.

In conclusion, it should be evident that the quest for a workable fusion power gystem is more than the satisfaction of a scientiflc curlosity; It may be essential to the future well-being of mankind. 


\section{APPFODX A}

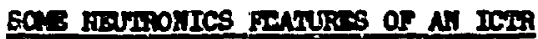

by C. W. Watsan

\section{Introduction}

Iuclear radietion-trangort cansideretion w111 be of central concern in the design and operetion of any controlled tharmonclear reetor (CAR) for electrlicel power genaration. Genaraliy, these consideretion fall Into one or ware of Five area (11stod belos in arder of deareaning iportance in deternining the onginearing feedb111ty of a Cist deolen):

- Inerey-deposition sates and epetial distributione in the rectar copiex.

- Iritiun production rate.

- Rediation-dnuse errecte.

- Iritiur proceseing and handins (arety).

- Sarety and milebllity problen axising frow the bulldup os Induced cotivities and ascocinted afterhast in the plnit coponente.

The first tro categaries, in jarticular, are of fundewentel ipartance in the infiel coneptinel deGign of any CHR.

For the present etudy of inartiellymconeined therwomelear rosctors (ICIRe), neutron and $y$-ray tranoport calculations were required to dafine opecisic reactor wotem and to provide nuremical resulto for corcontent decifo studies. The firot

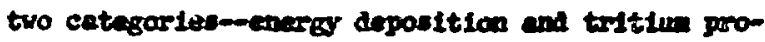
duetion-mare trented in this Appandix.

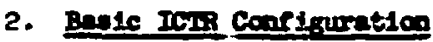

A rither spocisic overall concept he doulnated

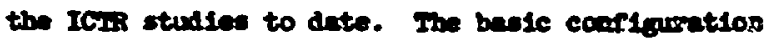
conisto of on meunted griesien cority in wieb (D+g) burning palets are exploded. The certy is

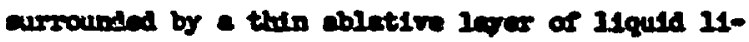

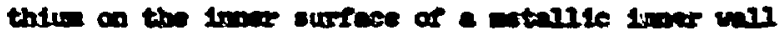

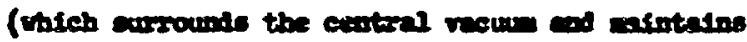

the cartty), followed by a 11quid-11thin binitet. Ine blenket function an a teitivabreding regios,

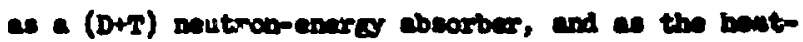

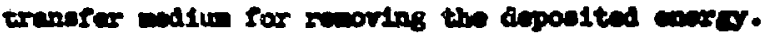

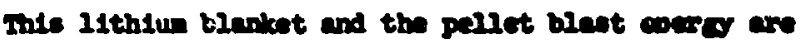
cootalned by an outer, relatively thiek, netrinso proveure rosenl. Doth the Innex and the outer now

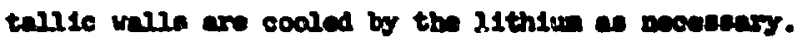
A cobmetic repreantation of the wotem is fhoum in 1.1. A.1.

In a now tevilotic deston a man blowdown

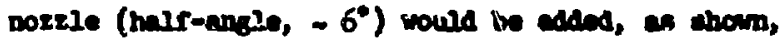

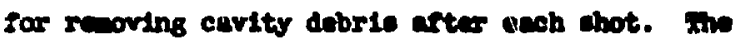
nozele would cecup onf - 15 as the total binn'set rolues, and rould drexnes the tertitu produotion ad energ deposition in the blentet by no are then a sos perout. Coserquenthy, the nowelo vas not included in the nevtronice studtes.

\section{Pavet Sowres}

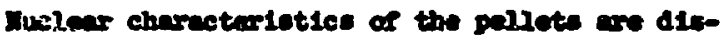

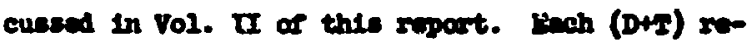

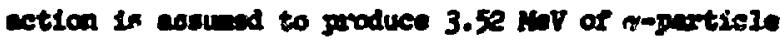
ance. depoested locelly in the pallet, and on

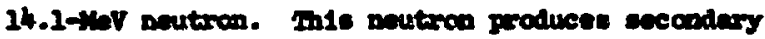

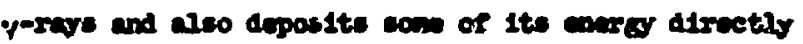

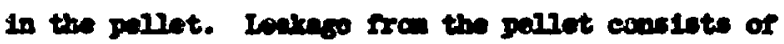

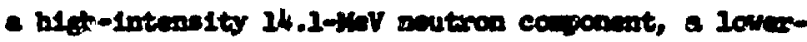

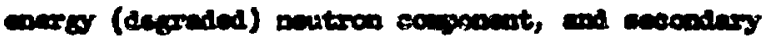

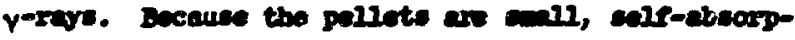
tion in the peliots is ale restively and (but not meligible): for couvenience, the blarket heat-

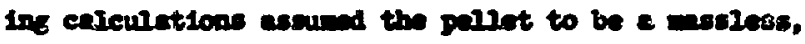

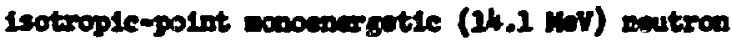

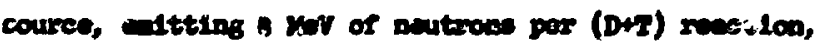

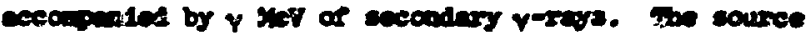

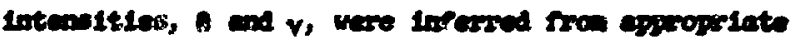

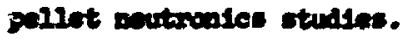




\section{Irielin Produation}

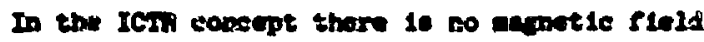
penctratise the blanket rogion, in contratet to a

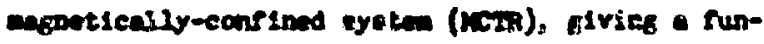
dasentel breadins edventage to the ICgn. The absence of manetic rields soas that the blanket 11thiue can be offleleatly puped out of the blasket dirwetly to external bat exchangere, poviatios the need for opecial bent-transfer struetures (and codia) vithln the bjenket; ax ouch structure would Dormilly roduce the tritlum-productors potential in the blanket.

Anothor tritilu-breeding Avantage is inherent in the coxcopt of Mg. A.1. The prioulpal wethande. by wich blanket atrueturee reduee the tritil production is through degradaticen of the fast-poution opectrue vie imelectic-seatcering roctions, partecularily in the laser portion or the blasket; this reduces the rites $T_{L 1}\left(n, n^{\circ},\right)_{T}$ resetion rate. This degradation vould de relatively omil in the seos werty of F18. A.1 because wot of the structural material 10 located in the prosusure vesel avay rron the innar part of the lithilu blanket.

Because adequate tritiun breeding in an ICIR would probably be reletively wey to secraplich and becauce there are no compelling mesons for keoping the blanitet thicknose andill (1n contrast to tha Mash,

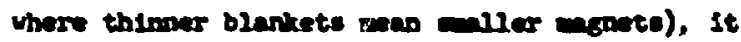

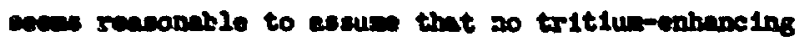
or blanket-thickness-reducing dditives sound be roquined in the ICsR. (Wote eleo tinat good beutionxacovel propertien for ahlelding ere not necessasy

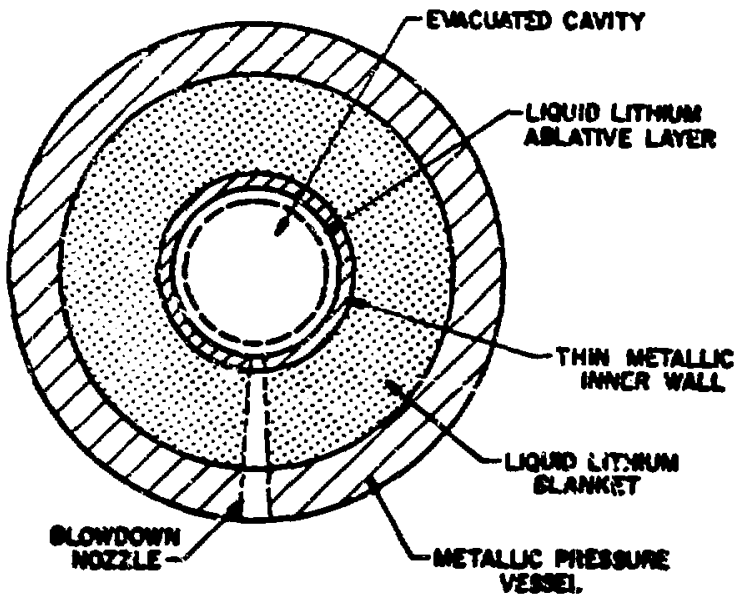

F18. A.1. ICLS sebemet1e.
In the ICBi blariset.) Thus, for tse preseat vork,

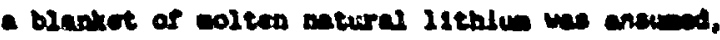
with so internal otructurs. saequate interral eupport could be provided by the blandors soevie anelaod carlier.

Tritlum production calculations wor pertornd vith the reth Mopte Carlo code, wich 10 elelliar to

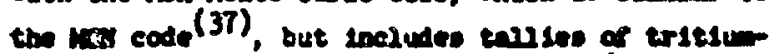

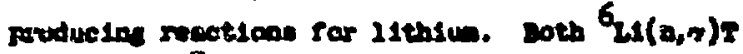

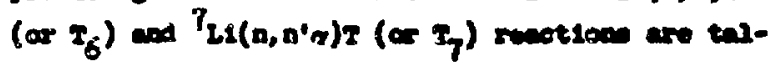

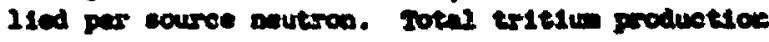
$10 \mathrm{~T}=\mathrm{T}_{6}+\mathrm{T}_{7}$

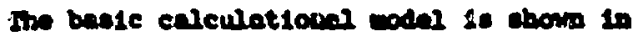
F1s. A.2. Bers, in orter will 1e lboluded for 200 reapons: (1) a plesula 10 repuired to colleot litblin nor tron the 1oner blanket, and (2) the 20ontion

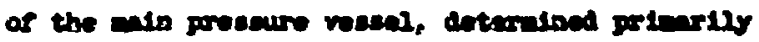

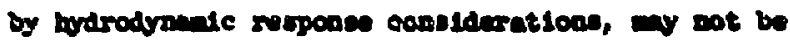

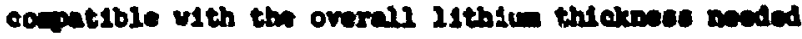

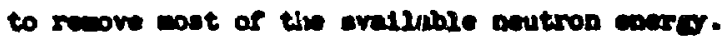

Tritlum production etuales ware ado by raryins

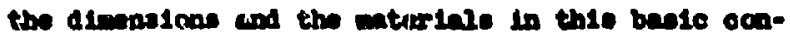
plouration. Nunning tiwe for colh of thase probleas, for relative errore of $<5 \%$, wes -5 in on the CDC-7600 couputer.

Floure A.3 obowe tritic production ve posttion of a 2.54-ca-thick 1 ron min preasure veawal In * 100-en-thick 11thes blanket (total thicknose

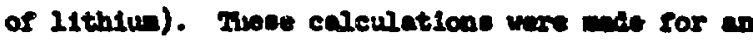
IICA having a rusion pellet at the sentex of a carlty of 100-ce rediue, with a 0.5-en-thick nlobluse

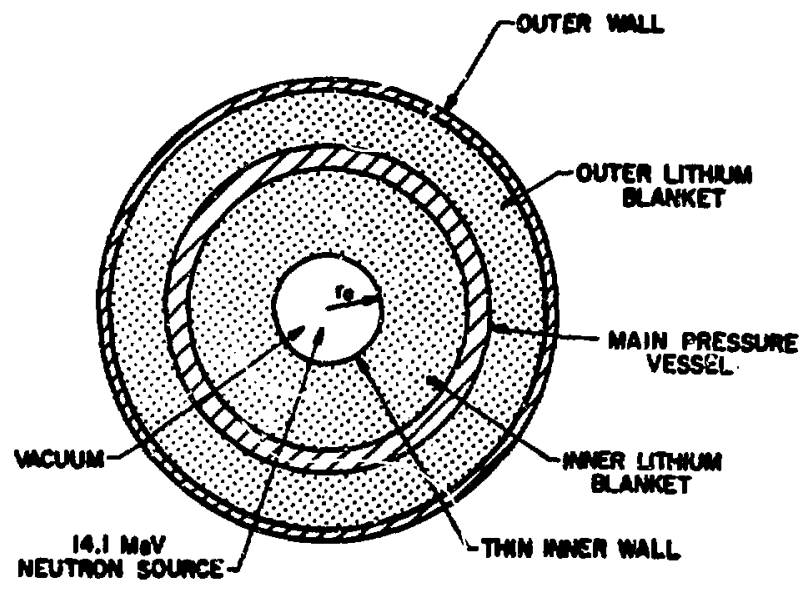

F1g. A.2. Basic ICIR configuration. 


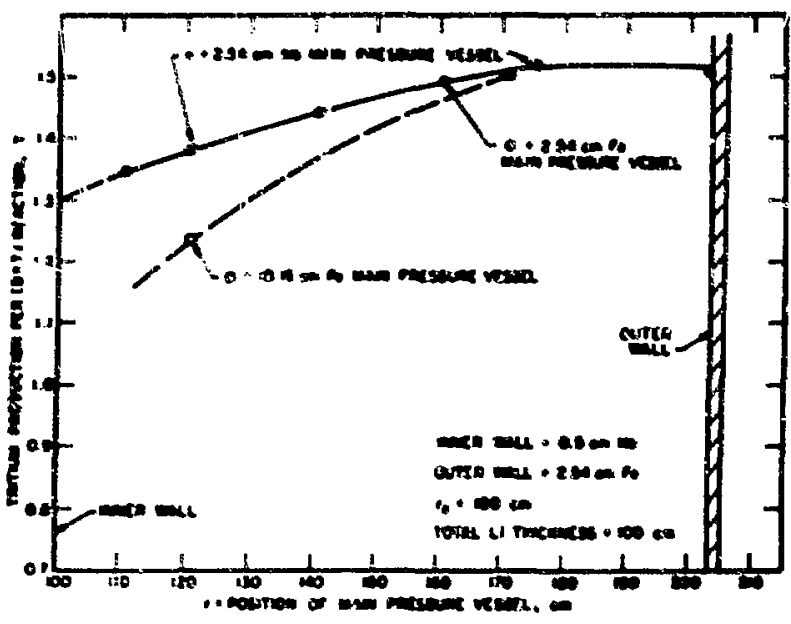

F16. A.3. Trit1u production (S) par (D+g) ro ection for configuretion of 18.8 .2 .

luner vall and a a.54-ce-thick Iron cuter will. To celculations far a 2.5b-ce-thlek njoblue an prencure reatial are also plotted; these results are alnost 1 dentical to those for the Iron veses. Finalyy, two pointe are hown far a 10.16-ce-thlck Iron in proseure vessel.

Note thas the erfect of the min proseure veseel upon tritlun production is wall if the veasel is loceted at - To sw or ware into the 11thium. Also, the roduction fran the exinu value ( $T=1.51$ ) produced by joceting $10.16-c 0-t h L k$ veasel at $20 \mathrm{~cm}$ into the 11 thitu 1 e very nearly tulce that produced by $=2.54-c-$-thick vessel at that location, 1.e., the tritiun production is reduced approxinate $2 y$ inversely as the square root of the ressel thickness.

This veriation is consistent with a caleulated breeding-ratio roduction produced by adding a relettraily thick $(-5 \mathrm{~cm}$ ) inner structural wall for restratnt of Inward motion of the Inner wall (soe Section II.C.3 of main body of report). A calculation using the configuration of FIg. A.2 with a 5.08-cm-thick irols inner wall indicated that $T$ I.23, which is not a prohibitive reduction in the breeding ratio.

Additional tritium estimates for a more specIfIc ICIR design will be presented later.

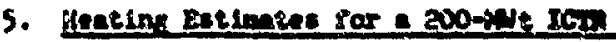

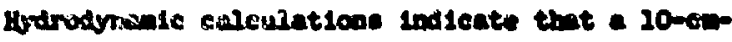

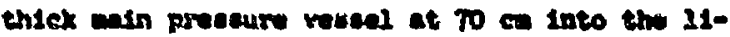
thim blanitet ar Fis. A.3 (5 = 170 on) would bo edequet to contenin a pilet explosion with a

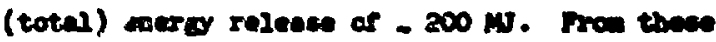
realts, comind vits cority blowors seneulation,

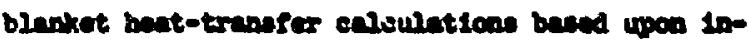
1tial basting eotintas, and tritiv poduction

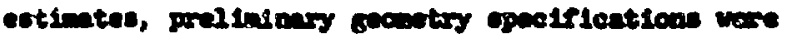

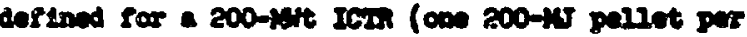

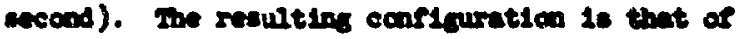

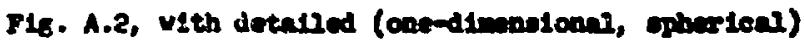

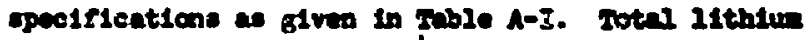
In thie goten $181.47 \times 10^{4} \mathrm{ke}$.

Neutson heatirs extInte wor based upon lonte carlo calculation, usins coles that ware modstieer

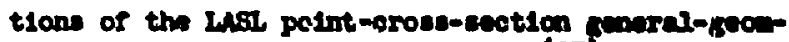
etry mante carlo noutron code, Mat. (37) In the codes, several optloral tallies or value to envers depositien estintes mare Inoorporated.

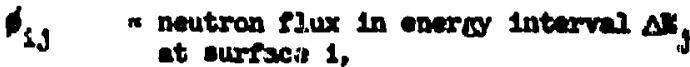

$$
\begin{aligned}
& J_{1 j}=\text { noutrun curremts }(t \text { and }- \text { ) in onaras }
\end{aligned}
$$

Totel computer running time per problem was - $20 \mathrm{~min}$ (CDC-7600) for rolative urara or 1 to $5 \%$. Two problews were run, one with 1! thium coolant in the stainless steel (BS) and one without lithium, to separate the beating for the twi materials. A tritium production calculation Witl the MCH codo was also run for this geometry; res ults are shown in Table A-II. 
(Oni Pnllet per Second)

\begin{tabular}{|c|c|c|c|c|}
\hline $\begin{array}{l}\text { Cels } \\
\text { No. }\end{array}$ & 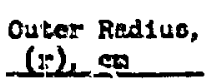 & Mnceringl & $\begin{array}{l}\text { Dens1ty, } \\
\mathrm{ser} / \mathrm{cm}^{3}\end{array}$ & Deser1ption \\
\hline 1 & 98.9 & $\mathbf{L S}$ & 0.0018 & Cuvity \\
\hline 2 & 99.0 & $\mathbf{W}$ & 0.495 & Ablative $\mathrm{LI}$ on Inner val \\
\hline 3 & 200.0 & $\begin{array}{l}\text { Stadnless Steel } \\
+ \text { Il }\end{array}$ & $\begin{array}{l}S S=4.72 \\
1.1=0.197\end{array}$ & $\begin{array}{l}\text { Inner wall, with } \\
\text { vold rroction }=40 \%\end{array}$ \\
\hline 4 & 103.25 & $\mathbf{L 1}$ & 0.492 & lat blanket \\
\hline$s$ & 106.49 & $\mathbf{L 1}$ & 0.490 & lot blanket \\
\hline 6 & 11.0 .30 & L1 & 0.488 & lst blanket \\
\hline$T$ & 113.91 & II & 0.486 & lot blanket \\
\hline 8 & 113.08 & l.1 & 0.484 & lst blanket \\
\hline 9 & 123.19 & $\mathbf{L 1}$ & 0.482 & lst blanket \\
\hline 10 & 129.22 & $\mathbf{L t}$ & 0.480 & let blanket \\
\hline 11 & 137.10 & $\mathbf{L I}$ & 0.478 & lat blanket \\
\hline 12 & 147.76 & L1 & 0.476 & lst blanket \\
\hline 13 & 159.43 & WI & 0.474 & lst blanket \\
\hline 14 & 169.55 & LI & 0.473 & lat blanket \\
\hline 15 & 272.88 & $\begin{array}{l}\text { Stad.less Steel } \\
+ \text { LI }\end{array}$ & $\begin{array}{l}85=7.07 \\
L 1=0.047\end{array}$ & $\begin{array}{l}\text { Pressure vessel, with } \\
\text { vold Praction = Inp }\end{array}$ \\
\hline 16 & 176.21 & $"$ & $"$ & $"$ \\
\hline 17 & 179.55 & $n$ & $"$ & $"$ \\
\hline 18 & 189.55 & $\mathbf{I I}$ & 0.472 & and blanket \\
\hline 19 & 199.55 & $\mathbf{L 1}$ & 0.472 & and blanket \\
\hline 20 & 209.55 & L1 & 0.472 & 2nd blankec \\
\hline 21 & $22: .09$ & SS & 7.86 & Outer shell \\
\hline
\end{tabular}




\begin{tabular}{|c|c|c|c|c|c|c|c|}
\hline Cell & $\begin{array}{c}\Delta s_{\text {al }} \\
\text { yov/fioution }\end{array}$ & $\begin{array}{c}\Delta \mathbf{s}_{\mathbf{n}, 1} \\
\text { MV/houtron }\end{array}$ & $\begin{array}{l}\Delta \mathrm{B}_{\operatorname{man}} \\
\text { NV/Aaltaron }\end{array}$ & $\begin{array}{c}\Delta B_{n,}, x \\
\text { Lovfiention }\end{array}$ & $\begin{array}{l}\text { Captureo/ } \\
\text { Eeution }\end{array}$ & $2 / 6$ & $T$ \\
\hline 3 & 0.0020 & 0.0059 & 0.0514 & 0.011 & 0.0011 & 0.0008 & 0.0049 \\
\hline 2 & 0.0089 & 0.0023 & 0.0151 & 0.0037 & 0.0008 & 0.0010 & 0.0010 \\
\hline $3(\mathrm{~L} 1)$ & 0.0336 & 0.0081 & 0.0490 & -0 & 0.0041 & 0.0036 & 0.0064 \\
\hline $3(s s)$ & 0.0127 & - & 0.6128 & 0.2494 & 0.0098 & 0 & 0 \\
\hline 4 & 0.2551 & 0.0728 & 0.4846 & 0.0752 & 0.0306 & 0.0276 & 0.0468 \\
\hline 5 & 0.2460 & 0.0690 & 0.4518 & 0.0697 & 0.0317 & 0.0315 & 0.0516 \\
\hline 6 & 0.2736 & 0.0761 & 0.4996 & 0.0736 & 0.0365 & 0.0366 & 0.0625 \\
\hline 7 & 0.2610 & 0.0670 & 0.4610 & 0.0630 & 0.0369 & 0.0348 & 0.0510 \\
\hline 8 & 0.2752 & 0.0767 & 0.4742 & 0.0662 & 0.0433 & 0.0422 & 0.0553 \\
\hline 9 & 0.3235 & 0.0860 & 0.5219 & 0.0729 & 0.0540 & 0.0546 & 0.0623 \\
\hline 10 & 0.3372 & 0.0916 & 0.5301 & 0.0703 & $0.06+3$ & 0.0625 & 0.0647 \\
\hline זנ & $0.388 ?$ & 0.1025 & 0.5947 & 0.0700 & 0.0848 & 0.0636 & 0.0738 \\
\hline 22 & 0.4361 & 0.1157 & 0.6106 & 0.0625 & 0.1190 & 0.2162 & 0.0741 \\
\hline 13 & 0.3432 & 0.0852 & $0.45^{1}+9$ & 0.0453 & 0.2232 & 0.2211 & 0.0573 \\
\hline 14 & 0.2869 & 0.0676 & 0.3428 & 0.0327 & 0.137 & 0.1370 & 0.0468 \\
\hline 15 (II) & 0.0059 & 0.0025 & -0 & -0 & 0.0042 & 0.0048 & 0.0010 \\
\hline 15 (ss) & 0.0245 & -- & $0.528 T$ & 0.0745 & 0.0125 & 0 & 0 \\
\hline $26(\mathrm{LI})$ & 0.0037 & 0.0011 & -0 & -0 & 0.0034 & 0.0040 & 0.0004 \\
\hline 16 (Ss) & 0.0184 & - & 0.3239 & 0.0392 & 0.0004 & 0 & 0 \\
\hline $17(\mathrm{LI})$ & 0.0024 & 0.0005 & .0 & $\approx 0$ & 0.0024 & 0.0028 & 0,0001 \\
\hline 17 (ss) & 0.0130 & -- & 0.1957 & 0.0202 & 0.0064 & 0 & 0 \\
\hline 18 & 0.0610 & 0.0127 & 0.0423 & 0.0054 & 0.0512 & 0.0499 & 0.0067 \\
\hline 19 & 0.0434 & 0.0093 & 0.0378 & 0.0042 & 0.0415 & 0.0417 & 0.0054 \\
\hline 20 & 0.0307 & 0.0057 & $0.0 .24 \overline{3}$ & 0.0023 & 0.0363 & 0.0344 & 0.0031 \\
\hline 21 & 0.0024 & $\infty$ & 0.0578 & 0.1035 & 0.0015 & 0 & 0 \\
\hline Total (II) & 3.618 & 0.958 & $5: 646$ & 0.727 & 0.9064 & 0.891 & 0.675 \\
\hline Dotal (SS) & 0.071 & 0 & 1.899 & 0.387 & 0.0396 & 0 & 0 \\
\hline Total (LI+SS) & 3.669 & 0.958 & 7.545 & 1.114 & 0.9460 & 0.891 & 0.675 \\
\hline
\end{tabular}


With the exception of $\Delta s_{\text {of }}$, the terrus in Table foII do not give energy daposition directly; nor do they, because of the implied secondary $Y$-ray production, generaly give the spatial distributions. The rasiety and copplexity of reactions that 14-WaV neutrons undergo in most aterinle, especially in lithlus, ako a caplete andyess of the tlanket energy deposition very diffleult, even in princlplo. In mractlee, the lack of requisite detall in avaslable phyoles wate wares such an andysis ipoesible.

It becowes nosessary to assess the relative rates of the various roactions and to direct attentlan only to those that are of primary importance. Such aseesewents vere made for the ICIR, using Norte Carlo tabulated Ilux opectrin. Restite for lithlim are shown as a runction of dlatance Into the blanket In Addencium 1 to this Append $1 x$. Based upon these results, the energy deposited was estimated by wisusts the followtng:

1. AII 11thiun captures are $6_{I, t}(n, r) T$ events which depostt $~ 4.79 \mathrm{KoV}$ locally per cajture.

2. Bnargy deposition via ss captures 18 negligibly omall. Thut, all of $\Delta E_{n, x n}$ for SS 10 a direct anergy loss (no nuclear recoll erergy doposited).

3. All of $\Delta S_{\text {nanl }}$ far sS reappears as inelestic Y-rays.

4. All of $\triangle B_{\text {non }}$ for lithium is trom $T_{\text {LI }}$ $\left(n, n^{\prime} \gamma\right) T$ eventa.

For ${ }^{\prime} \mathrm{IL}\left(\mathrm{n}, \mathrm{n}^{\prime} \alpha\right) \mathrm{N}$, assure 2.47 NeV lost por event, 1.e., $2.47 \mathrm{MeP}$ ts lost per unit $\mathrm{T}_{\mathrm{T}}$ producticn. The rensinder af $\Delta B_{\text {non }}$ is deposited loceily as recoll enerey of the helium and tritiun produced. The following questians irematn:

1. How wuch of $\Delta E_{n, 3}$. far Itthtum reappears as inelastic $y$-rays and what are their energies?

2. Wat fraction of $\Delta B_{n, x n}$ for lithium is deposited locally as recoll energy of the lithium nucle1?

Detalled estimates were made for Item 2, using MCN cross-sections, $(n, x)$ ) nentron mroduction spertra, and calculated fluxes, plus equations for recoll energy from Ref. 38. (Isotropic center-of-mass neutron emission was assumed.) The results gave
- ees of $\Delta B_{n, x n}$ depcsited, vith a man rarintiot over the blanket of - 2\%. (A constent $22 \%$ vas asstived.)

Itea 1 poses a gare banic, and wore inportant probles. It 1s basic, because the dnta sequired to unequivoculy ancion 11 thius inclastic-sestexing $y$-ray apectre (and, thus, the $y-20 y$ production ructions) are appixently not avaliable; it is inpartagt, hocause heating in Internel strustures, aspecielly structures weh as the inner woll, can be prodoninently from the lithiu inelentic-scettering $Y^{\prime} s$. Bstinates of these henting rutes are sensitive to the I1thiug inalatier opectrus ansuod; In gomeral, a sorter 11thiun yarwy opoctoru wil inly a higher inner-vall heating rate.

Addendum 2 to this Appendix diccusens the approsel uhich was uses for Ilthiu inelevtic $y^{\prime}$ In the present case, besed upon inelest 1c-senttoring Y-ray spootra Trom Rer. 38. Although otld1 uneertain, this approash wes used bicence 18 conet1tutes an exaple of a opocteral nodel that includes both the dominarit ecattering nom low-Lying levels $\left(0.478 \mathrm{HV}\right.$ in $T_{Z 1}$ and $3.56 \mathrm{HoV}$ in $\mathrm{Z}_{11}$ ) an well as an evaparation cosponent for vary-lulgh-energy noutrans (14 kiv). The develognant is radendur 2 uses, In effect, only the $\gamma$-opectore Ira Rer. 3A; the ovarall Inelastle-scattering anerey balcuce is besed. upon the Monte Carlo-ealeulated energy changes, It: is impartart to note, however, that there is an incansiatency in this approech. The MAI code asourse ( $\left.n, n^{\prime} y\right)$ scattoring only from the lon-lying 2 evele of lithlum; thus, the resiltarit total vante carlo lithium Inelastion enersy is 20 wer than that inplied by the assumed apectra Rron Rer. 38.

lisiag revults from Addeodum 2 and rron Table A-II, $Y$-source intensities and spectra were inferred for the ceils of Table A-I. Gama-roy transpart calculations were then performed to eotinats secondary $y$-heating rates throughout the system.

Theae results wexe normalized to a given pellat output on the basis of the following assumptions: $r$-particle deposition in the pellet $5.52 \mathrm{MeV}$ Nuclear energy absorbed in the pellet $0.89 \mathrm{MeV}$ Neutron leakage from the pellet $12.2 \mathrm{MoV}$ $y$-ray leakage from the pellet Total energy per $(D+T)$ reaction in the pellet.
$0.9 \mathrm{MeV}$

$17.51 \mathrm{MeV}$ 


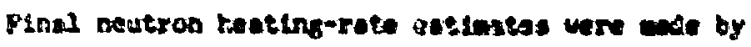
culetglydas the polnt-wroce ralues by (12.2/16.1) .

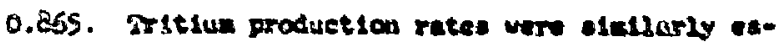

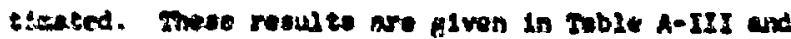

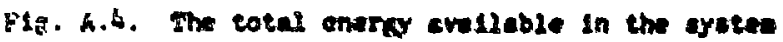

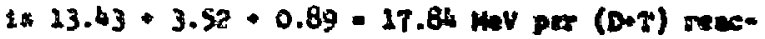
Qton.

Hote that a error in inpleft is thie narmal120t10a. It astunes that 0.869 newerons par (D.T) reacelor lacre the pellet, vith owh butron having en ensrgy of 14.1 MeV. This to probably edequete for estincths direet noutron-enercy dapastion

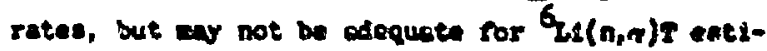

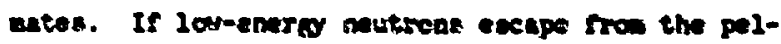
let arter having depoolend coes of ehes entry in the pallet, cormetion difte to roquired. For exnople, 15 an etultional $(2.0-0.865)=0.135$ beutrons per (D+T) are cenund to be of thla upp, terco

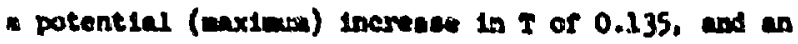
iperease in blenket enero depoettion or (0.135) (4.79) - 0.65 ur are poselble pur (D+g) reaction.

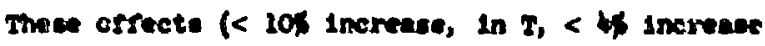
in avelleble enrrol can be propurly cetinated only with coupled pellet-blanket enlculations, which hire are not juetsfied.

An overell energ bulance, based ubon the steted numilintion essuption and the kente Corlo celculations, can be eatinted as follore:

Sharry Produped/(D+2) Benction:

(D+T) reweston

$G_{\text {I.I }}(n, \sigma) \mathrm{r}$ renctions

(0.T7) (4.79)

Total

$\frac{\text { Dyer.\%, keV }}{17.62}$
$\frac{1.69}{21.51}$

Bnerey Loso/(D+r) Beaction:

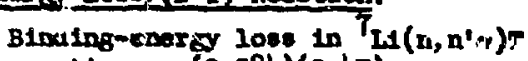
reactions $=(0.584)(2.47)$

1.44

Bindingwenersy IOse in $(n, 2 m)$

resctions

Ioss in capture reactions,

e.8., $(n, p),(n, D)$

0.55

$\gamma$ ray leakage trom the blanket

0.48

Neutron leakage from the blanket.

0.12

Assumed jellet losses

0.11

0.28

Miscellaneous other losses

17.84

Total

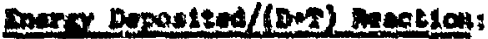

peldet

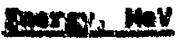

cersey coend (alnue the galde)

1.42

Ionas vald

c.ora

Inner gethiu glentret

0.870

Waln preature vasnel

12.045

Outer Iithsun hloritet

0.951

0.712

Outer mis

aren

17.83

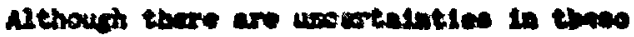

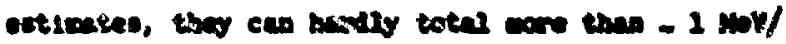

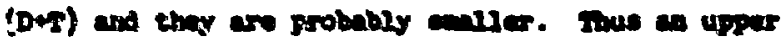

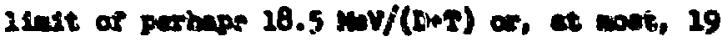

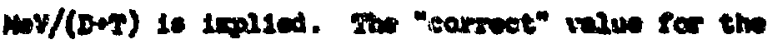

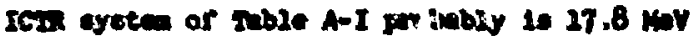

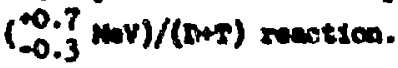

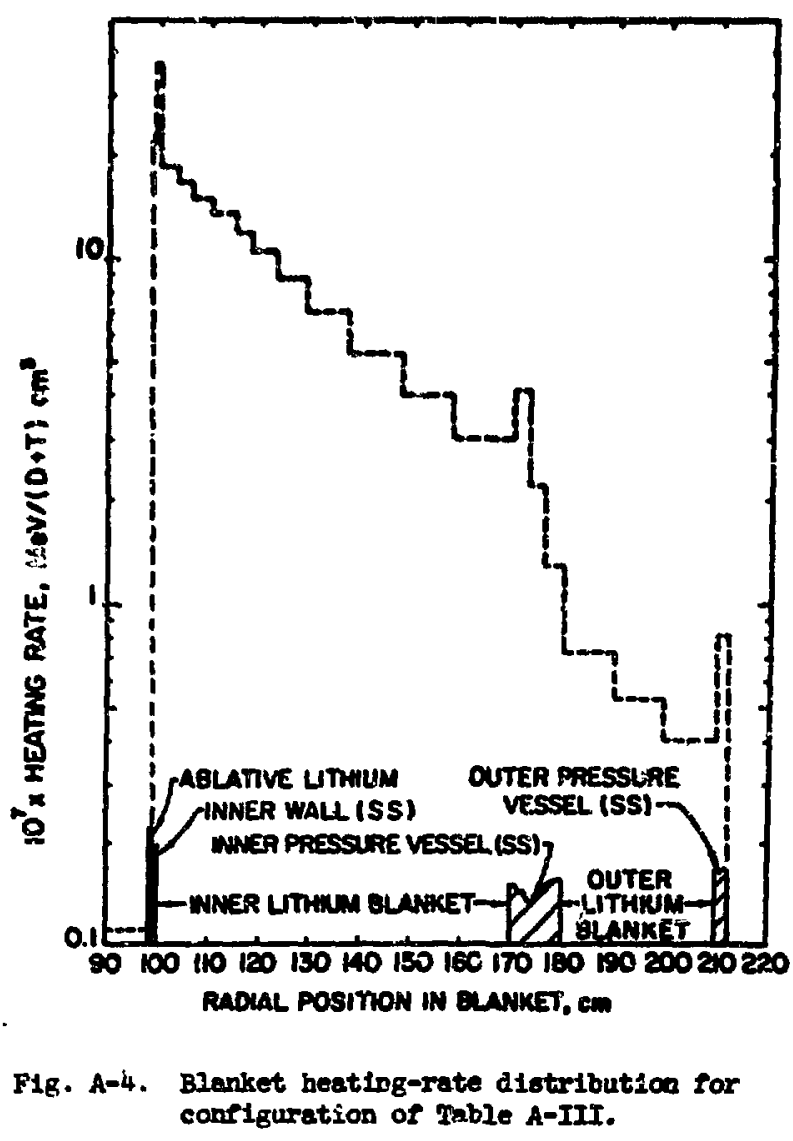




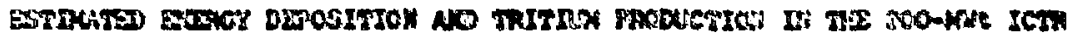
Congeth

\begin{tabular}{|c|c|c|c|c|c|c|}
\hline \multirow[b]{2}{*}{ Sol } & \multicolumn{3}{|c|}{$\operatorname{sev} /(0+2)$} & \multicolumn{3}{|c|}{ Sressux produceion/(D+T) } \\
\hline & Neutrone & Peline y-raya & Totel & $3 i$ & 2 & $x$ \\
\hline 3 & 0.045 & 0 & 0.045 & 0.0007 & $0.00 \mathrm{~h} 2$ & 0.0049 \\
\hline 2 & 0.028 & 0.003 & 0.097 & 0.0009 & 0.0009 & $=.0018$ \\
\hline 3 & 0.270 & 0.200 & 0.470 & 0.0031 & 0.0055 & 0.0086 \\
\hline 4 & 0.737 & 5.059 & 0.792 & $0.0 \leqslant 39$ & 0.0422 & 0.0661 \\
\hline$s$ & 0.698 & 0.050 & 0.746 & 0.0273 & 0.0346 & 0.079 \\
\hline 6 & 0.750 & 0.053 & 0.815 & 0.0327 & 0.0542 & 0.0858 \\
\hline 7 & 0.738 & 0.048 & 0.786 & 0.0301 & 0.0442 & 0.0729 \\
\hline 8 & 0.787 & 0.049 & 0.836 & 0.0365 & 0.0478 & 0.0643 \\
\hline 9 & 0.911 & 0.054 & 0.965 & 0.0472 & 0.0539 & 0.2001 \\
\hline 10 & 1.010 & 0.055 & 1.065 & 0.0542 & 0.0560 & 0.2102 \\
\hline $\boldsymbol{\nu}$ & 1.170 & 0.060 & 1.230 & 0.0723 & 0.0639 & 0.2362 \\
\hline 12 & 2.380 & 0.054 & 2.454 & 0.2025 & 0.0694 & 0.1629 \\
\hline$i 3$ & 1.196 & c. 150 & 1.246 & 0.1048 & 0.0496 & 0.1544 \\
\hline 14 & 1.082 & c :40 & 1.222 & 0.1185 & 0.0405 & 0.1590 \\
\hline 15 & 0.431 & 0.059 & 0.500 & 0.0042 & 0.0009 & 0.0051 \\
\hline 16 & 0.249 & 0.032 & 0.280 & 0.0035 & 0.0003 & 0.0038 \\
\hline I7 & 0.158 & 0.013 & 0.27 & 0.0024 & 0.0001 & 0.0025 \\
\hline 18 & 0.307 & $0 . \cos$ & 0.310 & 0.0432 & 0.0058 & 0,0490 \\
\hline 19 & 0.249 & 0.031 & 0.250 & 0.0361 & 0.0047 & 0.0408 \\
\hline$\approx$ & 0.211 & 0.041 & 0.212 & 0.0298 & 0.0021 & 0.0325 \\
\hline 21 & 0.115 & 0.002 & 0.115 & 0 & 0 & 0 \\
\hline btal & 12.53 & 0.90 & 13.43 & $0.7 m$ & 0.584 & 1.355 \\
\hline
\end{tabular}




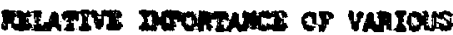

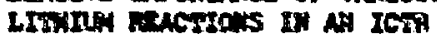

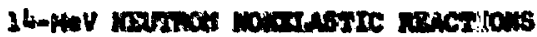

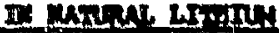

Redetsve sportence for the varieun neteron

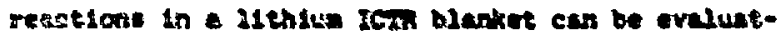

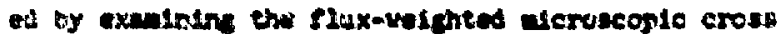
cestion for shese rovetians a a runction of position in the bianket. 2he Ingartabes sto the sture-

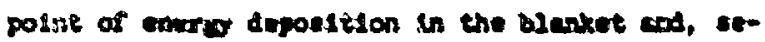

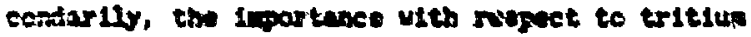
prodisetion in the slarket are of interent.

Withlu nonelustle recotion thet eurt be con-

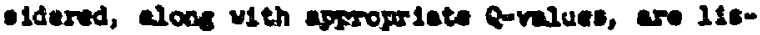
end in Muble a-IV. Fosut crose eactions fer these

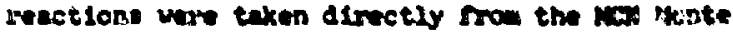

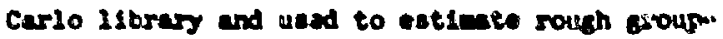
averesed crase-tection in the enero groupe, $\Delta{ }_{j}$ for which Ponte carlo Muxen ver celculeted.

Ithace cross ections war thes uned to esternte the pencent of all aonelestlc rections in sutural 11thium for ench remotion, as ghom in Tuble $A-V$.

Tules $A-I V$ and $A-V$ indlecte that, vith in er-

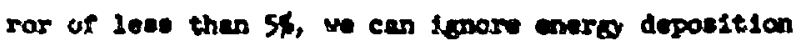
rro all rewetions except $G_{L I}(n, r) T$, and y-rays now

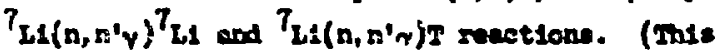
latter racetion jrobahly produces no $\left.y^{\prime} 0\right)$. Frt PDers looses to binding energ in $T_{\mathrm{L}}\left(\mathrm{n}, \mathrm{n}^{\mathrm{N}} r\right) \mathrm{T}$ and

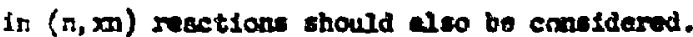

\begin{tabular}{|c|c|}
\hline Roection & 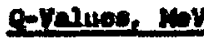 \\
\hline$G_{\text {Le }}\left(n, n^{+} v\right)^{G}{ }_{L}$ & - \\
\hline$G_{L:}\left(n, n^{0}, n\right) D$ & $-1,47$ \\
\hline$G_{L}(\mathrm{n}, 2 \mathrm{2m})_{\mathrm{p}}$ & -3.70 \\
\hline$G_{21}(x, v)^{7}$ & +7.25 \\
\hline${ }^{6} \mathrm{w1}(0, p)^{6}$ & -2.73 \\
\hline$\left(5_{110}-6_{21}\right)$ & +0.815 \\
\hline$\sigma_{11}(n, n) T$ & +4.79 \\
\hline$T_{\text {IUL }}\left(n, n^{\prime} y\right)^{T_{21}}$ & $\cdots$ \\
\hline$T_{L 1}(n, 2 n)^{6}$ & -7.25 \\
\hline$T_{L U}\left(n, n^{0} N\right) \mathrm{T}$ & -2.47 \\
\hline$T_{L}(0,2 n y) D$ & -8.72 \\
\hline$T_{W}(n, v)^{8} u$ & +2.03 \\
\hline$\left(a_{11} \rightarrow 2^{4} H_{0}\right)$ & +25.9 \\
\hline$T_{L 1}(n, D)^{6}$ & -7.76 \\
\hline
\end{tabular}

DABTS A-V

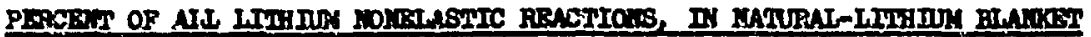

Dlotanes nto the Elaniret, $\mathrm{Cm}$

\begin{tabular}{|c|c|c|c|c|c|c|}
\hline & & & & & & \\
\hline Seectian & 1 & 1 & 20 & 40 & 160 & 300 \\
\hline$G_{L 1}\left(n, n^{\prime} y\right\rangle^{G_{L 1}}$ & 0.2 & 0.1 & 0.2 & 0.1 & $\sim 0$ & -0 \\
\hline$G_{L 1}\left(n, n^{\prime} n\right) D$ & 5.3 & 5.2 & 4.8 & 3.9 & 0.6 & -0 \\
\hline & 0.4 & 0.4 & 0.3 & 0.2 & -0 & .0 \\
\hline & -0 & -0 & -0 & -0 & -0 & -0 \\
\hline $6_{\mathrm{LI}}(n, p)^{6} \mathrm{He}$ & 0.2 & 0.1 & 0.1 & 0.1 & $\sim$ & -0 \\
\hline$G_{\text {LI }}(n, \gamma) T$ & 30.8 & 33.2 & 38.6 & $5 C .9$ & 92.3 & 97.3 \\
\hline $7_{L 1}\left(n, n^{\prime} \gamma\right)^{7}{ }_{L 1}$ & 24.3 & 25.1 & 25.0 & $2: .9$ & 4.6 & 2.3 \\
\hline $7_{L \perp}(n, 2 n)^{6}{ }_{L 1}$ & 1.5 & 1.3 & 1.1 & 0.7 & 0.1 & -0 \\
\hline$T_{L+1}\left(n, n^{\prime} r\right) T$ & 35.1 & $\$ 2.7$ & 28.5 & 21.2 & 2.3 & 0.1 \\
\hline $\mathrm{T}_{\mathrm{L}-1}\left(\mathrm{n}, \mathrm{2n}_{\mathrm{O}}\right)_{\mathrm{D}}$ & 1.7 & 1.4 & 1.1 & 0.7 & -0 & -0 \\
\hline${ }^{7_{L I}(n, v)}{ }^{L_{L I}}$ & -0 & $\sim 0$ & $\sim$ & .0 & -0 & $\sim 0$ \\
\hline${ }^{7}{ }_{X i}(n, D)^{6} \mathrm{He}$ & 0.6 & 0.5 & 0.4 & 0.3 & -0 & $\sim 0$ \\
\hline
\end{tabular}




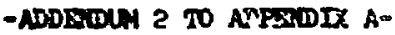

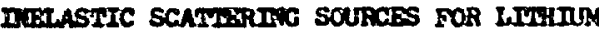

The Monte Carlo code used for ICIR heating estwates in this otudy Includes as ane of its options a c-2l-wise tally of $\Delta E_{n, l}$ e neutron enerey lost in $\left(n, n^{\prime} y\right)$ reactions in 11 thium. To eatirate the resulting enersy deposition it 18 necessary to estinte what fraction of $\Delta B_{n, l}$ is deposited as enerey of the 11thiue recoll nucle1, and what froction reappears of inelastle-scattering $y-5 a y b$. The enerey opoctron of these $v$-rays wust also be letermined. This latter probler is particulariy difflcult if the Inelastic scattering occurs vis several nuclear levels, plus continuum-region scat. tering; the neutron spectrum varies greatly from ins1de to outside in a typ:cel CTR blanket and, in general, this implieo a rusition-dopendent inelasticy apoctrum. Correspanding recoll onergteo far the Ifthium nuclel wust also be estineced, sinco this rraction of $\Delta 8_{n, 1}$ 1s deposited locally, in cantrast to the Inolastic $y^{\prime} B$.

Such pirviblems have been examined by Ritts, Solcalto, and Steiner. (38) In that otudy, Inelastic sattering was as sumed to be via the $0.478-\mathrm{KaV}$ leval in $T_{\text {it }}$ and the 3.56-yev lovel in $6_{L 1}$, plus a contimuin reglon in with an evaparat on scatitering nodel uns used for incident neutron energies above

9 Nep. Kesulting group-wise Bowondary $v$-ray spectra are tabuzeted in this refarence for 100 neuticonenerey groups between $0.414 \mathrm{eV}$ and $14.92 \mathrm{MeV}$.

Far the present vark, the ORKL inelast1cscattering y-ray production spictra will be norwalied to the MAN-calculated neutran-eneray losses to ostain inelestic $y$ sources for $r$-heating estiwates. Carrespanding recoll energles will also be estimsted that are corsistent with the ORNL spectrs.

To do this, consider only $\left(n, n^{\prime} y\right)$ evertis in 11thium and assume 1sotroplc emisston of the $n^{\prime}$ neutrons in the center-of-mass system (energles are in the labaratory system). The following definftions w11 be used:

1 = Incident neutrou energy (or group) Index,

$J$ = exc1tation energy (ar group) Index, for an $\left(n, n^{2}\right)$ event in lithium,

$k=$ position (or region) index,
$B_{1}=$ incident neitron enerey,

$E_{i j}=$ excitation energy of the residual nucleus after $\left(n, n^{\prime}\right)$ scattering of a neutron w1th inctaent enersy $B_{1}$,

$\mathbf{E}_{1 \mathrm{f}}^{\mathrm{n}}=$ energy of the outgoing neutron in an $\left(n, n^{\prime}\right)$ event which lesves the residual nuclaus with exc1tation enerey $B_{1 j}$ (inclient neution energy $=E_{1}$ ),

$\mathbf{B}_{1, j}=$ energy of recoil nucleus for $\left(n, n^{\prime}\right)$ event as above,

$r_{1 j}=$ Trastion of $\left(n, n^{\prime}\right)$ evente which produce residual nuclel with excitation energy $E_{i j^{\prime}}$

$\phi_{\text {ik }}=$ flux at position $k$ of neutrons with energy $\mathrm{B}_{1}$,

$\sigma_{\text {IK }}=\left(n, n^{\prime} y\right)$ cross section at position $k$ for neutrons of energy $B_{1}$,

$\Delta S_{k}^{n}=$ calculated total neutron energy change at position $k$ via $\left(n, n^{\prime}\right)$ resctions, per source neutron.

Thus, by the above definitions,

$$
\mu_{k}^{n}-A_{k} \sum_{1} \sum_{j} f_{t j} o_{1 k} \phi_{t k}\left(B_{t}-E_{1 j}^{n}\right)
$$

where the $A_{k}$ are froducts of the proper norwalizetion factors, as required. Also, vis an enersy balance for a given $\left(n, n^{t}\right)$ event,

$$
B_{1}=E_{I J}^{n}+E_{1, j}+E_{1, j} \text {. }
$$

The mechantes of the $\left(n, n^{\prime}\right)$ scattering eront are described by the following (see Rer. 38):

$$
\begin{aligned}
E_{1 j}(\theta) & =\frac{2 A E_{1}}{(1+A)^{2}}\left[1-\frac{(1+A) E_{1,}}{2 A E_{1}}\right. \\
& \left.-\sqrt{1-\frac{(1+A) E_{1,1}}{A E_{1}}} \cos \theta\right],
\end{aligned}
$$

where A Is the ratio of the nuclear mass to the neutron mass, and $\theta$ 1o the center-of-mass (c.tu.) scattering angle. If 1sotropic c.m. bcattering is essumed,

$$
E_{1 j}^{r}=\left[E_{1 j}(A)\right]_{a v}=\frac{2 A E_{1}}{(1+A)^{2}}\left[1-\frac{(1+A) E_{1 j}}{2 A E_{i}}\right] \text {. }
$$

\footnotetext{
*There are data which indicate that this maj not be a good assumption for 14-heV neutrons in 11th1um, and a algaificant error can be implied. However, available data are not oufficlent to Ellow a better analyols at this time; further, the Monte Carlo calculations use isotropic inelastic scattering models. Any other asiumption would, therefore, be inconsistent with the MCN results.
} 
Finally, the total recolis enerby at $k$ is

$$
\Delta E_{k}^{r}=A_{k} \sum_{i} \sum_{j} \rho_{1 j} \phi_{1 k} \sigma_{1 k} E_{1 j}^{r} .
$$

Thus, the fraction of $\Delta \mathrm{K}_{\mathrm{k}}^{\mathrm{n}}$ that reappears as recoll energy of the lithium nuclel 18

$$
B_{k}=\frac{\Delta F_{k}^{r}}{\Delta E_{k}^{n}}=\frac{\sum \sum f_{1 j} \phi_{1 k} \sigma_{i k} E_{1 j}^{r}}{\sum \sum_{1 j} f_{1 j} \phi_{1 k} \sigma_{1 k}\left(E_{1}-B_{i j}^{n}\right)} \quad(A-4)
$$

The excitation energy, $E_{1 j}^{Y}=B_{1 j}-B_{1 j}^{Y}$. 10 assumed to reappear as a single photon of energy $\mathbf{B}_{1 J^{\prime}}$

To estirate $A_{k}$ and the resultant inelastic $\gamma$ spectrum, the following enerby groups are assumed (corresponding to Intervals in the tebles of Rer.

\begin{tabular}{|c|c|c|}
\hline 1 & $\Delta \mathrm{s}_{1,1}(\mathrm{MeV})$ & $\begin{array}{c}\text { Assumed } \\
\left.\mathrm{B}_{1,1} \text { ( } \mathrm{NeV}\right)\end{array}$ \\
\hline 1 & to 14.1 & 12.3 \\
\hline 2 & to 12 & 11.0 \\
\hline 3 & 8 to 10 & 9.0 \\
\hline 4 & 3.5 to 4 & 3.56 \\
\hline 5 & 0.4 to 1.0 & 0.478 \\
\hline
\end{tabular}
38.)

\begin{tabular}{|c|c|c|c|}
\hline 1 & $\Delta \mathrm{B}_{1}(\mathrm{MeV})$ & & $\begin{array}{c}\text { Assumed } \\
\mathrm{E}_{1} \quad \text { (KeV) }\end{array}$ \\
\hline 1 & 23.5 & 14.92 & 14.1 \\
\hline 2 & 12.21 to & 13.5 & 12.9 \\
\hline 3 & 11.05 to & 12.21 & 11.6 \\
\hline 4 & 10.0 to & 21.05 & 10.5 \\
\hline 5 & 9.048 to & 10.0 & 9.52 \\
\hline 6 & 8.187 to & 9.048 & 8.62 \\
\hline$T$ & 6.703 to & 8.187 & 7.45 \\
\hline 8 & 5.488 to & 6.703 & 6.10 \\
\hline 9 & 4.066 to & 5.488 & 4.78 \\
\hline 10 & 3.012 to & 4.066 & $3 \cdot 54$ \\
\hline 11 & 2.019 to & 3.012 & 2.52 \\
\hline 12 & 1.353 to & 2.019 & 1.69 \\
\hline 13 & 0.9072 tc & 01.353 & 1.13 \\
\hline 14 & $0.4979 t$ & 00.9072 & 0.70 \\
\hline
\end{tabular}

Neutron Bnersy Groups
Data ror $7_{L 1}$ and $6_{L 1}$, from Tables 6 and " of Rer. 38, can be collapsed and combined to produre eatimstes of $\left(f_{1 j} \sigma_{1 k}\right)$ in notural 1 .thium for these groups. Using $\mathrm{Bq} .(\mathrm{A}-3), \mathrm{B}_{1 \mathrm{j}}$ can be calculated a a function of $B_{1}$ and $\mathrm{B}_{1,}$; with these results, $\mathrm{B} \mathrm{q}_{4}$. $(A-2), B y .(A-4)$ and the Monte Carlo fluxes, $A_{k}$ can be calculated wo function of postion in the blenket of the ICIR bystem of frable A-I. Thede reaulte are given in rable $A-\sqrt{I}$.

The opectrum of the reaulstag ineleetic y-rays can aloo be escinated as in function af position:

$$
\begin{aligned}
& \text { "jk = Irection of the total. Inelustic- } \\
& \text { energy at } z \text { that is untted in } \\
& y=\text { group } \mathfrak{j}
\end{aligned}
$$

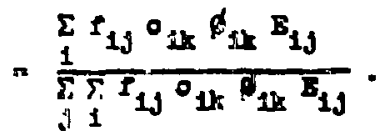

Table A-VII GIves the reaulting $\alpha_{\text {jlc }}$ (Wote the lexge variation in these spectre se runction ar position in the blanket.)

In dunary, to get lithite inelection courees for the geosetry of mble A-I, the Honte Corlo-

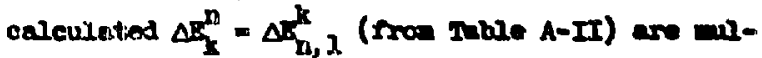
tipled by the appropritete $\left(2-\theta_{2}\right)$ from Toble A-VI, to set $y$-source intensitiog. These are then angund

\begin{tabular}{|c|c|c|c|}
\hline 1 & $\pm(\mathrm{ces})$ & $A_{2}$ & $1-\theta_{1}$ \\
\hline .2 & 98.9 & 0.378 & 0.602 \\
\hline 2 & 200.0 & 0.384 & 0.616 \\
\hline 3 & 203.25 & 0.390 & 0.610 \\
\hline 4 & 110.2 & 0.420 & 0.590 \\
\hline 5 & 118.08 & $0.4 \mathrm{Ze}$ & 0.578 \\
\hline 6 & 129.22 & 0.432 & 0.568 \\
\hline 7 & 147.96 & 0.442 & 0.558 \\
\hline 8 & $16 x .55$ & 0.419 & 0.581 \\
\hline 9 & 179.55 & 0.392 & 0.609 \\
\hline 10 & 189.55 & 0.402 & 0.598 \\
\hline 11 & 209.55 & 0.416 & 0.584 \\
\hline
\end{tabular}
to hav' the epactre of Mals A-VII. In daltion, a

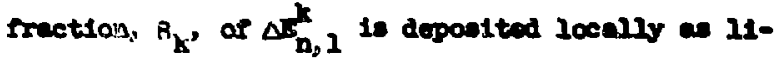
thiun racols exars.

\section{TABRS A-VI}


TABLE A-VII

$\alpha_{1 j}=$ FRACTICN OF TOTAL DIETLASTIC $\gamma$-RAY ENERGY CARRIIID BY PHOTONS WIHH ENERGY B $(\mathrm{MeV})$, Va POSTMION IN THE BLARKET OF ICTR SHOWN IN TABLE A-I

\begin{tabular}{|c|c|c|c|c|c|}
\hline \multirow[b]{2}{*}{$\underline{r}(\mathrm{~cm})$} & \multicolumn{5}{|c|}{$\alpha_{1 j}$} \\
\hline & $\mathrm{s}_{\mathrm{J}}=12.3 \mathrm{KeV}$ & 11.0 & 2.0 & 3.56 & 0.478 \\
\hline 98.9 & 0.248 & 0.318 & 0.002 & 0.004 & 0.428 \\
\hline 100.0 & 0.237 & 0.307 & 0.004 & 0.004 & 0.448 \\
\hline 103.25 & 0.216 & 0.309 & 0.010 & 0.004 & 0.457 \\
\hline 120.2 & 0.178 & 0.300 & 0.018 & 0.004 & 0.500 \\
\hline 118.08 & 0.144 & 0.284 & 0.025 & 0.004 & 0.543 \\
\hline 129.22 & 0.110 & 0.262 & 0.032 & 0.004 & 0.592 \\
\hline 147.76 & 0.073 & 0.227 & 0.041 & 0.004 & 0.655 \\
\hline 169.55 & 0.042 & 0.173 & 0.048 & 0.003 & 0.734 \\
\hline 179.55 & 0.027 & 0.105 & 0.021 & 0.002 & 0.845 \\
\hline 189.55 & 0.025 & 0.104 & 0.036 & 0.002 & 0.833 \\
\hline 209.55 & 0.018 & 0.097 & 0.040 & 0.002 & 0.843 \\
\hline
\end{tabular}


APFEWTDX B

\section{MEMHODS OF CAICITAMTOIY}

by A. R. Laraon and I. A. Booth

1. Pellet-Wetted-Wall Interaction ad Wall-Strain Analysis

The fintte-difference technique in solving Eqs. (1), (2), (3), (27), and (29) (see matn body of repart) is based an the following sequence. At the beginning of each time interval (computation cycle), now velocities for each zano boundesy are determined from prevlous pressure gradients, Bq. (2). From the new velocitis8, the changes in zane boundarles are computel $(\Delta R=U \Delta t)$. Densitias ars computed next, Eq. (1), and time-centered by averaging with old values. New spectrlc Internal energtes and jaressures are then computed by 1 teration of temperatures to sat1sfy Eq. (3) or (2T) and the equation of state (see Appendix $c$ ) by using the time-centered densities. Viscous pressures, $Q$ are calculated by the method of van Neumann and Richtmorer, (39) viz.

$$
Q= \begin{cases}\ell^{2} p\left(\frac{\partial u}{\partial x}\right)^{2} & \text { for } \frac{\partial u}{\partial x}<0 \\ \text { zero } & \text { for } \frac{\partial u}{\partial x}>0\end{cases}
$$

where $\ell^{2}$ is the damping coerficient. The time interval for the next computstion cycle 18 based on the Courant-Friedrichs-Iewy condition ${ }^{(40)}$, and 16 determined by:

$$
\frac{\Delta t}{\Delta R} \leqq \frac{1}{2 l s} \sqrt{\frac{2 n}{r+1}}\left(\frac{1}{n-1}\right) \text {, }
$$

where 8 is the time derivative of the shock's Lagrangtan coorainate and $\eta$ is the volume compression ratio of the shock. With this new time interval, pressure, and viscous pressure, the next computation cycle is started as before.
2. Radlation Transport across the Vold for Pellet/Hetted-Wail Analyolo

The energy equation, Bq. (3) of the main body of the report, includes a diffusion equation to trensfer electromagnetic radiation across zone boundarles, 1.e.,

$$
\begin{aligned}
& s=\frac{a c}{3} A \lambda \operatorname{erad} \theta^{4} \\
& F=\text { energy flux (erg/sec) } \\
& a=40 / \mathrm{ck}^{4} \\
& 0 \text { - Stefan-Boltzmann constant } \\
& \left(5.67 \times 10^{-5} \mathrm{erg} \sec ^{-1} \mathrm{~cm}^{-2} \mathrm{~K}^{-4}\right) \\
& c=\text { speed of light in vacuum } \\
& \lambda=\text { mean free path for radiation (on } \\
& \text { average of the mean free pathe on } \\
& \text { elther side of the boundary) } \\
& T \text { = temperature } \\
& k=\text { Boltzwann constant }\left(1.381 \times 10^{-16} \mathrm{erg} / \mathrm{k}\right) \\
& \theta=k T \\
& A=\operatorname{area} \\
& \text { In finite-difference form } \mathrm{Bq} \text {. (B-3) becomes } \\
& P=\left(\frac{\Delta c}{3} \frac{\lambda}{\Delta x}\right)^{4} \quad A \bar{\theta}^{3} \Delta \theta
\end{aligned}
$$

where $\Delta r$ is a distance across a zone. Values of $\bar{\theta}$ and $\Delta r / \lambda$, the numbers of wean free paths, are determined by averaging the values for the sones on each side of the interface for which $F$ is opplicable.

Equations $(B-3)$ and $(B-4)$ are appropriatie if mstter is present. In this calculation, howerer, a large void 1s assumed at the start of .the calculation, and these equations therefore are in-. appropriate. Io treat the rediation transport across this vold, an improved formulation vas devised without a major modification to the code. 
The wid Iegion is divided into severel zones, two of whicis $(1$ and $1+1)$ are considered here.

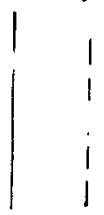

(i)<smiles></smiles>

$(1+1)$
An Imaginary radiating surface (Indicated by dotted Ines) is placed at the center of rach zone. Accarding to Huygen's principle, the wave front at the center of zone $(1+1)$ can be generated from a wave front at the center of Zone 1. Energy lensities for each zone, $\epsilon_{1}$, are calculated in the code by integrating the pluxes across the boundarles over time. Zone temperatures are then calculated from $c_{1}=a$ $\theta_{1}^{4}$. Assuming that this is a reasonable approximstion for $\theta_{1}$ and that Huygen's principle can be used, the energy flux between the two Imaginary surfaces is

$$
F=\frac{\operatorname{ac}}{4}\left(A_{1+1} \theta_{1+1}^{4}-A_{1} \theta_{1}^{4}\right)
$$

If the zane thicknesses are amall, $A_{1+1}=A_{1}=A$ (A 18 the area of the surface between the zones.) Then

$$
\begin{aligned}
F & =\frac{a c}{4} A\left(\theta_{1+1}^{4}-\theta_{1}^{4}\right) \\
& =\frac{a c}{4} A 4<\theta^{2}>\left\langle\theta>\left(\theta_{1+1}-\theta_{1}\right),\right.
\end{aligned}
$$

or

$$
F=\operatorname{ac} \bar{\theta}^{-3} \Delta \theta
$$

where $\langle\theta\rangle$ is the average value of $\theta$.

In $\mathrm{Bq} .(\mathrm{B}-4), \theta$ has the same value as $\bar{\theta}$ in Bq. (B-7) when $\theta_{1}$ or $\theta_{1+1}$ approsches sero. Upon couparing $\mathrm{Bq} .(B-4)$ and $(B-7)$, approximate radia$t$ ion transport can be calculated across a vold if $\frac{4}{3} \frac{\lambda}{\Delta t}$ is replaced by unity in Eq. $(B-4)$.

\section{Lithlum Vaporization for Pellet-Wetted-Wali Analyois}

The computer code used in this calculation includes an explicit scheme for solving the ivirodynamic equation in the Lagrangian-oyace coordinate system and is not applicable for a liquid or solid phase. In the explicit sehome, zone boundary motion for a given time step is determined only iy the pressures on each side of the boundary at the bejinring of the time step. In using the liquid-lithlum equation-of-state (see Append $1 \times \mathrm{C}$ ), the 11quid-zone prescures varied irrationally, resulting In an unrealistically low value for the time step.

The following modiffications were made to alleviate this problem. The vaporization tempexeture of the lithium was arbitrarily assumed to be $5800 \mathrm{~K}-$ 11thium zones below this temperature were liquid and those gbove were gaseous. All 11 guid zones had the same pressure as the gas zone adjilicent to the 11quid, resulting in no hydrodynamic viotion for the 11quid. The Courant time-siep calculaltion was modifled to allow the time step to increase without limt as adjacent gas-zcne pressures bercome equal.

\section{Analygis of Blowdown through Condenser}

The finite-difference techntque in colving EqB. (10) through (14) 1.8 the backward-apace difference mothod of Richtzyer for Bulerien equations. (4I)

Equations (15) through (19) were differenced in a simllar manner. The sequerse of calculatione during each time interval (computation cycle) was as follows. New veloctties vere calculated for both the Ilquid and the gas phase (Eq. 12) by ustar the cambined density, preseures, and viscous pressures from the previous computation cycle (Initial sonditions for the first cyrle). Changes in mase and energy (Bqs. 10, 11, 13, and 14) in each zone were then calculated by using the aev velocities and time-centered deraities. Gas pressures vere calculated by Eq. (20), and compared with the vapor pressure ( $\mathrm{Bg} . \mathrm{Cm}, \mathrm{A}$,pend Ix $\mathrm{c}$ ). If the 8 . Is was superheated, the temperature was changed by the heat-tranafer Dq. (15). After a zone became a:turated, the changes in temperature (and energy). mass, density, and vold fraction were calculated by Eqs. (16) through (19), and Eq. (C-1) was the equetion-of-state. The viscous pressures and the new time interval were calculated from Eqs. (B-l) and $(B-2)$, and the next computation cycle started as before. 


\section{APPENDIX 6}

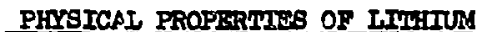

by J. C. Hedotron and A. R. Iarson

\section{General}

Transport and thermodynamic state propertiles of IIthium have been obtained from the open literature, where posolble. Ilquid-ithium densities, viscosities, and thermal conductivities used for the varlous analyses in Section II of the repart were obtained from three sources. $(21,22,42)$

2. H1gh-Temperaturo Proporties far Pollet WattodWall Interaction Analyses

For the pellet wettod-wall analyolo, the state (pressure and internal energy) and trenoyort (radiation-absorption cross section, 1.e., opacity, and thermal conductivity) properties vare needed over a temperature range of 0.09 to 20.0 of and a density range of $2.7 \times 10^{-6}$ to $0.534 \mathrm{~g} / \mathrm{cm}^{3}$. The deta uaed in the calculations vere calculated at IASS ${ }^{(43)}$ and vere included in a tabulas interpolation subroutine in the computrition code. The opacIty date included electron thermal conductivity.

The most uncertain of these properties is the opaclty. Some calculated data are plotted in Flg. C.1, in which the wide rariability of opecity is 1llustrated. Missing sections in the curves ind1cate ranges for which data could not be couputed, and Interpolated values vere used. For the particular calculation in Section II.B.2 of the repart the temperature-density points were such that the interpolated values were, for the wost part, outside the region of Interest. This is 117ustrated by a domain diagram in FIg. C.2. Values for $\mathrm{T} \leq$ $0.2 \mathrm{eV}$ (which are the most uncertals of those shown) are accurate within a factor of 2 .

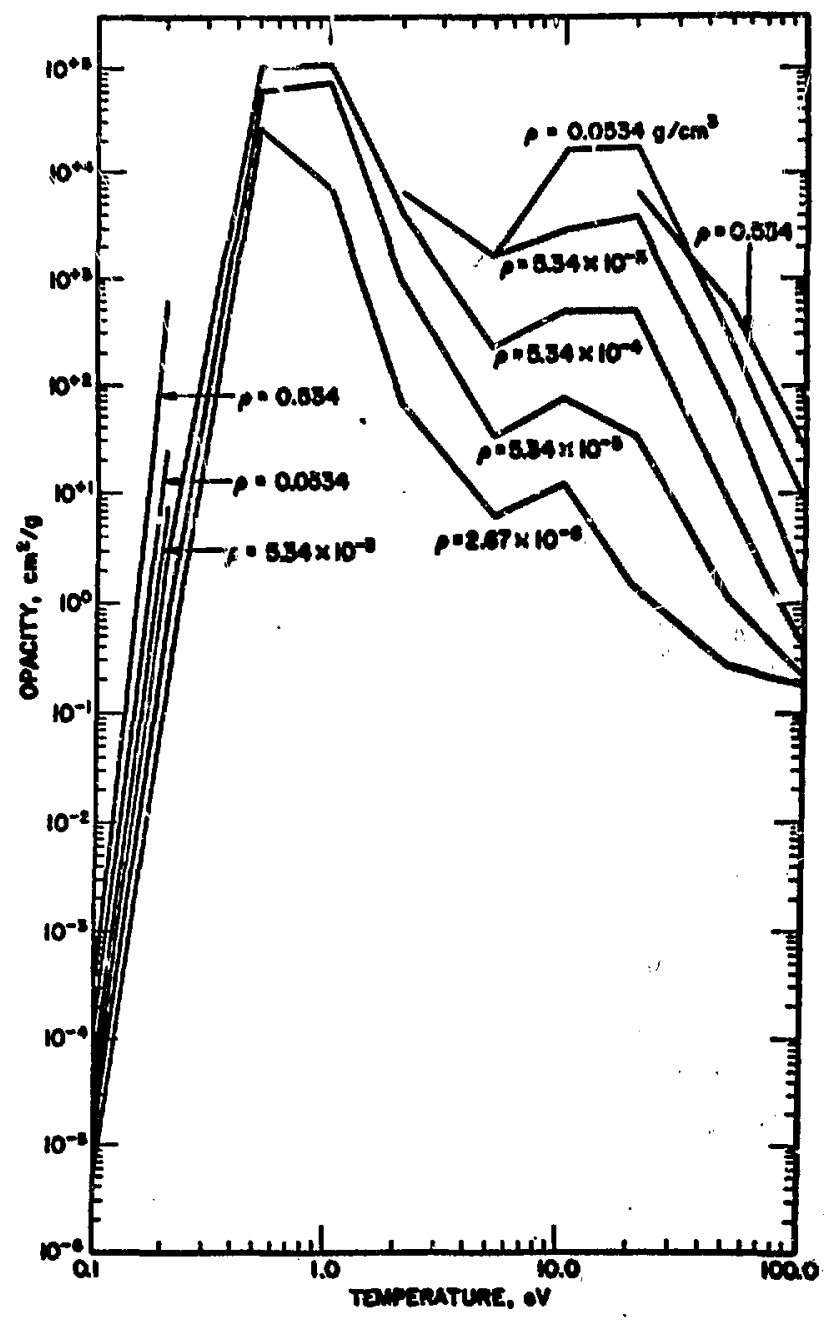

Fig. C.I. Celculated IIthium opacity (includiog electacon conduction) as a runction of temperature. 


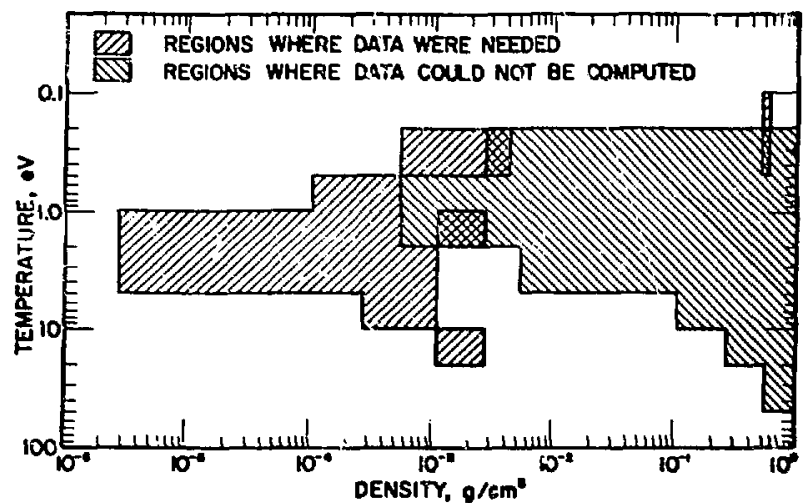

Fig. C.2. Temperature and density domains that were used in pellet wetted wall interaction calculations.

The tabular interpolation subroutine includes the calculated data in the following form:

The dependent variables are the logarithms of:

$P_{0}$, the pressure at zero temperatiure,

$P-P_{0}$, where $P$ is the pressure.,

$E_{0}$, speciflc internal energy at zero temperature,

$\mathrm{E}-\mathrm{E}_{0}$, where $\mathrm{S}$ is the specific internal energy, and

$K$, the opacity (includes electron heat conductIvity).

The independent variables are logarithms of:

$k T$, where $T$ is the teriperature and $k$ is Boltzmann' $s$ constant; and $\rho / \rho \circ$, the coupressiow, where $\rho$ is the density and $\rho_{0}$ is the density at zero terperature.

Iower and upper Jimits on kT aid $p / \rho_{0}$ may be chosen for each material. The interpolation points for $P-P_{0}, E-E_{0}$, and $x$ are evenly spaced (on a $l o g-$ arithmic scale) between the lower and upper limits to mirimize carputer time. Values of the logarithm of $\mathrm{ks}$ and $\rho / \rho_{0}$ for $P_{0}$ and $\mathrm{E}_{0}$ are fixed.

\section{Bquation-of-State jor Cavity Bquilibration, Blordown,and Conderear Anslybes}

For these analyses, the state propertles for saturation and superheated vapor conditions must be obtained. However, because complete pressure-dependent properties are not avallable, an equationof-state model was developed, based on dats from the JANAF Thermochemical Tabjes ${ }^{(44)}$. This model, which assumes a perfect gas for tine auperheated vapor, Includes the following from the JAllaF data.

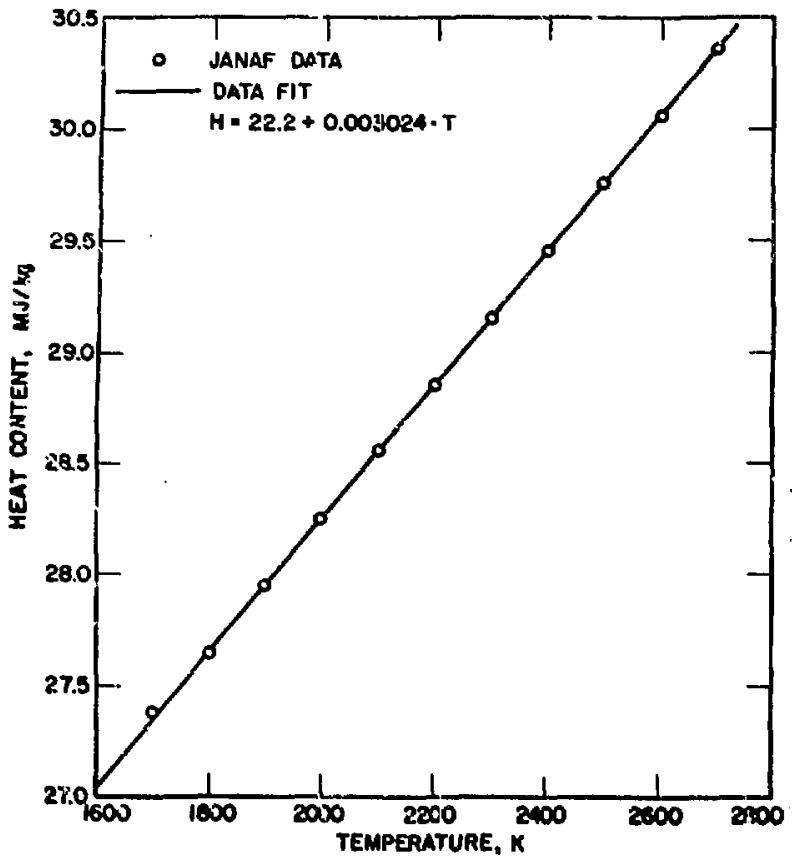

Fig. C.3. Heat content of saturated lithium vapor.

- Heat content of saturfsed vapor (H,) as a function of texperature, and

- Specific-heat ratio $(Y)$ as a function of temperature.

Heat cuntent, $\mathbf{H}_{\mathbf{r}}$ as a function of vapor temperature is plotted in Fig. C.3 along with a Iinear It to the data. Velines of $Y$ were culculated from the $C_{p}$ data, assuming $\gamma=C_{p} /\left(C_{p}-R\right)$, Results are p.lotted in Fig. C.4 again with an anaiytic fit to the date. The dip due to the Increase in dimer concentration was 1gnored because it 1.8 generajly below the current range of interest.

The saturation conditions fiere dietermined by calculating vapor pressures from the equilibrium constant data. The relationshlp which f1ts these results 1s:

$$
\begin{aligned}
& P_{v}=\exp \left[25.379 l_{1} \cdot \cdot\right] 7754.9 / T_{v} \\
& \left.-0.39515 \text { In } \mathbb{R}_{\mathrm{v}}\right] \text {, }
\end{aligned}
$$

where $P_{v}$ is the saturation pressure and $T_{v}$ is the saturation teraperature. 


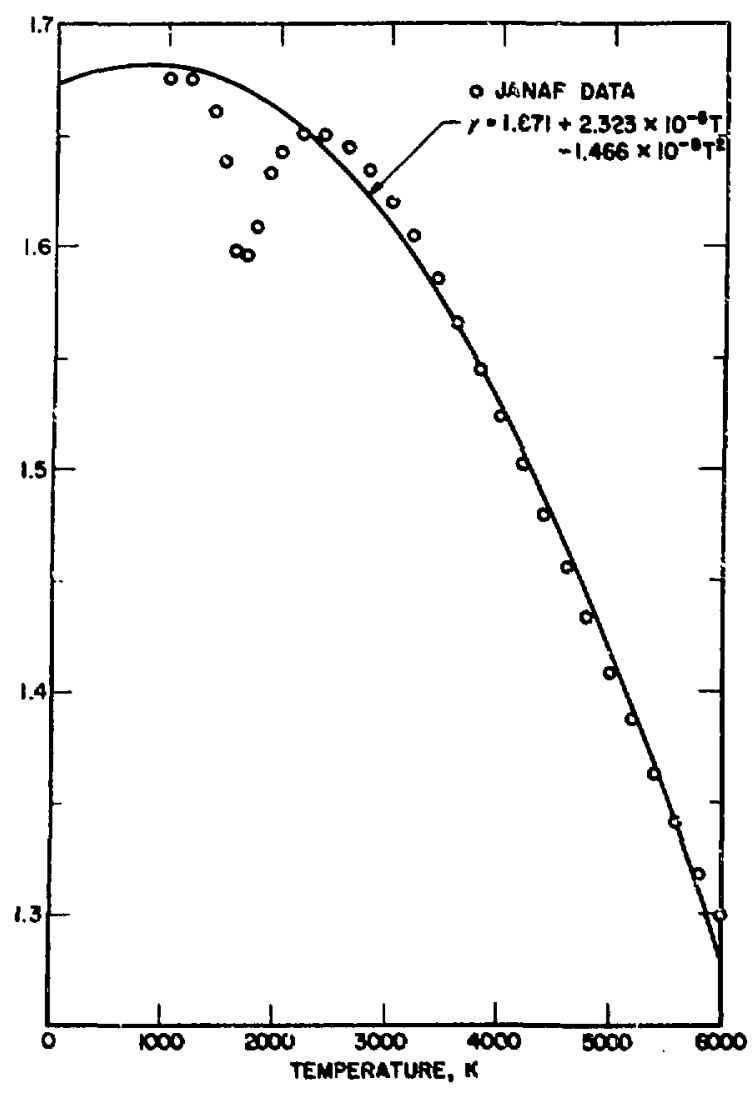

FIg. C.4. Ratio of speciflc heats $(\gamma)$ of ithium vapor assuming perfect gas.

The internal energy is then given by

$$
E=H_{v}+R \int_{T_{v}}^{T} \frac{d T}{(y-1)},
$$

and the pressure is given by

$$
P=\rho \mathbf{R T}=\mathbf{P}_{\mathbf{V}} \cdot \mathbf{T} / \mathbf{T}_{\mathbf{r}}
$$

These tiree equations are the basis for the pressuretemperature diagram in Fig. 6 of the $x$ pport.

The constant energy/volume IIne in F18. 6 was derived by combining Eqs. (c-2) and (c-3) to obtain:

$$
\frac{I}{V}=\frac{P_{v}}{T_{v}} \frac{H_{v}-E_{O}}{R}+\int_{T}^{T} \frac{d T}{Y-I}
$$

where

$I=$ total energy in the cavlty lithium after peliet initiation,

$E_{0}=$ Initial specific internal energy of lithlum vapor in the cavity prior to pellet initiation.
$P_{V}$ is evrluated by $\mathrm{Eq} .(\mathrm{C}-1), \mathrm{K}_{\mathbf{V}}$ Is evaluated by the daita fit in Fig. C.3, and $\gamma$ is evaluated ' $y$ the data fIt in FIg. C.4.

Given $I, V$, and $E_{0}$ and assuming a final $T$, this equation can be solved iteratively for $T_{v}$ from which the otner parameters can be calculated. The operating liwe on Fig. 6 is for $I=50 \mathrm{~kJ}, V=$ $4.189 \mathrm{~m}^{3}$ ( $1.0 \mathrm{~m}$ railus), and $\mathrm{E}_{0}=2.09 \mathrm{~m} / \mathrm{kg}$ (saturated vapar assumed at $700 \mathrm{~K}$ ). The conditions in Table I of the repart are also calculated on this operating line from Eq. (C-4).

\section{IIquid Equation-of-State for Blanket Response Analysis}

The equation-af-state for liquid lithium is developed from the definitions of the volumotric rvefficlent of thermal expansion and the compressibility coefficient. The compressiblitty coofficlent 18

$$
\theta_{c}=-\frac{1}{V}\left(\frac{\partial V}{\partial P}\right)_{T},
$$

and the coefficient of thermal expansion ic

$$
R_{T}=\frac{l}{V}\left(\frac{\partial V}{\partial T}\right)_{p}
$$

Since $\mathbf{v}=\mathbf{f}(\mathrm{T}, \mathrm{P})$, we have

$$
d v=\left(\frac{\partial v}{\partial T}\right)_{p} d T+\left(\frac{\partial v}{\partial P}\right)_{T} d P
$$

Bxpressing the two coerricients, Eqs. (C-5) and (c-6), in terms of $v$ and substituting in $\mathrm{sq} .(\mathrm{C}-\mathrm{q})$ gives

$$
d P=-\rho \frac{d v}{B_{c}}+\frac{B_{T}}{B_{c}} d T
$$

or

$$
P=P_{0}+\frac{\rho-\rho_{o}}{\rho_{0} B_{c}}+\frac{B_{T}}{B_{c}} \frac{B}{C_{p}},
$$

where $\left(\mathrm{T}-\mathrm{T}_{0}\right)=\mathrm{E} / \mathrm{C}_{\mathrm{p}}$ and the subseript zero refers to a reference state.

For the calculations in section. II.c.3, $\rho_{0}=50 r \mathrm{~kg} / \mathrm{m}^{3}, T_{0}=473 \mathrm{k}$, ana $P_{0}=10^{5} \mathrm{~N} / \mathrm{m}^{2}$. The compressibility coefricient $(\ell)$ was calculated from published data ${ }^{(45)}$ to be $1.42 \times 10^{-11} \mathrm{~m}^{2} / \mathrm{N}$. Values of the other constants, taken from the literature, (?I) were: $c_{p}=4183 \mathrm{~J} / \mathrm{kg} \mathrm{K}_{\mathrm{K}} \beta_{\mathrm{T}}=1.38 \times 10^{-4} \mathrm{~K}^{-1}$. 
1. A. P. Freas, "The Blascon - An Exploding Pellet Fusion Reactor," USAEC Report ORNL-IN-323l, Oak RIdge Nationa'l Iaboratory (July, 1971).

2. "Design Study Report for TARGET, a 1000-M/(e) High Temperature Gas-Cooled Reactor," USAEC Report GA-4706, General A tomic Div. (1964).

3. D. J. Roehling, D. B. Fradkin, T. F. Strattor, "Experimental Performance of Superaonic Nozzles using IAthium vapor as a Propellant," to be presented at AIfA 9th Electric Propilsion Conference, Bethesda, NR. (April, 1972).

4. J. E. Kemme, "Ultimate Heat-Plpe Performance," IFEE Trans. on Electron Devices, ED-16, No. 8, p. 717-723 (Augusi, 1969).

5. E. E. Hoffman, "Corrosion of Materials by Lithium at Elevated Tenperatures," USAEC Report CRNL-2674, Oak RIdge National Laboratory (1959).

6. T. E. Mletz, J.W. Wilson, "Behavior and Propertles of Refractory Metals," Starford Un'versity Ps 288 (1965).

7. G. I. M1ler, "Metalluray oi the Rarer Metals - 6 Tantalum and Niobium," Academic Press (1959).

8. "Metals Kandbook," Elghth Ed., American Society of Motals (1961).

9. "Aerospece Structural Metals Handbook," Syracuse University Prese (1963).

10. H. Dreicer, D. B. Henderson, "Faclilty for Duplicating 14-MeV Neutron Effacts in Fusion Pover Reactors, "USAEC Report IA-4709-NS, LOB Alamois Scientific Laboratory (1971).

11. "Neutron Cross Sections," USAEC EN-325, Second Bd., Brookhaven National Laboratiury (1964 to 1966).

12. D. G. Martin, "Radlation Damage sffects in the Containment Vescel of a Thenumuclear Reactor," UKAEA Report CIM-R-103, Culham Laboratory (1970).

13. Cited In Ref. 12.

14. W. N. MaElroj, N. Ferrar IV, "HeJizm Production In Stainless steel and Ivo Constituents as Relsted to IMFBR Development Programs," USAEC Report HiML-SA-193, Hanford Development Iaboratories (1971).

15. W. V. Green, private comunication, Los Alaros Scientific Iaboratory (1971).

16. J. D. Lee, "Some Neutron1c Aspects of a DI Fusicn Reactor," USAEC Report UCRL-T2493, Iaw rence Kadjation Labcratory (Hay, 1970).

17. A. P. Frass, 'Prelininary Appraisal of the Hezards Problems of a D-I Fusion Reactor Power Plant," JSAEC Report ORNL-IM-2822, Dak Rlilge National Ialbaratory (Apr11, 19T0).

18. D. Steiner, "The Neutron-Induced Activ'ity and Decay Faior of the N1oblum Structure of a D-T Fusion Reactor Blanket," USABC Report OAM-MM-3C94, Oak Riage National Laboratory (Ausust, 1970).

19. D. J. Ludziak, "A Pechnical Note on D-T Fusion Reactor Afterheat," Nuclear Technology, 10, p. 391 (March, 19T1).

20. C. M. Lederer, J. M. Hollander, I. Perlman, "Iable of Isotopes," Sixth Ed., John Wiley z Sons, Inc. (1967).

21. "Mellor's Ccaprehensive Treatise on Inorganic and Theoretical Chemistry - Volume I supplement II, The Alkalf Metals, Part I," Wiley and Sons (1961).

22. "Liquia Metals Hendbook," USAEC, Dept. of Navy (1955). 
23. E.F. Johnson, "Recorery of Pritium from Dilute solutions of Ifthium Tritide in Lithium, " USASC Report No. NYO-6370, Princeton Unjversity (1956).

24. A. P. Fraas. "A Difrusion Process for Removirg Tritium from the Blanket of a Thermonuclear Reactor," USAEC Report ORMI-MM-2358, Cak RIdge National Jaboratory (December, 1968).

25. R. W. Webb, "Permeation of Fydrogen through Matals, "USAEC Report INAA-aSR-10462, Atomies International (Nuly, 1965).

26. A. P. Fraas, "Comarison or" Two Tritium Removal Systems Designed to Minimize Contsmination of stean syatems in Fuil-Scale Thermoauclear Power Plants," USAEC Report ORNL-mi-2932, Oak RIdee National Laboratory (Nay, 1970).

27. "Standards for Radiation Proteciton," USABC Manual Cuapter 0524 (February, 1969 ).

28. J. D. Iane, M. I. Nyers, K. C. Olson, "Power Plant Capital Cost Normalization," USAEC Report ORNL-TML-2385, Cak Rlage National Laboratory (June, 1969).

29. A. P. Frass, "Conceptual Dosign of a Fuston Porer Plant to Neet the lHotal Bnergy Requirements of an Urban Conplex," Invited peper, Proceedings of the British nuclear Energy soctety Conference on Nuclear Fusion Reactors, whum Laboratisyy (September, 1959).

30. C. Keller, "We Use of the Closed -Grcle Helsum Gas TurbIne in Atomic Power Plants," Escher Wyss Newe, 39, No. 1, 40 (1966).

31. J. A. Signorell1, "Perspective on Stoam Tycles for Muiear Porer costs," Nucleonics, 23 , No. 4, p. 45 (Apr11, 1965).

32. M. S. iube1l, et al, "Fngineel-1ng Design Studies on the Supercontucting Nagnet syatem of a Toliamak Fusion Reactor," Froc. uf Conf. on Plama Physics and Ccrifrolled Muclear Fusion, InEA saper CN-28/K-10, Nadison, W1sc. (June, 19T1).

33. F. L. Ribe, "Iconcollc Consilecations and Mgnetic Energy Storage for H1gh- $\beta$, BuIsed Reactors," USAEC Report IA-DC-11330, IOB AJemOs Scientific Laboratory (19T0).

34. "Civilian Nuciear Pover: A Repnrt to the President," with supplement, UsABC, (1967), and as Ilsted in "Wew York pinss 1970 World Almanac," cited from Federal Power Comission statistics (1971).

35. J. L. Tuck, "bn Muclear Fusion Objectives," Paper No. 1.1, Proceedings of the British Nuclear Energy society Conference on Nucleas Fueton Reactors, Culham Iabo:atody (Sept,ember, 1969).

36. E. E. Teller, Keynote address to 5th Intersociety Bnergy Comersion Enginsering Conference, Las Vegas, Nevada (September, 1970).

3T. E. D. Cashe11, J. R. Teergaard, W. H. Tuylor, G. D. Turner, Mar, A konte Carlo Code " USABC Report IA-475I, LOE Alomos Selenttfle laboratory (December, 1971).

38. J. J. Ritts, M. Salounto, D. Stelner, "KGRMA Factoris and Secondary Gawm-Ray Soures for Scme Elements of Interest in Therwonuclear Blaniset Assemblies," USABC Report ORTL-NY-2564, Dak Ridge National Labonitory (June, 1970).

39. J. von Neumann and R. D. Rlehturer, "A Method for tle Manerical Calculations of Eydrodynamical Shocks," J. Appl. Pinys., 2l, p. 232 (1950).

40. R. Courzant, K. U. Frieärichs, H. Lexy, "Uber die partilellen DLfferenzengleichungen der Mathematischen Physik," Math. Ann., 100, p. 32 (1928).

41. R. D. Richtiller, "Difference Nethods for Initial-Value Problems," Interscience Publishers, Ine., New York (1957).

42. C. I. Nantell, Bd., "Engineering Materlels Handbook, " MaGraw-H111 (1958).

43. W. F. Buebner, A. I. Nerts, umpublished woric, Ios Alamos scientific Iaboratory (1971).

44. D. R. Stull, et al, "JAIAT Thermochemical Twbles," PB I68 370, clearinghouse for Federal Ecientific and Technical Informatios (Ausust, 1965).

45. A. D. Pasternak, "Isothermgl Compressibililty of the Ifiquid Aikali Netals," Nat. Sei. F z ., 3, No. 2, F. 65 (1968). 